Simulação Numérica do Transporte das Propriedades Durante o Enchimento de Compartimentos de Reservatórios 


\title{
Simulação Numérica do Transporte das Propriedades Durante o Enchimento de Compartimentos de Reservatórios ${ }^{1}$
}

\author{
Ana Cristina Pivem
}

Orientador: Prof. Dr. Antonio Castelo Filho

Dissertação apresentada ao Instituto de Ciências Matemáticas e de Computação - ICMC/USP, como parte dos requisitos para obtenção do título de Mestre em Ciências de Computação e Matemática Computacional.

\section{USP - São Carlos \\ Outubro/2007}

\footnotetext{
${ }^{1}$ Trabalho realizado com o apoio de FURNAS.
} 
Aos meus pais Aurelice e João, com carinho. 


\section{Agradecimentos}

Primeiramente tenho muito que agradecer a Deus pelo dom da vida, por todas as bênçãos recebidas, por me guiar, me proteger e me ajudar em todos os momentos da minha vida, bem como no desenvolvimento deste trabalho.

Em especial à minha mãe Aurelice, ao meu pai João e as minhas irmãzinhas queridas Léia e Tatiani, pelo apoio, carinho, amor, orações e por estarem sempre ao meu lado me dando forças para vencer os obstáculos. Amo muito vocês!

Ao meu amor Leandro que mesmo de longe tem me apoiado e me dedicado muito carinho, amor e companheirismo todos os dias.

Agradeço ao meu avô José e meu tio Osmar pelo carinho e incentivo.

Aos amigos Paulo, Jacy e Rafael pelas palavras de apoio e orações.

Ao meu orientador Castelo pela orientação e apoio durante o desenvolvimento deste trabalho.

Aos professores do grupo GESAR: Norberto, Cássio, Pontes, Luís Gustavo, Adenilso e Fabrício pelas dicas valiosas e fundamental colaboração.

Agradeço também aos jamais esquecidos amigos de graduação e aos professores da FCT-UNESP, Messias Meneguette Junior e José Roberto Nogueira, pela amizade e incentivo.

Às minhas amigas Evelise e Kémelli muito obrigada pela amizade, carinho e ajuda nos momentos difíceis e também pelos momentos de descontração.

Aos meus amigos e amigas de laboratório: Mário, Alex, Cláudio, Fernando, João Paulo, Carol, Alexandre, Fernanda, enfim aos amigos do LCAD, pela amizade e ajuda.

À FURNAS Centrais Elétricas S.A., pelo apoio financeiro no desenvolvimento deste trabalho.

Enfim, agradeço a todos que de maneira direta ou indireta fizeram parte da minha vida durante essa fase e que contribuíram para a realização deste trabalho.

Ana Cristina 


\section{Resumo}

O enchimento de reservatórios hidrelétricos provoca impactos ambientais, interferindo nos ecossistemas e nos modos de vida das populações envolvidas, pois durante este processo a biomassa terrestre é decomposta lançando substâncias que se concentram nos volumes dos diferentes compartimentos do reservatório. Nestas condições, algumas regiões do reservatório passam por períodos em que os teores de oxigênio dissolvido e a concentração de matéria orgânica comprometem o equilíbrio da flora e fauna locais, afetando tanto a qualidade das águas como também os ecótonos vizinhos. Neste trabalho, será tratado o problema do transporte das concentrações das espécies constituintes, da temperatura e da turbulência, 2D e 2DH, durante o enchimento de compartimentos de reservatórios.

Palavras-chave: Temperatura. Espécies Constituintes. Semi-Lagrangeano. Método de Elementos Finitos 


\section{Abstract}

The wadding of hidroelectric reservoirs provokes ambient impacts, intervening with the ecosystems and the ways of life of the involved populations, because during this process the terrestrial biomass is decomposed launching substances that stay concentrated in the volumes of the different compartments of the reservoir. In these conditions, some regions of the reservoir pass for periods where the texts of dissolved oxygen and the concentration of organic substance compromise the balance of the local flora and fauna, affecting as much the quality of waters as the neighboring ecotones. In this work, will be treated the problem of the transport of the concentrations of the constituent species, of the temperature and the turbulence, 2D and 2DH, during the wadding of compartments of reservoirs.

Key-Words: Temperature. Constituent Species. Semi-Lagrangian. Method of Finite Elements 


\section{Lista de Figuras}

2.1 Um elemento finito $\Omega_{e}$ no plano $x-y$ obtido como a imagem de $T_{e}$ do correspondente elemento mestre $\hat{\Omega}$ no plano $\xi-\eta$. O mapeamento inverso também é indicado. . . . . . . . . . . . . . . . . . . . . . . . 14

2.2 Mapeamento linear do elemento $\Omega_{e}$ para o elemento mestre $\hat{\Omega}$ e o mapeamento inverso. . . . . . . . . . . . . . . . . . . 17

2.3 Áreas dos subtriângulos e as coordenadas de área. . . . . . . . . . . . . . . 19

3.1 Esquema da formulação Semi-Lagrangeana. . . . . . . . . . . . . . . . . 22

6.1 Profundidade $(h)$, elevação $(\eta)$ e superfície de referência. . . . . . . . . . . 40

7.1 Escoamento de um fluido entre duas placas planas e paralelas. . . . . . . . . 46

8.1 Comparação entre os resultados numéricos e a solução analítica da temperatura na saída de fluido do canal . . . . . . . . . . . . . . . . . 52

8.2 Solução numérica em todo o canal . . . . . . . . . . . . . . . . . . . . . 52

8.3 Teste de convergência para a temperatura com, $\Delta t=0,01, \Delta t=0,001 \mathrm{e}$

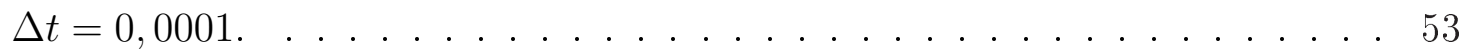

8.4 Comparação entre os resultados numéricos e a solução analítica no meio do canal e na direção do escoamento. . . . . . . . . . . . . . . . . . . 55

8.5 Solução numérica em todo o canal para a DBO. . . . . . . . . . . . . . . . 55

8.6 Solução numérica em todo o canal para o OD. . . . . . . . . . . . . . . 55

8.7 Mancha de DBO no canal. . . . . . . . . . . . . . . . 56

8.8 Comportamento do OD. . . . . . . . . . . . . . . . . . . . . . . 56

8.9 Geometria utilizada na simulação do problema com saída de fluido em região

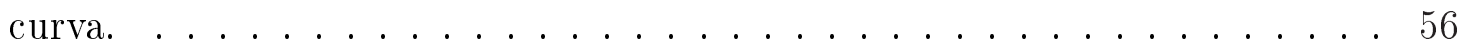

8.10 Malha da geometria curva gerada pelo Easymesh. . . . . . . . . . . . . . 57

8.11 Velocidade com saída de fluido na curva da geometria. . . . . . . . . . . 57

8.12 Temperatura com saída de fluido na curva da geometria. . . . . . . . . . . 58

8.13 Temperatura com saída de fluido na curva da geometria. . . . . . . . . . 58

8.14 Transporte de DBO na geometria curva. . . . . . . . . . . . . . . . . 59

8.15 Transporte de OD na geometria curva. . . . . . . . . . . . . . . . 59

8.16 Mancha de DBO na entrada de fluido da geometria curva em $t \approx 60 \mathrm{~s} . .60$

8.17 Mancha de DBO na entrada de fluido da geometria curva em $t \approx 24 h$. . . 60

8.18 Mancha de OD na entrada de fluido da geometria curva em $t \approx 60 \mathrm{~s}$. . . . 60

8.19 Mancha de OD na entrada de fluido da geometria curva em $t \approx 24 h \ldots 60$ 
8.20 Geometria utilizada na simulação do problema em uma placa com contração. 60

8.21 Malha gerada pelo Easymesh. . . . . . . . . . . . . . . . . . . . . . 61

8.22 Velocidade na placa com contração. . . . . . . . . . . . . . . . . 61

8.23 Transporte da temperatura na placa com contração. . . . . . . . . . . . . . 62

$8.24 \mathrm{DBO}$ em $t \approx 60 \mathrm{~s} \ldots \ldots \ldots \ldots \ldots \ldots \ldots$

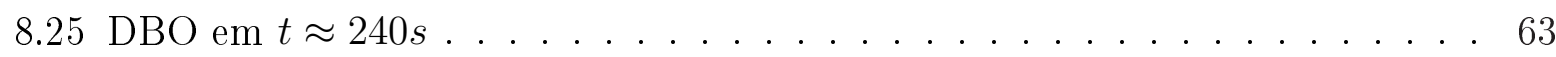

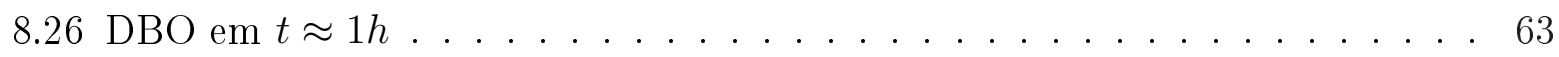

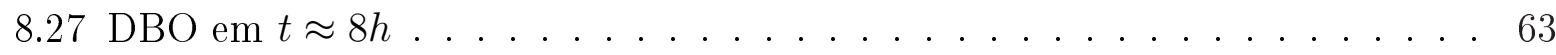

$8.28 \mathrm{DBO}$ em $t \approx 12 h \ldots \ldots \ldots \ldots \ldots \ldots$

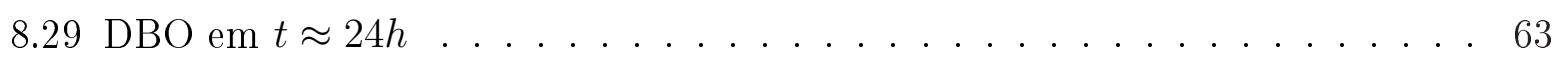

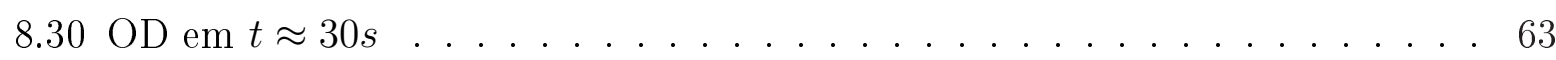

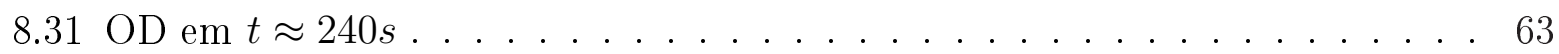

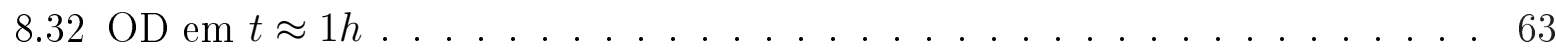

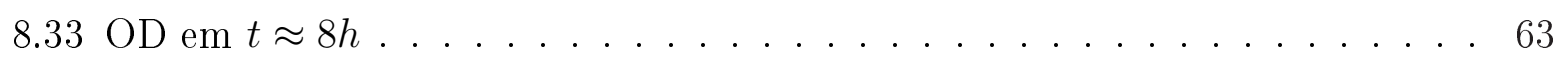

8.34 OD em $t \approx 12 h \ldots \ldots \ldots \ldots \ldots \ldots$

8.35 OD em $t \approx 24 h \ldots \ldots \ldots \ldots \ldots$

8.36 Geometria utilizada para a simulação do problema numa expansão brusca. . 64

8.37 Malha não estruturada gerada pelo Easymesh. . . . . . . . . . . . . . . . . 64

8.38 Transporte da temperatura numa expansão brusca. . . . . . . . . . . . . . 65

8.39 Transporte de DBO numa expansão brusca. . . . . . . . . . . . . . . . . 65

8.40 Transporte de OD numa expansão brusca. . . . . . . . . . . . . . . . . . 66

8.41 Malha não estruturada gerada pelo Easymesh. . . . . . . . . . . . . . 66

8.42 Transporte de temperatura. . . . . . . . . . . . . . . . . . 67

8.43 Transporte de duas manchas de DBO em $t \approx 60 s \ldots \ldots$. . . . . . . . 68

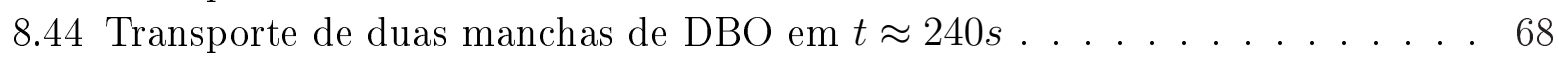

8.45 Transporte de duas manchas de DBO em $t \approx 1 h \ldots \ldots$. . . . . . . . . 68

8.46 Transporte de duas manchas de DBO em $t \approx 8 h \ldots \ldots$. . . . . . . . 68

8.47 Transporte de duas manchas de DBO em $t \approx 12 h \ldots \ldots$. . . . . . . . . . 68

8.48 Transporte de duas manchas de DBO em $t \approx 24 h \ldots \ldots$. . . . . . . . 68

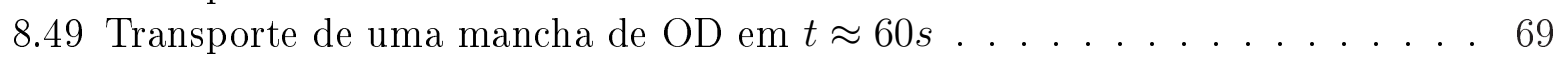

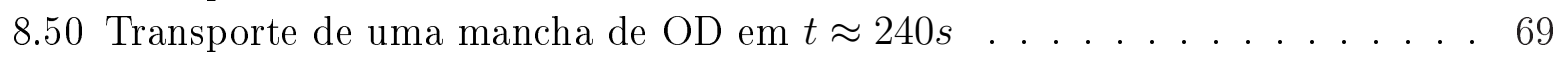

8.51 Transporte de uma mancha de OD em $t \approx 1 h \ldots \ldots . \ldots . . \ldots 9$

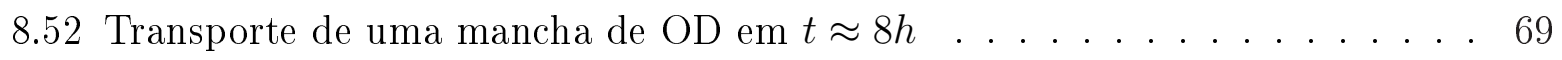

8.53 Transporte de uma mancha de OD em $t \approx 12 h \ldots \ldots . . . . . . . .69$

8.54 Transporte de uma mancha de OD em $t \approx 24 h \ldots \ldots . . . . . . . .69$

8.55 Malha representando um terreno a ser alagado: Caledônia. . . . . . . . . . . 70

8.56 Entradas e saída de fluido na malha da Caledônia. . . . . . . . . . . . . . . . 70

8.57 Velocidade em toda a Caledônia. . . . . . . . . . . . . . . . . 71

8.58 Transporte de temperatura em toda a Caledônia. . . . . . . . . . . . . . . 72

8.59 Transporte de DBO em toda a Caledônia. . . . . . . . . . . . . . . . . 72

8.60 Transporte de OD em toda a Caledônia. . . . . . . . . . . . . . . . 73

8.61 Geometria do canal 2DH. . . . . . . . . . . . . . . . . 74

8.62 Comparação entre a solução numérica e a analítica para a temperatura $2 \mathrm{DH}$ na saída de fluido do canal. . . . . . . . . . . . . . . . . . . 75

8.63 Solução numérica para a temperatura 2DH em todo o Canal. . . . . . . . . . 75

8.64 Comparação entre a solução numérica e a analítica do Modelo OD-DBO. . . 75

8.65 Solução para DBO em todo o canal. . . . . . . . . . . . . 76 
8.66 Solução OD em todo o canal. . . . . . . . . . . . . . . . . . . 76

8.67 Geometria Cocho 2DH. . . . . . . . . . . . . . . . . 76

8.68 Solução numérica para a temperatura 2DH na geometria Cocho. . . . . . . . 76

8.69 Solução numérica para a DBO na geometria cocho. . . . . . . . . . . . . . . 77

8.70 Solução numérica para o OD na geometria cocho. . . . . . . . . . . . 77

8.71 Escala de cores. . . . . . . . . . . . . . . . . . . . . 77

8.72 Geometria para o problema. . . . . . . . . . . . . . . . 78

8.73 Valores de $\mathrm{x} 1$ para Reynolds 100 e 200. . . . . . . . . . . . . . . . . . 79

8.74 Valores de $\mathrm{x} 1$ para Reynolds 400, 600 e 800 . . . . . . . . . . . . 79

8.75 Comparação entre resultados numéricos e experimentais. . . . . . . . . . . . 80 


\section{Lista de Tabelas}

1.1 Relação de algumas das espécies constituintes citadas na literatura. . . . . . 12

8.1 Atribuições para cada parâmetro da equação geral do transporte das concentrações de espécies constituintes de acordo com o modelo de cinética de reação química OD-DBO. . . . . . . . . . . . . . . . . 54

8.2 Estimativas para $x_{1} \ldots \ldots \ldots \ldots \ldots \ldots \ldots$ 


\section{Sumário}

$\begin{array}{ll}\text { Introdução } & 1\end{array}$

1 Equações Governantes $\quad \mathbf{5}$

1.1 Introdução . . . . . . . . . . . . . . . . . . . . . . . . 5

1.2 Equações de Navier-Stokes . . . . . . . . . . . . . . . . . . . . . . 6

1.3 Equação do transporte da Temperatura . . . . . . . . . . . . . . . . 7

1.4 Equação do transporte das Concentrações de Espécies Constituintes . . . . . 7

1.4.1 Modelo Cinético para duas Concentrações de Espécies Constituintes . 9

1.4.2 Modelo Cinético para três Concentrações de Espécies Constituintes 10

2 Método de Elementos Finitos $\quad 13$

2.1 Introdução . . . . . . . . . . . . . . . . . . . . . 13

2.2 Conceitos Básicos de Elementos Finitos . . . . . . . . . . . . . . . . . 13

2.3 Cálculo Sobre o Elemento Mestre . . . . . . . . . . . . . . . . . . . 14

2.3.1 Elementos Triangulares . . . . . . . . . . . . . . . . 17

3 Formulação Semi-Lagrangeana $\quad 21$

3.1 Introdução . . . . . . . . . . . . . . . . . . . . . . . . . . . 21

3.2 Esquema da Formulação . . . . . . . . . . . . . . . . . . . . 21

4 Discretização das Equações dos Transportes $\quad 23$

4.1 Introdução . . . . . . . . . . . . . . . . . . . . . . . 23

4.2 Discretização da Equação do Transporte da Temperatura . . . . . . . . . . . . 23

4.2.1 Formulação Variacional da Equação do Transporte da Temperatura . 24

4.2.2 Método de Galerkin para a Equação do Transporte da Temperatura . 25

4.3 Discretização da Equação do Transporte das Concentrações de Espécies Constituintes . . . . . . . . . . . . . . . . . 28

$4.3 .1 \quad$ Linearização . . . . . . . . . . . . . . . . . . . . . . . . . . . . 28

4.3.2 Formulação Variacional da Equação do Transporte das Concentrações de Espécies Constituintes . . . . . . . . . . . . . . . 29

4.3.3 Método de Galerkin para a Equação do Transporte das Concentrações de Espécies Constituintes . . . . . . . . . . . . . . . . . 31 
5 Modelo de Turbulência

5.1 Incorporação de um Modelo de Turbulência às Equações de Navier-Stokes . . 35

5.2 Modelo Algébrico . . . . . . . . . . . . . . . . . . . . . . 38

6 Modelo 2DH $\quad 39$

6.1 Introdução . . . . . . . . . . . . . . . . . . . . . . . . . . . . . . 39

6.2 Modelo Baseado na Média Vertical . . . . . . . . . . . . . . . . . 41

6.3 Modelo 2DH para o Transporte da Temperatura . . . . . . . . . . . . . . . 42

6.4 Modelo 2DH para o Transporte das Concentrações de Espécies Constituintes 42

7 Problemas-teste para o Transporte da Temperatura e das Concentrações de Espécies Constituintes $\quad 45$

7.1 Introdução . . . . . . . . . . . . . . . . . . . . . . 45

7.2 Transporte da Temperatura . . . . . . . . . . . . . . . . . . 45

7.3 Transporte de Concentrações de Espécies Constituintes . . . . . . . . . . . . 47

7.4 Modelo de Cinética de Reação Química . . . . . . . . . . . . . . . . . . . . . 48

7.4.1 Modelo OD-DBO . . . . . . . . . . . . . . . 48

8 Resultados Numéricos e Validação $\quad 51$

8.1 Introdução . . . . . . . . . . . . . . . . . . . . . 51

8.2 Simulação do Escoamento em um Canal . . . . . . . . . . . . . . . . . . . 51

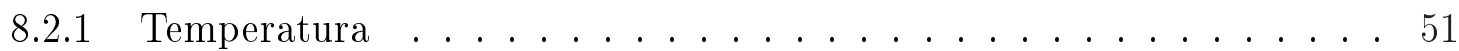

8.2.2 Espécies Constituintes . . . . . . . . . . . . . . 53

8.3 Simulação em Domínio com Geometria Curva . . . . . . . . . . . . 56

8.3 .1 Temperatura . . . . . . . . . . . . . . . 57

8.3.2 Espécies Constituintes . . . . . . . . . . . . . . . 58

8.3.3 Simulação de uma mancha de DBO e OD na geometria curva . . . . 58

8.4 Simulação de uma Placa com Contração . . . . . . . . . . . . . . . . . 60

8.4 .1 Temperatura . . . . . . . . . . . . . . . . . 61

8.4.2 Espécies Constituintes . . . . . . . . . . . . . . . . 62

8.5 Simulação numa Expansão Brusca . . . . . . . . . . . . . . . . . . . 64

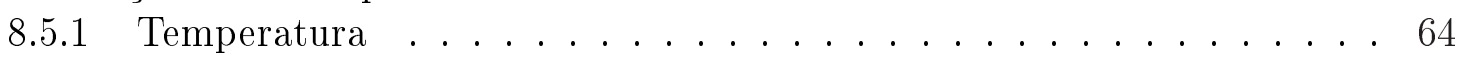

8.5.2 Espécies Constituintes . . . . . . . . . . . . . . . 65

8.6 Resultados com uma geometria complexa . . . . . . . . . . . . . . . . 66

8.6.1 Temperatura ...................... 66

8.6.2 Espécies Constituintes . . . . . . . . . . . . . . . 67

8.7 Simulação em uma geometria de um terreno: Caledônia . . . . . . . . . . . 70

8.7 .1 Velocidade . . . . . . . . . . . . . . . . . . . 71

8.7.2 Transporte da Temperatura . . . . . . . . . . . . . . . . 71

8.7.3 Transporte dos constituintes OD-DBO . . . . . . . . . . . . . . 71

8.8 Resultados para o Modelo 2DH . . . . . . . . . . . . . . . . 74

8.8.1 Simulação no Canal 2DH . . . . . . . . . . . . . . . . . . . . 74

8.8.2 Temperatura $2 \mathrm{DH} \ldots \ldots \ldots \ldots$. . . . . . . . . . . . 74

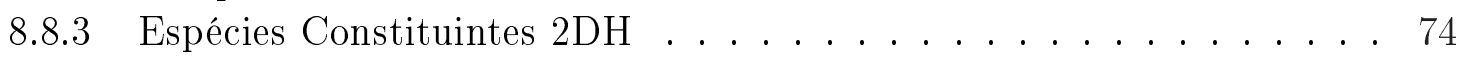

8.9 Simulação na Geometria Cocho . . . . . . . . . . . . . . . 76

8.9 .1 Temperatura . . . . . . . . . . . . . . . 76

8.9.2 Espécies Constituintes 2DH . . . . . . . . . . . . . 77 
8.10 Resultados para o Modelo de Turbulência . . . . . . . . . . . . . . . . 78

$\begin{array}{lr}\text { Considerações Finais } & 81\end{array}$ 


\section{Introdução}

Neste trabalho são apresentadas as equações que governam o transporte de propriedades, temperatura e espécies constituintes, consideradas durante o enchimento de compartimentos de reservatórios, que são terrenos a serem alagados na construção de uma Usina Hidrelétrica.

O objetivo deste trabalho é resolver numericamente estas equações dadas de uma forma geral, mas que podem ser aplicadas à diferentes modelos e diversos números de escalares. A equação do transporte de espécies constituintes é dada e resolvida numericamente de uma forma geral, isto é, considerando $n$ espécies e diferentes reações cinéticas entre elas e tem a flexibilidade de se adaptar à diversos modelos cinéticos de reações químicas de espécies constituintes, como é o caso do modelo OD-DBO aqui considerado.

O presente trabalho é parte integrante de um conjunto de módulos que tem por objetivo final gerar um software capaz de simular diversos cenários, relacionados à fatores que possam vir a afetar a qualidade da água, durante o enchimento de compartimentos de reservatórios.

Mais especificamente, este trabalho pertence ao módulo que compõem os simuladores, são eles: Hydro e Transport. Onde o simulador Hydro resolve as equações de Navier-Stokes e o simulador Transport que é composto pelos simuladores Thermo e Species resolvem as equações do transporte da temperatura e das espécies constituintes respectivamente.

A resolução das equações do transporte segue uma abordagem euleriana e depende da solução das equações de Navier-Stokes, isto é, com as velocidades fornecidas por Navier-Stokes, utiliza-se a formulação Semi-Lagrangeana e os escalares no tempo anterior para calcular os mesmos no tempo $(n+1)$.

O foco deste trabalho foi desenvolver os simuladores do transporte, Thermo e Species, e também o simulador da turbulência através da introdução de um modelo de turbulência ás equações de Navier-Stokes, construindo assim o simulador Turb utilizando o simulador Hydro já existente.

Dentre os escoamentos que usualmente ocorrem no âmbito de interesse da engenharia, praticamente todos são turbulentos, tais como em canais, condutos forçados, lagos, estuários, oceanos, entre outros. Muitos dos problemas clássicos da engenharia relacionados à turbulência ainda não foram satisfatoriamente resolvidos devido ao nível de complexidade apresentado pela turbulência, entretanto, modelos simplificados dessa realidade tem sido propostos como forma de se analisar alguns problemas [Eiger, 1981]. Neste trabalho é adotado um modelo Algébrico para a turbulência.

As questões voltadas a disponibilidade e ao uso da água no planeta, começaram por 
volta do século XX e têm gerado preocupações, despertando assim a necessidade de se realizar estudos e projetos voltados às questões ambientais.

As evidências de que a água não é um recurso inesgotável, sobretudo a sua porção denominada águas doces ou continentais geram preocupações quanto ao uso e a ocupação das bacias e/ou microbacias hidrográficas, pois esses agentes são capazes de alterar a qualidade da água, mesmo que estes efeitos e impactos ambientais possam vir a acontecer daqui a dezenas de anos, como é o caso da construção de barragens hidrelétricas, onde com o enchimento dos compartimentos, a qualidade da água pode ser comprometida devido à vários fatores tais como detritos orgânicos e inorgânicos a serem incorporados no reservatório [Soares, 2003].

Sendo assim, faz-se necessário o estudo da qualidade dessa água, para tanto, a simulação do transporte das propriedades é importante para que possa ser diagnosticado como ficará a qualidade da água dos reservatórios levando-se em consideração a distribuição da temperatura, oxigênio dissolvido, a biomassa e as concentrações presentes.

Isso é possível graças ao avanço da tecnologia e da informatização, devido a sua capacidade em armazenar uma grande quantidade de dados, permitindo a geração de prognósticos sobre as questões relativas aos sistemas aquáticos, podendo assim, antever os diversos cenários decorrentes das alterações das condições hidrodinâmicas.

O principal parâmetro de caracterização dos efeitos da poluição das águas por despejos orgânicos, é o oxigênio, sendo este um dos principais indicadores de qualidade da água. Isto é, a presença de poluentes tais como os de origem orgânica provocam a diminuição da concentração de oxigênio. Os modelos de qualidade da água têm sido usados para monitoramento e principalmente controle de poluição de corpos de água. Estes modelos consistem em simular as concentrações de substâncias que podem estar dissolvidas ou em suspensão. O modelo de cinética de reação química OD-DBO (Oxigênio Dissolvido e Demanda Bioquímica de Oxigênio), considerado neste trabalho, descreve o lançamento de uma fonte pontual de DBO em um corpo de água [Rosman, 2006].

A simulação de escoamento de fluidos é uma área de fundamental importância nas simulações numéricas. A modelagem matemática das leis de conservação, no estudo dos escoamentos de fluidos incompressíveis, é estabelecida pelas equações de conservação de massa e de Navier-Stokes [Landau, 1959], que será utilizada aqui como uma ferramenta fundamental juntamente com a formulação Semi-Lagrangeana para a simulação dos transportes térmicos e de espécies constituintes. Será utilizada também uma estrutura de dados topológica para manipulação das equações e demais dados do problema. Foram resolvidos aqui problemas considerando as abordagens $2 \mathrm{D}$ e $2 \mathrm{DH}$.

O presente trabalho está organizado da seguinte maneira:

- No capítulo 1 apresenta-se as equações governantes para o problema;

- No capítulo 2 é apresentado o método de Elementos Finitos utilizado na discretização das equações;

- No capítulo 3 é apresentada a Formulação Semi-Lagrangeana;

- No capítulo 4 as equações utilizadas são discretizadas;

- No capítulo 5 apresenta-se um modelo de turbulência; 
- No capítulo 6 apresenta-se o modelo 2DH;

- No capítulo 7 são apresentados os problemas-teste utilizados na validação numérica;

- No capítulo 8 tem-se a validação e os resultados das simulações para $2 \mathrm{D}$ e 2DH;

- Finalmente, tem-se as conclusões e contribuições deste trabalho; 



\section{CAPÍTULO 1 \\ Equações Governantes}

\subsection{Introdução}

A simulação de escoamento de fluidos é uma área de fundamental importância nas simulações numéricas. A modelagem matemática das leis de conservação, no estudo dos escoamentos de fluidos incompressíveis, é estabelecida pelas equações de conservação de massa, quantidade de movimento e energia.

Para resolver problemas de escoamento de fluidos deve-se definir o que é um fluido e classificar o tipo de escoamento. Um fluido pode ser definido como uma substância, que normalmente encontra-se nos estados líquido ou gasoso sendo estes incapazes de resistir as forças que causam tensões. Um escoamento pode ser definido como laminar ou turbulento, em que:

Escoamentos Laminares: é um tipo de escoamento ordenado e bem comportado.

Escoamentos Turbulentos: quando ocorre um aumento da vazão o escoamento sofre transição para um regime desordenado e caótico, dando origem a um escoamento mais complexo.

A dinâmica dos fluidos é a ciência que descreve o movimento de fluidos e estuda os fenômenos que envolvem fluidos em movimento. Suas leis são conhecidas como Leis de Conservação, pois durante a evolução temporal de um escoamento, propriedades como massa, movimento e energia são consideradas.

As variáveis que identificam o estado de um fluido incompressível e isotérmico são: a velocidade $\mathbf{u}$ em cada ponto e a pressão $p$, sendo estas variáveis agrupadas em equações conhecidas como equações de Navier-Stokes.

Para se especificar o movimento de um fluido em uma dada região do espaço, são encontradas na literatura dois tipos de abordagens: a descrição Euleriana e a descrição Lagrangeana.

Na formulação Lagrangeana, define-se uma região material formada por um conjunto de partículas de fluido denominada de volume de controle Lagrangeano, ou ainda região material. Conforme as partículas se movimentam no escoamento, esta região se deforma, e 
não há fluxo de massa através de suas fronteiras.

$\mathrm{Na}$ formulação Euleriana, define-se uma região fixa no espaço, que não se deforma com relação ao tempo, onde o comportamento do fluido será estudado. Nesse caso, há fluxo de massa pelas faces desse volume de controle, e as equações para o escoamento são determinadas a partir do balanço de fluxos neste volume de controle.

Neste trabalho será considerada a formulação Euleriana.

Serão apresentadas aqui as equações de Navier-Stokes, do transporte da temperatura e as equações de transporte das concentrações de espécies constituintes.

\subsection{Equações de Navier-Stokes}

As equações de Navier-Stokes são apresentadas neste trabalho, pois possui uma fundamental importância na discretização e resolução das equações do transporte da temperatura e das espécies constituintes, que serão descritas com mais detalhes no Capítulo 4.

As equações de Navier-Stokes adimensional escrita na formulação Euleriana são dadas por:

$$
\begin{gathered}
\nabla \cdot u=0, \\
\frac{D \rho u}{D t}=-\nabla p+\frac{1}{R e} \nabla \cdot\left[\mu\left(\nabla u+\nabla u^{T}\right)\right]+\frac{1}{F r^{2}} \rho g
\end{gathered}
$$

que são as equações de conservação de massa e da conservação de quantidade de movimento respectivamente. Onde,

$\mathbf{u}=(u, v)$ é o vetor velocidade,

$\rho$ é a massa específica;

$\mu$ é a viscosidade;

$p$ : pressão;

$g$ : é a gravidade;

$\frac{D \rho u}{D t}$ é a derivada material dada por:

$$
\frac{D \rho u}{D t}=\frac{\partial \rho u}{\partial t}+\mathbf{u} \nabla \rho u
$$

onde $\mathbf{u}=(u, v)$, com $u$ e $v$ sendo as velocidades nas direções $x$ e $y$ respectivamente.

Número de Reynolds (Re): é a razão entre as forças viscosas no escoamento, dado por

$$
R e=\frac{\rho_{0} L U}{\mu_{0}}=\frac{L U}{\nu_{0}}
$$

em que os valores de referência são a massa específica $\left(\rho_{0}\right)$, comprimento $(L)$, velocidade $(U)$ e as viscosidades $\mu_{0}$ e $\nu_{0}$, onde $\mu_{0}$ é a viscosidade dinâmica e $\nu_{0}$ é a viscosidade cinemática.

Número de Froude (Fr): é a razão entre as forças inerciais e as forças gravitacionais, isto é,

$$
F r=\frac{U}{\sqrt{g L}}
$$

No Capítulo 5 será descrito e introduzido um modelo de turbulência à essas equações. 


\subsection{Equação do transporte da Temperatura}

Do ponto de vista da engenharia do meio ambiente, o conhecimento da variação da temperatura no corpo de água é particularmente importante por três razões: as descargas de efluentes em diferentes temperaturas podem causar efeitos negativos no ecossistema aquático, a temperatura influencia as reações químicas e biológicas e a variação da temperatura afeta a densidade da água, e como consequência, altera os processos de transporte [Rosman, 2006].

A forma geral da equação do transporte da temperatura aqui considerada é dada por [Sabatini, 2002]

$$
\frac{D T}{D t}=\nabla \cdot(\alpha \nabla T)
$$

que é a equação de conservação de energia, na qual,

$T$ : é a temperatura,

$\alpha=\frac{\kappa}{\rho \overline{c_{p}}}$ : é o coeficiente de difusividade térmica do fluido, onde:

$\kappa$ : é o coeficiente de condutividade térmica,

$\bar{c}_{p}$ : o calor específico a pressão constante, e

$\rho$ : é a densidade do fluido.

\subsection{Equação do transporte das Concentrações de Es- pécies Constituintes}

Em relação aos mecanismos de transporte de um constituinte em um corpo de água, o processo advectivo é dominante, surgindo assim uma enorme dependência entre a simulação hidrodinâmica e o processo de transporte. No entanto, os processos difusivos também são muito importantes para a definição do transporte.

Segundo [Eiger, 1981], um determinado constituinte é transportado de acordo com a seguinte equação:

$$
\frac{D c}{D t}=\Gamma \nabla^{2} c+S_{c}
$$

onde $c$ é o valor instantâneo da concentração do constituinte, $\Gamma$ é o coeficiente de difusão molecular desta concentração, e $S_{c}$ é o termo fonte-sumidouro de $c$.

A forma geral da equação do transporte das concentrações de espécies constituintes considerada neste trabalho é dada por:

$$
\frac{D c_{i}}{D t}=\nabla \cdot\left(\lambda_{D_{i}} \nabla c_{i}\right)+\sum_{\bar{n}=1}^{\bar{n}_{\max }}\left(\sum_{\substack{j=1 \\ \pi_{j} \in \Pi_{\bar{n}}}}^{N P_{\bar{n}}} \mu_{i j}^{\prime} \prod_{p=1}^{\bar{n}} c_{\pi_{j p}}^{\alpha_{j \pi_{j p}}}-\sum_{\substack{j=1 \\ \pi_{j} \in \Pi_{\bar{n}}}}^{N P_{\bar{n}}} c_{i}^{\gamma_{i j}} \mu_{i j}^{\prime \prime} \prod_{p=1}^{\bar{n}} c_{\pi_{j p}}^{\beta_{\pi_{j p} j}}\right)+S_{i}
$$

na qual

- $c_{i}$ : são as concentrações de espécies constituintes, onde $i$ varia de acordo com o número de constituintes;

- $\lambda_{D_{i}}$ : será um escalar; 
- $\mu_{i j}^{\prime}$ e $\mu_{i j}^{\prime \prime}$ : são as constantes cinéticas;

- $\alpha_{j \pi_{j p}}, \beta_{\pi_{j p} j}$ e $\gamma_{i j}$ : são os expoentes que aparecem nas concentrações de espécies constituintes;

- $N P_{\bar{n}}$ : é o número de termos no somatório, dado por:

$$
N P_{\bar{n}}=\left(\begin{array}{c}
n-1 \\
\bar{n}
\end{array}\right)=\frac{(n-1) !}{\bar{n} !((n-1)-\bar{n}) !}
$$

em que

$n$ : é o número de concentrações de espécies constituintes.

$\bar{n}$ : é o número de concentrações de espécies constituintes a serem combinadas nos produtórios.

- $\bar{n}_{\text {max }}$ : é o número máximo de espécies constituintes que podem ser combinadas nos produtórios.

Assim, para $n$ espécies constituintes tem-se,

$$
\bar{n}_{\max }=n-1
$$

e $\bar{n}=\left\{1, \ldots, \bar{n}_{\max }\right\}$.

- $S_{i}$ é o termo fonte e será baseado na massa do elemento e terá a seguinte forma

$$
S_{i}=f_{i}(x, y, z) \bar{k}_{i} M_{i}
$$

na qual

$M_{i}$ : é a massa a ser considerada, e

$$
\frac{d M}{d t}=-\bar{k}_{i} M_{i}
$$

$\bar{k}_{i}=\bar{k}_{i}(T, u, v, w) \quad T$ : é a temperatura

- $\Pi_{\bar{n}}$ : é um conjunto cujos elementos são todas as possíveis combinações de $I=$ $\{1, . ., n\}$, conjunto dos índices das espécies constituintes consideradas, a menos de um elemento $i$ que corresponde ao índice da espécie constituinte $c_{i}$ que estiver sendo calculada. Assim,

$\Pi_{\bar{n}}=\left\{\pi_{j} \mid j=1, \ldots, N P_{\bar{n}}\right\}$

com

$\pi_{j}=\left\{\pi_{j p} \mid p=1, \ldots, \bar{n}\right\}, \quad j=1, \ldots, N P_{\bar{n}}$

De posse da equação geral (1.8) pode-se obter equações específicas para modelos de cinética de reação química das espécies constituintes, considerando duas ou mais espécies constituintes.

Para ilustrar os procedimentos descritos acima para $n$ espécies constituintes, seguem os cálculos e considerações para dois e três constituintes. 


\subsubsection{Modelo Cinético para duas Concentrações de Espécies Cons- tituintes}

Considerando os cálculos para duas concentrações de espécies constituintes, tem-se:

Sejam $c_{1}$ e $c_{2}$ duas espécies constituintes a serem consideradas, logo $n=2$ e como $\bar{n}=\bar{n}_{\max }=1$, tem-se:

$$
N P_{1}=\left(\begin{array}{c}
n-1 \\
\bar{n}
\end{array}\right)=\frac{1 !}{1 !(1-1) !}=1
$$

Logo, $N P_{1}=1$.

Assim, a equação geral (1.8) será escrita

$$
\frac{D c_{i}}{D t}=\nabla \cdot\left(\lambda_{D_{i}} \nabla c_{i}\right)+\sum_{\bar{n}=1}^{1}\left(\sum_{\substack{j=1 \\ \pi_{j} \in \Pi_{1}}}^{1} \mu_{i j}^{\prime} \prod_{p=1}^{1} c_{\pi_{j p}}^{\alpha_{j \pi_{j p}}}-\sum_{\substack{j=1 \\ \pi_{j} \in \Pi_{1}}}^{1} c_{i}^{\gamma_{i j}} \mu_{i j}^{\prime \prime} \prod_{p=1}^{1} c_{\pi_{j p}}^{\beta_{\pi_{j p}}}\right)+S_{i}
$$

Como $n=2, \bar{n}=1$ e $N P_{1}=1$ tem-se $I=\{1,2\}$

$$
\begin{gathered}
\Pi_{1}=\left\{\pi_{1}\right\}, \text { onde } \\
\pi_{1}=\left\{\pi_{11}\right\}
\end{gathered}
$$

Calculando $\pi_{1}$ para cada espécie constituinte tem-se:

\section{Espécie Constituinte $c_{1}$}

Considerando a concentração de espécie constituinte $c_{1}$ o índice 1 deve ser eliminado de $I$, restando apenas o índice 2 , isto é, $I=\{2\}$. Logo

$$
\pi_{1}=\{2\}
$$

\section{Espécie Constituinte $c_{2}$}

Procedendo da mesma forma para a concentração $c_{2}$, tem-se:

$$
\pi_{1}=\{1\}
$$

Então, para $i=1$

$$
\frac{D c_{1}}{D t}=\nabla \cdot\left(\lambda_{D_{1}} \nabla c_{1}\right)-\mu_{11}^{\prime \prime} c_{1}^{\gamma_{11}} c_{2}^{\beta_{21}}+S_{1}
$$

e para $i=2$

$$
\frac{D c_{2}}{D t}=\nabla \cdot\left(\lambda_{D_{2}} \nabla c_{2}\right)-\mu_{21}^{\prime \prime} c_{2}^{\gamma_{21}} c_{1}^{\beta_{11}}+S_{2}
$$

Estas são as duas equações para um modelo de reação cinética entre duas concentrações de espécies constituintes considerando a forma geral. Para se obter uma formulação específica, basta especificar cada um dos parâmetros que aparecem nas equações (1.13) e (1.14). 


\subsubsection{Modelo Cinético para três Concentrações de Espécies Cons- tituintes}

Sejam $c_{1}, c_{2}$ e $c_{3}$ três espécies constituintes a serem consideradas, logo

- $I=\{1,2,3\}$,

- $n=3$,

- $\bar{n}_{\max }=2$,

- $\bar{n}=\{1,2\}$

Calculando $N P_{1}$ e $N P_{2}$, tem-se

$$
N P_{1}=2
$$

e

$$
N P_{2}=1
$$

Assim,

- Para $N P_{1}=2$ e $\bar{n}=1$, tem-se

$$
\begin{gathered}
\Pi_{1}=\left\{\pi_{1}, \pi_{2}\right\} \\
\pi_{1}=\left\{\pi_{11}\right\} \\
\pi_{2}=\left\{\pi_{21}\right\}
\end{gathered}
$$

Calculando $\Pi_{1}$ para cada espécie constituinte tem-se:

\section{Espécie Constituinte $c_{1}$}

Considerando a espécie constituinte $c_{1}$ o índice 1 deve ser eliminado de $I$ e as combinações deverão ser feitas com os índices restantes, isto é, $I=\{2,3\}$. Assim

$$
\begin{aligned}
& \pi_{1}=\{2\} \\
& \pi_{2}=\{3\}
\end{aligned}
$$

\section{Espécie Constituinte $c_{2}$}

Procedendo da mesma forma para o constituinte $c_{2}$ o índice 2 deve ser eliminado de $I$ e as combinações deverão ser feitas com os índices restantes, isto é, $I=\{1,3\}$. Logo,

$$
\begin{aligned}
& \pi_{1}=\{1\} . \\
& \pi_{2}=\{3\} .
\end{aligned}
$$




\section{Espécie Constituinte $c_{3}$}

De maneira análoga para o constituinte $c_{3}$ o índice 3 deve ser eliminado de $I$ e as combinações deverão ser feitas com os índices restantes, isto é, $I=\{1,2\}$. Assim

$$
\begin{aligned}
& \pi_{1}=\{1\} \\
& \pi_{2}=\{2\}
\end{aligned}
$$

- Para $N P_{2}=1$ e $\bar{n}=2$, tem-se

$$
\begin{gathered}
\Pi_{2}=\left\{\pi_{1}\right\} \\
\pi_{1}=\left\{\pi_{11}, \pi_{12}\right\}
\end{gathered}
$$

Calculando $\Pi_{2}$ para cada espécie constituinte tem-se:

\section{Espécie Constituinte $c_{1}$}

Considerando a concentração de espécie constituinte $c_{1}$ o índice 1 deve ser eliminado de $I$ e as combinações deverão ser feitas com os índices restantes, isto é, $I=\{2,3\}$. Assim

$$
\pi_{1}=\{2,3\}
$$

\section{Espécie Constituinte $c_{2}$}

Procedendo da mesma forma para o constituinte $c_{2}$ o índice 2 deve ser eliminado de $I$ e as combinações deverão ser feitas com os índices restantes, isto é, $I=\{1,3\}$. Assim

$$
\pi_{1}=\{1,3\}
$$

\section{Espécie Constituinte $c_{3}$}

De maneira análoga para o constituinte $c_{3}$ o índice 3 deve ser eliminado de $I$ e as combinações deverão ser feitas com os índices restantes, isto é, $I=\{1,2\}$. Assim

$$
\pi_{1}=\{1,2\}
$$

Logo, a equação (1.8) será escrita

$$
\frac{D c_{i}}{D t}=\nabla \cdot\left(\lambda_{D_{i}} \nabla c_{i}\right)+\sum_{\bar{n}=1}^{2}\left(\sum_{\substack{j=1 \\ \pi_{j} \in \Pi_{\bar{n}}}}^{N P_{\bar{n}}} \mu_{i j}^{\prime} \prod_{p=1}^{\bar{n}} c_{\pi_{j p}}^{\alpha_{j \pi_{j p}}}-\sum_{\substack{j=1 \\ \pi_{j} \in \Pi_{\bar{n}}}}^{N P_{\bar{n}}} c_{i}^{\gamma_{i j}} \mu_{i j}^{\prime \prime} \prod_{p=1}^{\bar{n}} c_{\pi_{j p}}^{\beta_{\pi_{j p} j}}\right)+S_{i},
$$

Portanto,

$$
\begin{aligned}
\frac{D c_{i}}{D t}= & \nabla \cdot\left(\lambda_{D_{i}} \nabla c_{i}\right)+\left(\sum_{\substack{j=1 \\
\pi_{j} \in \Pi_{1}}}^{2} \mu_{i j}^{\prime} \prod_{p=1}^{1} c_{\pi_{j p}}^{\alpha_{j \pi_{j p}}}-\sum_{\substack{j=1 \\
\pi_{j} \in \Pi_{1}}}^{2} c_{i}^{\gamma_{i j}} \mu_{i j}^{\prime \prime} \prod_{p=1}^{1} c_{\pi_{j p}}^{\beta_{\pi_{j p}}}\right) \\
& +\left(\sum_{\substack{j=1 \\
\pi_{j} \in \Pi_{2}}}^{1} \mu_{i j}^{\prime} \prod_{p=1}^{2} c_{\pi_{j p}}^{\alpha_{j \pi_{j p}}}-\sum_{\substack{j=1 \\
\pi_{j} \in \Pi_{2}}}^{1} c_{i}^{\gamma_{i j}} \mu_{i j}^{\prime \prime} \prod_{p=1}^{2} c_{\pi_{j p}}^{\beta_{\pi_{j p}}}\right)+S_{i}
\end{aligned}
$$


Então,

para $i=1$

$\frac{D c_{1}}{D t}=\nabla \cdot\left(\lambda_{D_{1}} \nabla c_{1}\right)-\mu_{11}^{\prime \prime} c_{1}^{\gamma_{11}} c_{2}^{\beta_{21}}-\mu_{12}^{\prime \prime} c_{1}^{\gamma_{12}} c_{3}^{\beta_{31}}+\mu_{11}^{\prime} c_{2}^{\alpha_{12}} c_{3}^{\alpha_{13}}-\mu_{11}^{\prime \prime} c_{1}^{\gamma_{11}} c_{2}^{\beta_{21}} c_{3}^{\beta_{31}}+S_{1}$

para $i=2$

$\frac{D c_{2}}{D t}=\nabla \cdot\left(\lambda_{D_{2}} \nabla c_{2}\right)-\mu_{21}^{\prime \prime} c_{2}^{\gamma_{21}} c_{1}^{\beta_{11}}-\mu_{22}^{\prime \prime} c_{2}^{\gamma_{22}} c_{3}^{\beta_{31}}+\mu_{21}^{\prime} c_{1}^{\alpha_{11}} c_{3}^{\alpha_{13}}-\mu_{21}^{\prime \prime} c_{2}^{\gamma_{21}} c_{1}^{\beta_{11}} c_{3}^{\beta_{31}}+S_{2}$

para $i=3$

$\frac{D c_{3}}{D t}=\nabla \cdot\left(\lambda_{D_{3}} \nabla c_{3}\right)-\mu_{31}^{\prime \prime} c_{3}^{\gamma_{31}} c_{1}^{\beta_{11}}-\mu_{32}^{\prime \prime} c_{3}^{\gamma_{32}} c_{2}^{\beta_{22}}+\mu_{31}^{\prime} c_{1}^{\alpha_{11}} c_{2}^{\alpha_{12}}-\mu_{31}^{\prime \prime} c_{3}^{\gamma_{31}} c_{1}^{\beta_{11}} c_{2}^{\beta_{21}}+S_{3}$

Estas são as três equações para um modelo de cinética de reação química para três concentrações de espécies constituintes, considerando a forma geral. Para se obter uma formulação específica, basta especificar cada um dos parâmetros que aparecem nas equações (1.17), (1.18) e (1.19).

Aumentando o número de constituintes segue-se de maneira análoga com os procedimentos anteriores e sua forma geral de obtenção.

Sendo assim, dado o modelo de cinética de reação química, obtido de forma geral para o número de espécies constituintes desejado, existem na literatura modelos para reações cinéticas envolvidas nos processos de transformação considerados para cada substância modelada e podem ser encontrados em [Schladow, 1997], sendo que algumas delas são expostas na Tabela (1.1).

\begin{tabular}{|c|l|}
\hline Espécie Constituinte & Símbolo \\
\hline Amônia & $c_{1}$ \\
\hline Nitrato & $c_{2}$ \\
\hline Fósforo total & $c_{3}$ \\
\hline Biomassa de Fitoplâncton & $c_{4}$ \\
\hline DBO: Demanda Bioquímica de Oxigênio & $c_{5}$ \\
\hline OD: Oxigênio Dissolvido & $c_{6}$ \\
\hline Nitrogênio Orgânico & $c_{7}$ \\
\hline Fósforo Orgânico & $c_{8}$ \\
\hline Clorofila & $c_{9}$ \\
\hline &
\end{tabular}

Tabela 1.1: Relação de algumas das espécies constituintes citadas na literatura.

Portanto, com a definição da obordagem adotada para as equações governantes e com as informações citadas pode-se determinar o caminho de obtenção do modelo cinético de reação química desejado. 


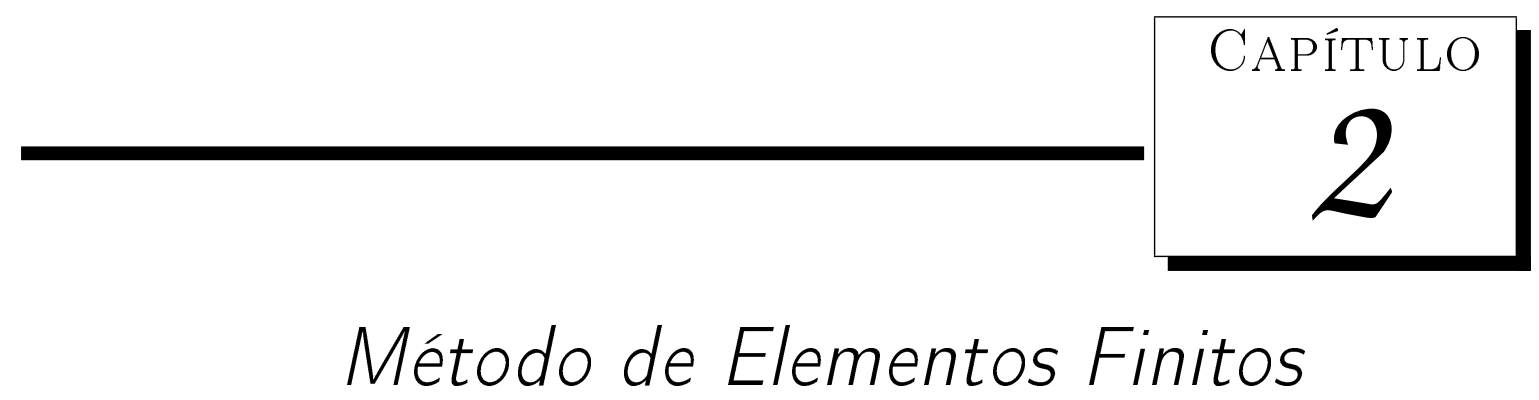

\subsection{Introdução}

Nesse capítulo é apresentado o método de Elementos Finitos. Este método estabelece que os valores das variáveis podem ser aproximados localmente por interpolação dentro de uma malha computacional, sendo sua aplicação mais vantajosa em problemas de domínios com geometrias complexas, que demandam malhas não estruturadas para aumentar a precisão das variáveis de interesse nas regiões mais irregulares.

\subsection{Conceitos Básicos de Elementos Finitos}

O método de Elementos Finitos (MEF) é uma técnica geral para construir soluções aproximadas para problemas de valor de contorno. Este método envolve a divisão do domínio de solução em um número de subdomínios simples, os elementos finitos, e usa conceitos variacionais para construir uma aproximação da solução sobre uma coleção de elementos finitos [Becker, 1981].

Os procedimentos essenciais para resolver um problema utilizando o método de Elementos Finitos são:

1. Escrever o problema em sua formulação variacional na qual o espaço apropriado $H$ de funções admissíveis é identificado.

2. Discretizar o domínio, no qual se pretende resolver o problema, em elementos finitos poligonais regulares, construindo assim uma malha e gerando um subespaço de dimensão finita $H^{h}$.

3. Construção de uma aproximação da formulação variacional do problema em elementos finitos no subespaço $H^{h}$ de $H$. Cálculo das matrizes dos elementos e a geração de um sistema esparso de equações algébricas lineares e os valores das soluções aproximadas nos pontos nodais da malha.

4. Solução algébrica do sistema resultante.

5. Exame das características da solução aproximada e, se possível, a estimativa dos 
erros inerentes à aproximação.

Estes passos formam a base do método de Elementos Finitos para problemas de valor de contorno em uma, duas ou três dimensões.

O elemento mestre é o principal conceito usado na técnica de aproximação por elementos finitos. Este, escrito nas coordenadas $(\xi, \eta)$, vai mapear qualquer elemento escrito nas coordenadas $(x, y)$. Isto será possível desde que exista uma transformação linear

$$
\begin{aligned}
T_{e}: x & =x(\xi, \eta) \\
y & =y(\xi, \eta)
\end{aligned}
$$

e sua transformação inversa

$$
\begin{aligned}
T_{e}^{-1}: \xi & =\xi(x, y) \\
\eta & =\eta(x, y),
\end{aligned}
$$

como mostra a Figura (2.1)

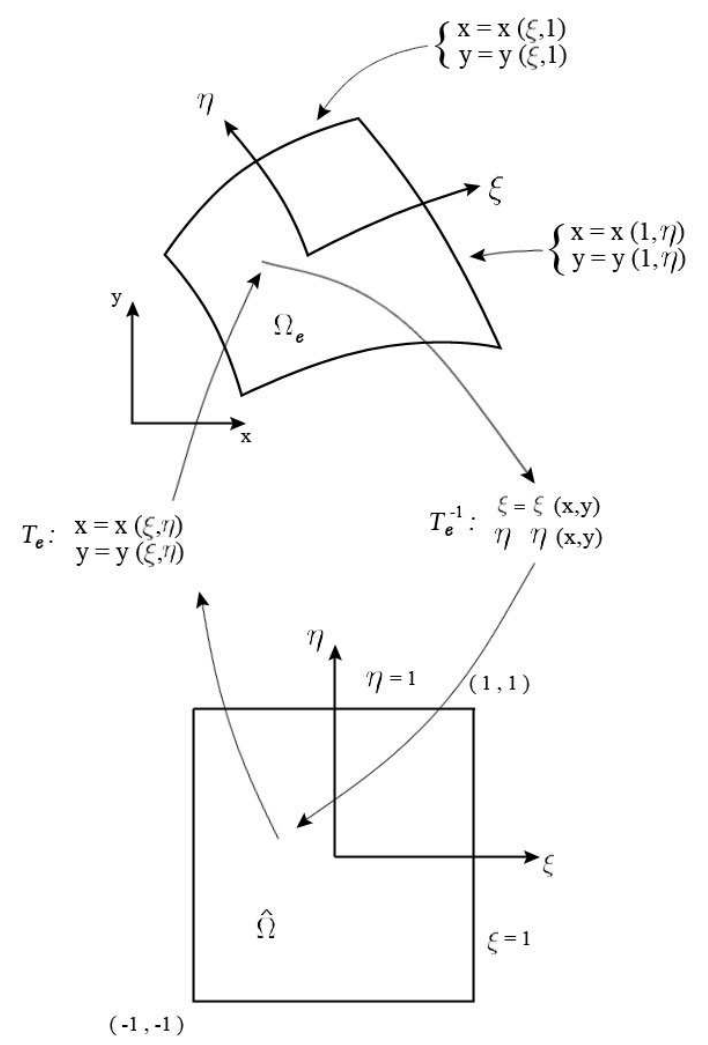

Figura 2.1: Um elemento finito $\Omega_{e}$ no plano $x-y$ obtido como a imagem de $T_{e}$ do correspondente elemento mestre $\hat{\Omega}$ no plano $\xi-\eta$. O mapeamento inverso também é indicado.

\subsection{Cálculo Sobre o Elemento Mestre}

Primeiramente escolhe-se um elemento mestre $\hat{\Omega}$ com coordenadas $\xi$ e $\eta$. Neste estágio é decidido o tipo de elemento a ser usado na aproximação. A geometria de $\hat{\Omega}$ é escolhida 
de maneira mais simples possível para facilitar os cálculos no elemento. Com a escolha de $\hat{\Omega}$, tem-se um correspondente conjunto de funções de forma $\hat{\psi}_{j}$ no elemento mestre.

Selecionado $\hat{\Omega}$ e $\hat{\psi}_{j}$, são seguidos os passos:

1. Mapear o elemento: As coordenadas do elemento mapeado, são construídas através de

$$
\begin{aligned}
T_{e}: x & =\sum_{j=1}^{N e} x_{j} \hat{\psi}_{j}(\xi, \eta) \\
y & =\sum_{j=1}^{N e} y_{j} \hat{\psi}_{j}(\xi, \eta)
\end{aligned}
$$

O elemento original $\Omega_{e}$ para o qual $T_{e}$ mapeia $\hat{\Omega}$ é completamente determinado especificando-se as coordenadas $\left(x_{j}, y_{j}\right)$ para os pontos nodais de $\Omega_{e}$.

2. Transformação das funções de forma: Seja $g$ uma função de $x$ e $y$ definida em um elemento $\Omega_{e}$. Então, pode-se converter $g$ para uma função $\hat{g}$ de $\xi$ e $\eta$ definida em $\hat{\Omega}$ por

$$
g(x, y)=g(x(\xi, \eta), y(\xi, \eta))=\hat{g}(\xi, \eta)
$$

na qual $x(\xi, \eta)$ e $y(\xi, \eta)$ são dadas por $(2.3)$. Similarmente, se $\hat{g}(\xi, \eta)$ é dado em $\hat{\Omega}$, define-se a transformação de $(\xi, \eta)$ em $(x, y)$ por

$$
\hat{g}(\xi, \eta)=\hat{g}(\xi(x, y), \eta(x, y))=g(x, y) .
$$

Assim, as funções de forma do elemento, $\psi_{j}^{e}=\psi_{j}^{e}(x, y)$ para $\Omega_{e}$ são simplesmente obtidas de $\hat{\psi}_{j}(\xi, \eta)$ por

$$
\hat{\psi}_{j}^{e}(x, y)=\hat{\psi}_{j}(\xi(x, y), \eta(x, y)), \quad j=1,2, \ldots, N_{e} .
$$

As derivadas de $\psi_{j}^{e}$ são obtidas pela regra da cadeia

$$
\begin{aligned}
\frac{\partial \psi_{j}^{e}}{\partial x} & =\frac{\partial \hat{\psi}_{j}}{\partial \xi} \frac{\partial \xi}{\partial x}+\frac{\partial \hat{\psi}_{j}}{\partial \eta} \frac{\partial \eta}{\partial x} \\
\frac{\partial \psi_{j}^{e}}{\partial y} & =\frac{\partial \hat{\psi}_{j}}{\partial \xi} \frac{\partial \xi}{\partial y}+\frac{\partial \hat{\psi}_{j}}{\partial \eta} \frac{\partial \eta}{\partial y}
\end{aligned}
$$

De acordo com (2.3),

$$
\begin{array}{rlrl}
\frac{\partial x}{\partial \xi} & =\sum_{k=1}^{N e} x_{k} \frac{\partial \hat{\psi}_{k}(\xi, \eta)}{\partial \xi}, & & \frac{\partial x}{\partial \eta}=\sum_{k=1}^{N e} x_{k} \frac{\partial \hat{\psi}_{k}(\xi, \eta)}{\partial \eta} \\
\frac{\partial y}{\partial \xi}=\sum_{k=1}^{N e} y_{k} \frac{\partial \hat{\psi}_{k}(\xi, \eta)}{\partial \xi}, & \frac{\partial y}{\partial \eta}=\sum_{k=1}^{N e} y_{k} \frac{\partial \hat{\psi}_{k}(\xi, \eta)}{\partial \eta}
\end{array}
$$

Como, 


$$
\left[\begin{array}{l}
d \xi \\
d \eta
\end{array}\right]=J^{-1}\left[\begin{array}{l}
d x \\
d y
\end{array}\right]
$$

em que

$$
|J|=\operatorname{det} J=\frac{\partial x}{\partial \xi} \frac{\partial y}{\partial \eta}-\frac{\partial x}{\partial \eta} \frac{\partial y}{\partial \xi} \quad \text { com } \quad|J| \neq 0
$$

$\mathrm{e}$

$$
\begin{array}{lll}
\frac{\partial \xi}{\partial x}=\frac{1}{|J|} \frac{\partial y}{\partial \eta}, & \frac{\partial \xi}{\partial y}=-\frac{1}{|J|} \frac{\partial x}{\partial \eta} \\
\frac{\partial \eta}{\partial x}=-\frac{1}{|J|} \frac{\partial y}{\partial \xi}, & \frac{\partial \eta}{\partial y}=\frac{1}{|J|} \frac{\partial x}{\partial \xi}
\end{array}
$$

Utilizando-se (2.11) em (2.8), a equação (2.7) torna-se

$$
\begin{aligned}
& \frac{\partial \psi_{j}^{e}}{\partial x}=\frac{1}{|J(\xi, \eta)|}\left[\frac{\partial \hat{\psi}_{j}}{\partial \xi} \sum_{k=1}^{N e} y_{k} \frac{\partial \hat{\psi}_{k}}{\partial \eta}-\frac{\partial \hat{\psi}_{j}}{\partial \eta} \sum_{k=1}^{N e} y_{k} \frac{\partial \hat{\psi}_{j}}{\partial \xi}\right] \\
& \frac{\partial \psi_{j}^{e}}{\partial y}=\frac{1}{|J(\xi, \eta)|}\left[\frac{\partial \hat{\psi}_{j}}{\partial \xi} \sum_{k=1}^{N e} x_{k} \frac{\partial \hat{\psi}_{k}}{\partial \eta}+\frac{\partial \hat{\psi}_{j}}{\partial \eta} \sum_{k=1}^{N e} x_{k} \frac{\partial \hat{\psi}_{k}}{\partial \xi}\right],
\end{aligned}
$$

na qual $|J(\xi, \eta)|$ é o Jacobiano da transformação $T_{e}$. Note que, as derivadas parciais de $\psi_{j}^{e}$ com respeito a $x$ e $y$ são completamente determinadas pelos cálculos definidos somente no elemento mestre $\hat{\Omega}$.

3. Integração: Seja $g$ e $\hat{g}$ as funções definidas em (2.5). Logo,

$$
\int_{\hat{\Omega}} \hat{g}(\xi, \eta) d x d y=\int_{\hat{\Omega}} \hat{g}(\xi, \eta)|J(\xi, \eta)| d \xi d \eta
$$

A integral das funções sobre o elemento original $\Omega_{e}$ pode ser avaliada sobre o elemento mestre. Note que, $\hat{g}$ e $|J(\xi, \eta)|$ podem ser determinados nas coordenadas do elemento mapeado, assim,

$$
\hat{g}(\xi, \eta)=g\left(\sum_{j=1}^{N e} x_{j} \hat{\psi}_{j}(\xi, \eta), \sum_{j=1}^{N e} y_{j} \hat{\psi}_{j}(\xi, \eta)\right) .
$$

Para se calcular (2.13), são usadas as fórmulas de quadratura como por exemplo quadratura Gaussiana. As regras de quadratura são tipicamente definidas por regiões padrão de integração, tal como no elemento mestre.

Em geral, algumas fórmulas de quadratura (Gaussiana ou outras) são definidas especificando-se as coordenadas $\left(\xi_{l}, \eta_{l}\right)$ de um número $N_{l}$ de pontos de integração no domínio, o qual a integral está sendo avaliada, bem como um conjunto de $N_{l}$ números $w_{l}$ chamados de pesos da fórmula de quadratura $\left(l=1,2, \ldots, N_{l}\right)$. Deste modo, se

$$
\hat{G}(\xi, \eta)=\hat{g}(\xi, \eta)|J(\xi, \eta)|
$$


for integrada em $\hat{\Omega}$, utiliza-se a fórmula

$$
\int_{\hat{\Omega}} \hat{g}(x, y) d x d y=\int_{\hat{\Omega}} \hat{G}(\xi, \eta) d \xi d \eta=\sum_{l=1}^{N_{l}} \hat{G}\left(\xi_{l}, \eta_{l}\right) w_{l}+\hat{E}
$$

onde $\hat{E}$ é o erro de quadratura.

\section{Matriz de Rigidez e Vetor de Carga no elemento:}

Matriz de rigidez é uma matriz que indica relações entre propriedades do elemento. As entradas $k_{i j}^{e}$ e $f_{i j}^{e}$ na matriz de rigidez e vetor de carga do elemento definidas de acordo com o problema a ser considerado, podem ser calculadas diretamente usando (2.15) e a regra de integração (2.16).

Somente os valores dos integrandos nos pontos de integração em $\hat{\Omega}$ necessitam ser usados em todos os cálculos.

Assim, como

$$
k_{i j} u_{i j}=F_{j}
$$

Encontra-se $u_{i j}$ resolvendo esse sistema linear.

\subsubsection{Elementos Triangulares}

Dado um triângulo $\Omega_{e}$ descrito em um sistema de coordenadas cartesianas, este pode ser mapeado, através de uma transformação linear para um sistema assimétrico, por um elemento mestre $\hat{\Omega}$, como mostra a Figura (2.2). Desde que o mapeamento seja linear e inversível, o mapeamento inverso de $\Omega_{e}$ para $\hat{\Omega}$ existe e é também linear. Esta linearidade implica também que bases polinomiais no plano $x-y$ serão transformadas para bases polinomiais no plano $\xi-\eta$ e vice-versa.

A transformação linear de $\Omega_{e}$ para $\hat{\Omega}$ pode ser derivada diretamente impondo o mapeamento das faces de $\hat{\Omega}$. Consequentemente, é natural usar-se o mapeamento paramétrico do elemento mestre.

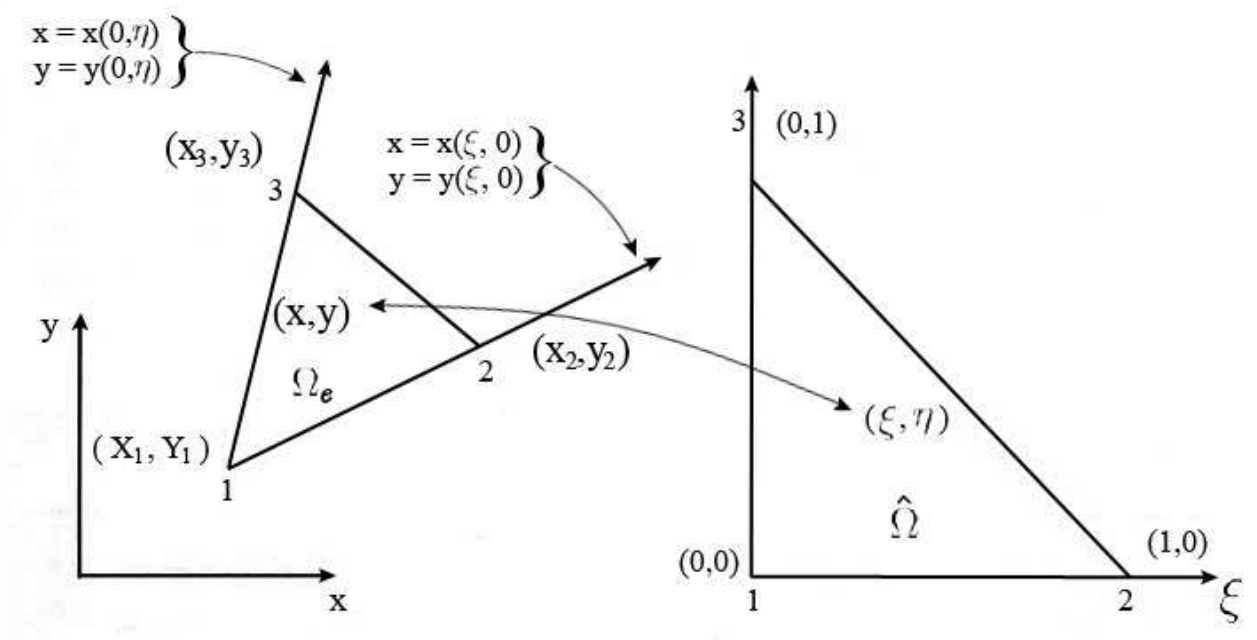

Figura 2.2: Mapeamento linear do elemento $\Omega_{e}$ para o elemento mestre $\hat{\Omega}$ e o mapeamento inverso. 
As três funções de forma lineares para o elemento mestre $\hat{\Omega}$, geralmente um triângulo isósceles, podem ser escritas de modo que cada função assuma um valor dado no vértice correspondente e zero nos demais vértices, isto é,

$$
\hat{\psi}_{1}(\xi, \eta)=1-\xi-\eta, \quad \hat{\psi}_{2}(\xi, \eta)=\xi, \quad \hat{\psi}_{3}(\xi, \eta)=\eta
$$

para os nós 1,2 e 3 respectivamente. As coordenadas mapeadas pela transformação $T_{e}$ são definidas por

$$
x=\sum_{j=1}^{3} x_{j} \psi_{j}(\xi, \eta), \quad y=\sum_{j=1}^{3} y_{j} \psi_{j}(\xi, \eta),
$$

em que $\left(x_{j}, y_{j}\right), j=1,2,3$ são as coordenadas $x-y$ dos vértices em um sistema local.

Introduzindo (2.18) em (2.19) e invertendo, obtêm-se para o mapeamento inverso $T_{e}^{-1}$ as seguintes relações

$$
\begin{aligned}
& \xi=\frac{1}{2 A_{e}}\left[\left(y_{3}-y_{1}\right)\left(x-x_{1}\right)-\left(x_{3}-x_{1}\right)\left(y-y_{1}\right)\right] \\
& \eta=\frac{1}{2 A_{e}}\left[\left(y_{2}-y_{1}\right)\left(x-x_{1}\right)-\left(x_{2}-x_{1}\right)\left(y-y_{1}\right)\right]
\end{aligned}
$$

na qual $A_{e}$ é a área de $\Omega_{e}$. O lado direito das equações $(2.20)$ e (2.21) são reorganizadas como funções de forma linear das equações

$$
\begin{aligned}
& \psi_{1}^{e}(x, y)=\frac{1}{2 A_{e}}\left[\left(x_{2} y_{3}-x_{3} y_{2}\right)+\left(y_{2}-y_{3}\right) x+\left(x_{3}-x_{2}\right) y\right] \\
& \psi_{2}^{e}(x, y)=\frac{1}{2 A_{e}}\left[\left(x_{3} y_{1}-x_{1} y_{3}\right)+\left(y_{3}-y_{1}\right) x+\left(x_{1}-x_{3}\right) y\right] \\
& \psi_{3}^{e}(x, y)=\frac{1}{2 A_{e}}\left[\left(x_{1} y_{2}-x_{2} y_{1}\right)+\left(y_{1}-y_{2}\right) x+\left(x_{2}-x_{1}\right) y\right]
\end{aligned}
$$

Assim,

$$
\xi=\psi_{2}^{e}(x, y), \quad \eta=\psi_{3}^{e}(x, y), \quad 1-\xi-\eta=\psi_{1}^{e}(x, y) .
$$

Com estes resultados, pode-se determinar as derivadas $\partial \xi / \partial x, \partial \xi / \partial y, \partial \eta / \partial x, \partial \eta / \partial y$ das funções coordenadas $\xi$ e $\eta$, o Jacobiano $|J|$, e consequentemente a matriz de rigidez e o vetor de carga.

Coordenadas de área: As expressões $\xi, \eta$ e $1-\xi-\eta$ em (2.23) podem ser convenientemente interpretadas em termos das proporções de área. Isso conduz à introdução das coordenadas de área que facilitam o desenvolvimento de famílias de funções de forma com grau mais elevado e também a derivação das fórmulas de integração.

Seja $(\xi, \eta)$ as coordenadas de um ponto arbitrário em $\hat{\Omega}$ e $(x, y)$ o ponto correspondente em $\Omega_{e}$. Suponha que seja construído linhas retas ligando $(\xi, \eta)$ e $(x, y)$ para os vértices, e denotadas por $\hat{a}_{i}$ e $a_{i}$ as áreas dos subtriângulos opostos ao nó $i$ em $\hat{\Omega}$ e $\Omega_{e}$, respectivamente. Os termos $1-\xi-\eta$, $\xi$ e $\eta$ em (5.16) são facilmente mostrados ser as proporções de área $\hat{a}_{i} / \hat{A}$, na qual $\hat{A}=\frac{1}{2}$ é a área do elemento mestre. Define-se as coordenadas de área em $\hat{\Omega}$ como

$$
\zeta_{i}=\frac{\hat{a}_{i}}{\hat{A}}, \quad i=1,2,3
$$


ou

$$
\zeta_{1}=1-\xi-\eta, \quad \zeta_{2}=\xi, \quad \zeta_{3}=\eta
$$

Visto que, a transformação $T_{e}$ é linear, o Jacobiano $|J|$ é constante e as áreas de $\Omega_{e}$ e $\hat{\Omega}$ são proporcionais. Isso implica que o mapeamento distorce as áreas uniformente. Assim, o significado das coordenadas de área é preservado pela transformação linear e tem-se:

$$
\zeta_{i}=\frac{\hat{a}_{i}}{\hat{A}}=\frac{a_{i}}{A_{e}}, \quad i=1,2,3 .
$$

Os subtriângulos e as linhas coordenadas são indicados na Figura (2.3). Esta propriedade não é preservada se o mapeamento $T_{e}$ não for linear.
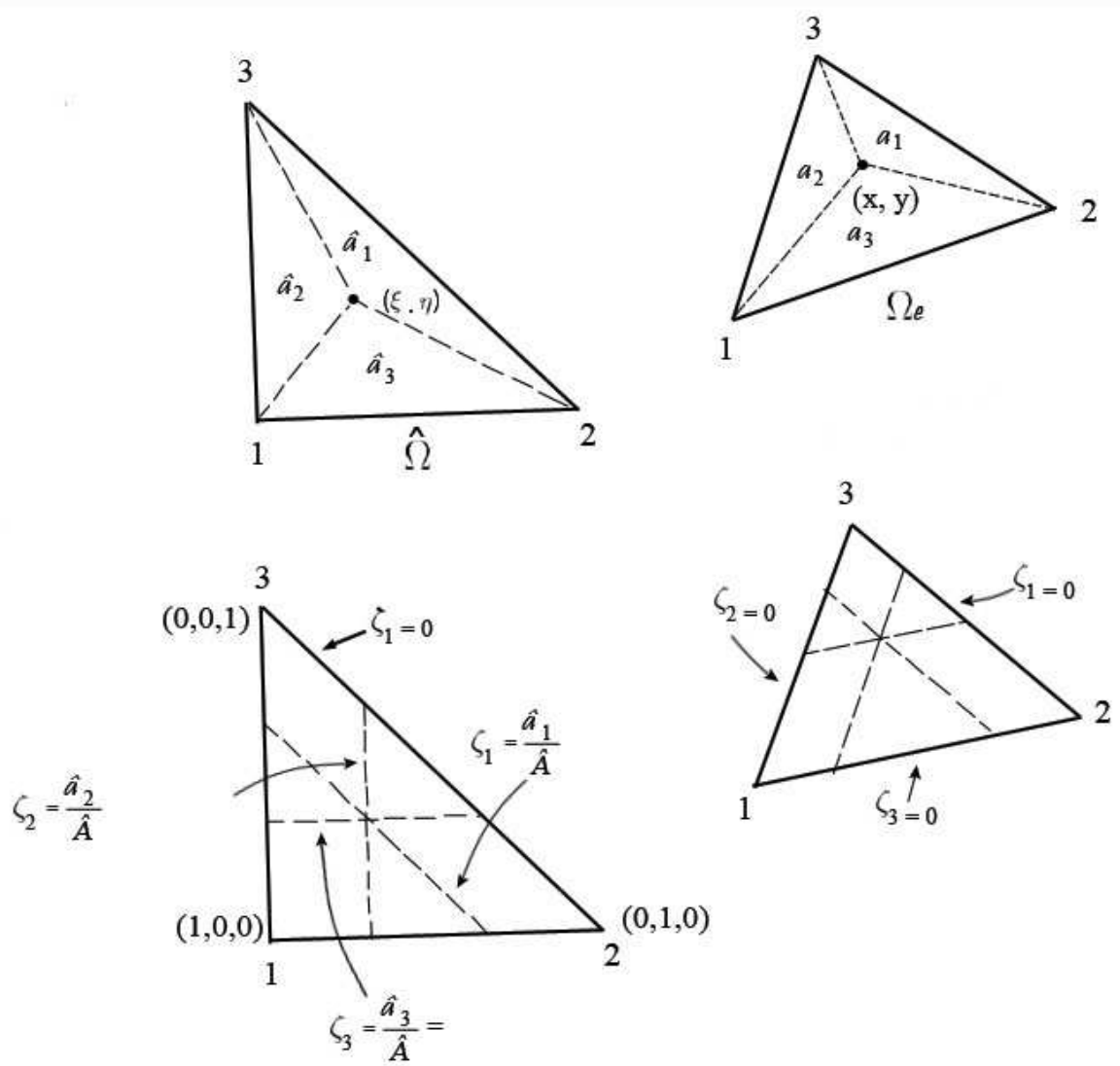

Figura 2.3: Áreas dos subtriângulos e as coordenadas de área.

Com relação as áreas de subtriângulos e linhas coordenadas na Figura (2.3), pode-se observar:

1. Sejam as coordenadas $\zeta_{i}$ de um ponto interior arbitrário $P,\left(\alpha_{1}, \alpha_{2}, \alpha_{3}\right)$. A linha coordenada $\zeta_{i}=\alpha_{i}=$ constante é paralela ao lado do triângulo oposto ao vértice $i: \zeta_{1}=\alpha_{1}$ é uma linha paralela ao lado $2-3, \zeta_{2}=\alpha_{2}$ é paralela a $1-3$, e $\zeta_{3}=\alpha_{3}$ é paralela a $1-2$.

2. A linha coordenada $\zeta_{i}=0$ define a fronteira do triângulo: $\zeta_{1}=0$ é o lado $2-3$ oposto ao vértice $1, \zeta_{2}=0$ é o lado $1-3$ oposto ao vértice 2 e $\zeta_{3}=0$ é o lado $1-2$ oposto ao vértice 3 . 
3. As coordenadas triangulares dos vértices 1,2 e 3 são $(1,0,0),(0,1,0)$ e $(0,0,1)$, respectivamente.

Estas propriedades são muito usadas na construção das funções de forma de alta ordem em triângulos.

Assim, pode-se escrever (2.15) em termos de coordenadas de área, como

$$
\int_{\hat{\Omega}} G\left(\zeta_{1} \zeta_{2} \zeta_{3}\right) d \hat{\Omega}, \quad\left(\zeta_{1}=1-\zeta_{2}-\zeta_{3}\right)
$$

Logo da fórmula de quadratura, tem-se

$$
\int_{\hat{\Omega}} G\left(\zeta_{1} \zeta_{2} \zeta_{3}\right) d \hat{\Omega} \simeq \sum_{l=1}^{N l} w_{l} G\left(\zeta_{l}\right),
$$

em que $\zeta_{l}=\left(\left(\zeta_{1}\right)_{l},\left(\zeta_{2}\right)_{l},\left(\zeta_{3}\right)_{l}\right)$ são as coordenadas de área dos pontos de quadratura em $\hat{\Omega}$. 


\section{CAPÍTULO}

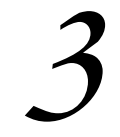

\section{Formulação Semi-Lagrangeana}

\subsection{Introdução}

A formulação Semi-Lagrangeana foi introduzida no início dos anos 80 por Robert, (1981) e Pironneau, (1982) e a idéia básica procedia na discretização da solução da derivada Lagrangeana no tempo ao invés da derivada Euleriana. Como exemplo pode-se citar uma equação do tipo convecção difusão qualquer que obedeça ao esquema Semi-Lagrangeano, onde apenas o termo responsável pela convecção é considerado, desprezando assim o termo difusivo.

\subsection{Esquema da Formulação}

A formulação Semi-Lagrangeana é utilizada aqui para discretizar o termo convectivo ou derivada material, que aparecem nas equações (1.6) e (1.8) dada por:

$$
\frac{D \varphi_{i}}{D t}=\frac{\partial \varphi_{i}}{\partial t}+\mathbf{u} \nabla \varphi_{i}
$$

onde $\mathbf{u}=(u, v)$, com $u$ e $v$ sendo as velocidades nas direções $x$ e $y$ respectivamente.

Através da formulação Semi-Lagengeana, discretiza-se (3.1) no tempo para cada ponto $p$ do domínio utilizando um esquema implícito de primeira ordem, ou seja:

$$
\frac{D \varphi_{i}}{D t}=\frac{\varphi_{i p}^{(n+1)}-\varphi_{i p^{*}}^{(n)}}{\Delta t}
$$

em que

$\varphi_{i p}^{(n+1)}$ : é a variável $i$ no ponto $p$ no tempo $(n+1)$;

$\varphi_{i p^{*}}^{(n)}$ : é a variável $i$ no ponto $p^{*}$ no tempo $(n)$;

$p^{*}=p-\Delta t \mathbf{u}_{p}$ com $\mathbf{u}_{p}$ sendo a velocidade no ponto $\mathrm{p}$. Onde $\mathbf{u}_{p}$ é obtida da resolução das equações de Navier-Stokes.

$\varphi_{i p^{*}}^{(n)}=\varphi_{i p^{*}}^{n}\left(x_{p^{*}}, t^{n}\right)$ e $x_{p^{*}}$ é chamado de ponto de saída. 

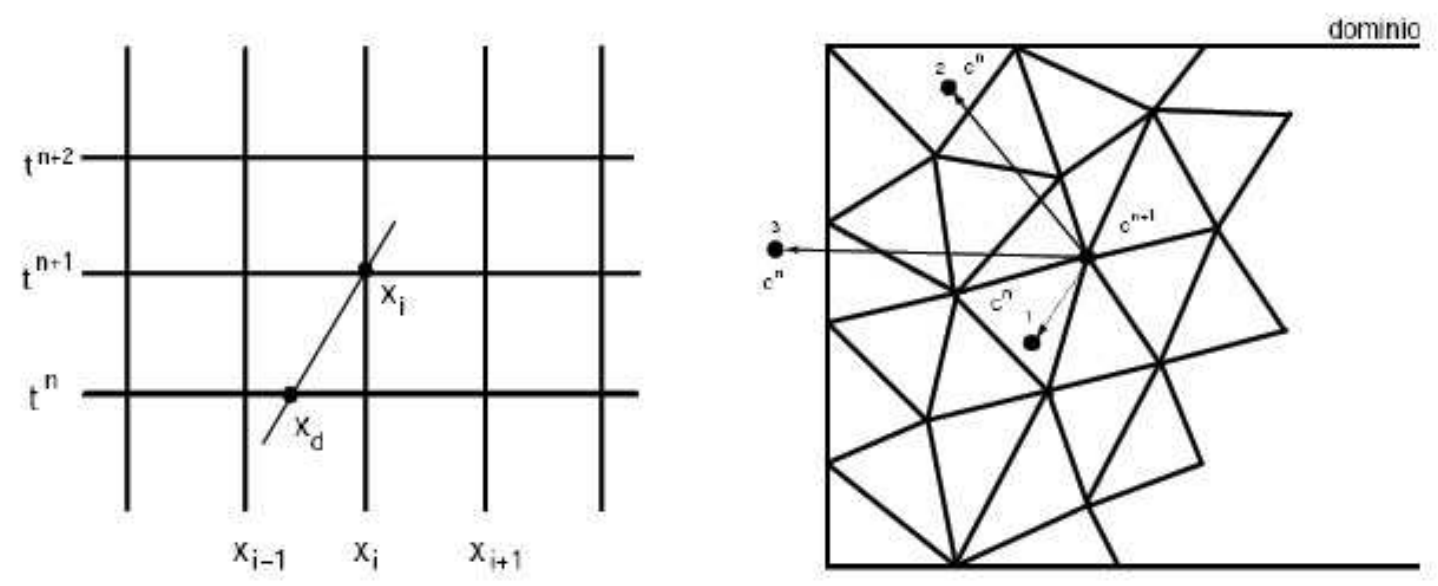

Figura 3.1: Esquema da formulação Semi-Lagrangeana.

$\mathrm{Na}$ forma forte, a derivada material é calculada ao longo do trajeto característico, determinando-se o ponto $x_{p^{*}}$ e resolvendo a equação $\frac{D \varphi_{i}}{D t}=a$ para trás no tempo $t^{n+1} \geq$ $t \geq t^{n}$ usando a condição inicial $x\left(t^{n+1}\right)=x_{p^{*}}$. Este esquema é mostrado na Figura (3.1) à esquerda. Um método de integração deve ser utilizado para se encontrar a posição do ponto do passo anterior na malha. Utilizando-se um esquema de discretização de primeira ordem, a trajetória é aproximada por uma reta. Dependendo da trajetória, três situações podem ocorrer, as quais são mostradas na Figura (3.1), à direita, pelos pontos 1,2 e 3 . Na trajetória 1 , o ponto do passo anterior $c_{n}$ se encontra próximo ao ponto do passo atual $c_{n+1}$ e dentro do domínio do problema. Depois de identificado o elemento que contêm o ponto 1, uma interpolação entre os nós do elemento é necessária para se conhecer seu valor. No caso do ponto 2, o ponto do passo anterior $c_{n}$ se encontra distante do ponto do passo atual $c_{n+1} \mathrm{e}$ dentro do domínio do problema. A diferença entre os pontos 1 e 2 está no comprimento da trajetória. No ponto 2, a trajetória também será aproximada por reta e no caso do ponto 3, o valor de origem é calculado utilizando as condições de contorno. 


\section{$-4$ \\ Discretização das Equações dos Transportes}

\subsection{Introdução}

A solução numérica de um problema de escoamento de fluidos pode ser obtida através das seguintes etapas: dado um problema físico, utiliza-se modelagem matemática através de equações governantes e em seguida obtêm-se uma solução aproximada aplicando um processo de discretização.

No presente trabalho utiliza-se o método de Elementos Finitos na discretização espacial, e a Formulação Semi-Lagrangeana na discretização temporal das equações.

A malha utilizada é triangularizada podendo ser regular estruturada ou não-estruturada.

\subsection{Discretização da Equação do Transporte da Tem- peratura}

A solução da equação do transporte da tempertatura obedece os seguintes procedimentos de resolução:

- Substituir a derivada material presente na equação, pela formulação Semi-Lagrangeana;

- Discretizar a equação através do método de Elementos Finitos, isto é, escrevê-la na formulação variacional e resolvê-la pelo Método de Galerkin;

- Resolver o sistema linear resultante.

Utilizando a formulação Semi-Lagrangeana para discretizar a derivada material presente na equação (1.6), tem-se

$$
\frac{T_{p}^{(n+1)}-T_{p^{*}}^{(n)}}{\Delta t}=\nabla \cdot\left(\alpha \nabla T^{n+1}\right)
$$




\subsubsection{Formulação Variacional da Equação do Transporte da Tem- peratura}

Considere a equação do transporte da temperatura, escrita em sua formulação Semi -Lagrangeana (4.1) válida num domínio $\Omega$ de dimensão $m$, sujeita as condições de contorno

$$
\begin{gathered}
T=g, \quad \text { em } \quad \Gamma_{1} \\
\frac{\partial T}{\partial n}=0, \quad \text { em } \quad \Gamma_{2}
\end{gathered}
$$

onde $\Gamma=\partial \Omega$ é o bordo de $\Omega$, com $\Gamma=\Gamma_{1} \oplus \Gamma_{2}$, isto é, $\Gamma=\Gamma_{1} \cup \Gamma_{2}$ e $\Gamma_{1} \cap \Gamma_{2}=\varnothing$ e $\mathbf{n}$ é o vetor normal a $\Gamma_{2}$. Note que (4.2) representa a condição de Dirichlet em $\Gamma_{1}$ e (4.3) representa a condição de Neumann, ou condição natural em $\Gamma_{2}$.

Considere o espaço de dimensão infinita,

$$
L^{2}(\Omega)=\left\{v: \Omega \longrightarrow \mathbb{R}, \int_{\Omega} v^{2} d \Omega<\infty\right\}
$$

e o espaço de Sobolev,

$$
H^{1}(\Omega)=\left\{v \in L^{2}(\Omega): \frac{\partial v}{\partial x_{i}} \in L^{2}(\Omega), i=1, \ldots, m\right\}
$$

Pode-se definir os subespaços

$$
\mathbb{V}_{T_{\Gamma}}=\left\{v \in H^{1}(\Omega): v=T_{\Gamma} \quad \text { em } \quad \Gamma_{1}\right\}
$$

e em particular, para $T_{\Gamma}=0$,

$$
\mathbb{V}_{0}=\left\{v \in H^{1}(\Omega): v=0 \quad \text { em } \quad \Gamma_{1}\right\}
$$

Para obter a formulação variacional do problema dado pelas equações (4.1)-(4.3), basta multiplicar (4.1) por uma função teste $v \in \mathbb{V}$ arbitraria e integrar o resultado no domínio. Assim, o problema agora consiste em obter uma solução $T \in \mathbb{V}_{T_{\Gamma}}$ de forma que

$$
\int_{\Omega}\left[-\Delta t \nabla \cdot\left(\alpha \nabla T_{p}^{(n+1)}\right)+T_{p}^{(n+1)}\right] v d \Omega=\int_{\Omega} T_{p^{*}}^{(n)} v d \Omega
$$

$\forall v \in \mathbb{V}_{T_{\Gamma}}$

Aplicando a primeira forma de Green na integral acima, tem-se

$$
\int_{\Omega} \alpha \nabla T^{n+1} \cdot \nabla v \quad d \Omega-\int_{\Gamma} v\left(\alpha \nabla T^{n+1}\right) \cdot \mathbf{n} d \Gamma-\int_{\Omega} T_{p^{*}}^{(n)} v d \Omega=0
$$

como

$$
\int_{\Gamma} v\left(\alpha \nabla T^{n+1}\right) \cdot \mathbf{n} d \Gamma=\int_{\Gamma_{1}} v\left(\alpha \nabla T^{n+1}\right) \cdot \mathbf{n} d \Gamma+\int_{\Gamma_{2}} v\left(\alpha \nabla T^{n+1}\right) \cdot \mathbf{n} d \Gamma
$$

Utilizando as condições de contorno (4.2) e (4.3), segue que,

$$
v \in \mathbb{V}_{0} \Longrightarrow v=0 \quad \text { em } \quad \Gamma_{1}
$$


e pelas condições naturais, $(\nabla T) \cdot \mathbf{n}=0 \mathrm{em} \Gamma_{2}$.

Segue,

$$
\int_{\Omega}\left[-\Delta t \nabla \cdot\left(\alpha \nabla T_{p}^{(n+1)}\right)+T_{p}^{(n+1)}\right] v d \Omega-\int_{\Omega} T_{p^{*}}^{(n)} v d \Omega=0
$$

Assim, define-se as seguintes formas:

$$
\begin{gathered}
K(\alpha, T, v)=\int_{\Omega}\left[-\Delta t \nabla \cdot\left(\alpha \nabla T_{p}^{(n+1)}\right)+T_{p}^{(n+1)}\right] v d \Omega \\
m(f, v)=\int_{\Omega} T_{p^{*}}^{(n)} v d \Omega
\end{gathered}
$$

A formulação variacional do problema de transporte da temperatura dado por (4.1)-(4.3) pode ser reescrito da seguinte maneira:

Encontrar $T \in \mathbb{V}_{T_{\Gamma}}$ tal que

$$
K(\alpha, T, v)=m(f, v)
$$

Esta formulação também é conhecida como forma fraca. Observe que as funções de peso $v$ satisfazem a condição de Dirichlet em $\Gamma_{1}$, onde é imposta a condição de Dirichlet do problema. As condições de Neumann aparecem naturalmente, por isso são chamadas de condições de contorno naturais.

\subsubsection{Método de Galerkin para a Equação do Transporte da Tem- peratura}

Considere a equação do transporte da temperatura, dada por (1.6) e sua respectiva formulação variacional dada por (4.12). Suponha que $\Omega$ seja discretizado por uma malha de elementos $\Omega^{e}$ aos quais estão associadas famílias de funções de interpolação lineares.

Considere ainda que em cada elemento $e$ da malha está definida uma família de funções

$$
\psi^{e}=\left[\psi_{1}^{e}, \ldots, \psi_{s}^{e}\right]
$$

onde $s$ é o número de nós que definem o elemento $(s=3$ no caso de elemento triangular linear). Para representar a numeração dos nós localmente em um elemento $e$ qualquer, serão utilizadas as letras $i, j$, com $i=j=1, \ldots, s$ e para representar a numeração global dos nós serão utilizadas as letras $m, N \operatorname{com} m, N=1, \ldots, M$, onde $M$ é o número total de nós na malha. Deste modo, se uma função de interpolação é referenciada como $\psi_{m}^{e}$, isto significa que $\psi_{m}^{e}=\psi_{i}^{e}$, onde $i$ é a numeração local do nó $m$ no elemento $e$.

Define-se função de interpolação nodal no nó $m$ como sendo a soma de todas as funções de interpolação definidas em $m$, isto é,

$$
\psi_{m}=\sum_{e \in S(m)} \psi_{e}
$$

onde $S(m)$ é o conjunto de todos os elementos que contêm o nó $m$. Assim, se $u_{N}$ é o valor nodal da variável avaliada no nó $N$, a aproximação da variável $u$ pode ser expressa em 
função de uma combinação linear de funções de interpolação nodais, como segue

$$
U(x, y)=\sum_{N} \psi_{N}(x, y) u_{N}
$$

Tal aproximação pode ser escrita em função da numeração local dos nós, isto é,

$$
U(x, y)=\sum_{e} \sum_{j \in e} \psi_{j}^{e}(x, y) u_{j}
$$

e em cada elemento $e$ da malha, $U(x, y)$ restrito a um elemento é dado por

$$
u^{e}(x, y)=\sum_{j \in e} \psi_{j}^{e}(x, y) u_{j}
$$

No método de Galerkin, a discretização da forma fraca da equação (4.12) é feita substituindo-se o espaço $H^{1}$ por um espaço de dimensão finita $\left(H^{1}\right)^{h}$, gerado pelas funções de interpolação $\psi_{m}$. Na prática tal procedimento se resume na substituição da função peso $v$ pelas funções de interpolação nodais $\psi_{m}$.

Utilizando-se o método de Galerkin para a equação (4.12), isto é, substituindo-se $v$ por $\psi_{m}$ e $T^{n+1}$ por $U^{n+1}$ dadas em (4.17) e (4.18) respectivamente, tem-se

$$
\int_{\Omega}-\Delta t \alpha \nabla\left(\sum_{N} \psi_{N} T_{N}^{(n+1)}\right) \cdot \nabla \psi_{m} d \Omega+\int_{\Omega} \sum_{N} \psi_{N} T_{N}^{(n+1)} \psi_{m} d \Omega=\int_{\Omega} T_{p^{*}}^{(n)} \psi_{m} d \Omega
$$

que define uma equação para cada nó livre da malha, isto é $m=1, \ldots, M$. Como $\Omega$ é discretizado por uma malha de elementos $\Omega^{e}$, e como a integral de um elemento $e$ não tem contribuição nas integrais dos outros elementos da malha, pode-se escrever

$$
\sum_{e} \int_{\Omega^{e}} \sum_{N}-\Delta t \alpha \nabla\left(\psi_{N} T_{N}^{(n+1)}\right) \cdot \nabla \psi_{m} d \Omega+\sum_{e} \int_{\Omega^{e}} \sum_{N} \psi_{N} T_{N}^{(n+1)} \psi_{m} d \Omega=\sum_{e} \int_{\Omega^{e}} T_{p^{*}}^{(n)} \psi_{m} d \Omega
$$

onde as integrais são agora avaliadas em cada elemento $\Omega^{e}$. Note que $\psi_{m}$ restrito ao elemento $e$ é exatamente $\psi_{m}^{e}$, e que $\sum_{N} \psi_{m}^{e} T_{N}^{n+1}$ restrito ao elemento e é $\sum_{j \in e} \psi_{j}^{e} T_{j}^{n+1}$, resultando

$$
\sum_{e} \int_{\Omega^{e}} \sum_{j \in e}-\Delta t \alpha \nabla\left(\psi_{j}^{e} T_{j}^{(n+1)}\right) \cdot \nabla \psi_{m} d \Omega+\sum_{e} \int_{\Omega^{e}} \sum_{j \in e} \psi_{j}^{e} T_{j}^{(n+1)} \psi_{m}^{e} d \Omega=\sum_{e} \int_{\Omega^{e}} T_{p^{*}}^{n} \psi_{m}^{e} d \Omega
$$

Note que em (4.23) o índice $j$ agora varia localmente dentro do elemento $(j=1,2,3)$ pois nesse caso será utilizado o elemento triangular linear, e que o índice $m$ ainda varia globalmente $(m=1, \ldots, M)$. Mantendo-se uma correspondência biunívoca entre a numeração local $\left(\psi_{i}^{e}\right)$ e a numeração global $\left(\psi_{m}^{e}\right)$, a equação $(4.23)$ pode ainda ser escrita como

$$
\sum_{e} \int_{\Omega^{e}} \sum_{i, j \in e}-\Delta t \alpha \nabla \psi_{i}^{e} \cdot \nabla\left(\psi_{j}^{e} T_{j}^{(n+1)}\right) d \Omega+\sum_{e} \int_{\Omega^{e}} \sum_{i, j \in e} \psi_{j}^{e} T_{j}^{(n+1)} \psi_{i}^{e} d \Omega=\sum_{e} \int_{\Omega^{e}} \sum_{i \in e} T_{p^{*}}^{(n)} \psi_{m}^{e} d \Omega
$$


Assim,

$$
\sum_{e} \sum_{i, j \in e}\left[\int_{\Omega^{e}}\left(-\Delta t \alpha \nabla \psi_{i}^{e} \cdot \nabla\left(\psi_{j}^{e}\right)+\psi_{i}^{e} \psi_{j}^{e}\right) d \Omega\right] T_{j}^{(n+1)}=\sum_{e} \sum_{i \in e} \int_{\Omega^{e}} T_{p^{*}}^{n} \psi_{i}^{e} d \Omega
$$

Logo a equação (4.25) define um sistema linear

$$
\sum_{j=1}^{N e} k_{i j}^{e} u_{j}^{e}=f_{i}^{e}
$$

onde, $N e$ é o número de elementos, assim

$$
\begin{gathered}
k_{i j}^{e}=\int_{\Omega^{e}}\left(-\Delta t \alpha \nabla \psi_{i}^{e} \cdot \nabla\left(\psi_{j}^{e}\right)+\psi_{i}^{e} \psi_{j}^{e}\right) d \Omega \\
f_{i}^{e}=\int_{\Omega^{e}} T_{p^{*}}^{n} \psi_{i}^{e} d \Omega
\end{gathered}
$$

O domínio será discretizado em elementos triangulares linear, onde são conhecidos os valores das velocidades nos vértices. Estes elementos são mapeados por um elemento mestre triangular linear como descrito no Capítulo 2 para o qual estão definidas as seguintes funções de forma:

$$
\begin{aligned}
& \hat{\psi}_{1}(\xi, \eta)=1-\xi-\eta \\
& \hat{\psi}_{2}(\xi, \eta)=\xi \\
& \hat{\psi}_{3}(\xi, \eta)=\eta
\end{aligned}
$$

Fazendo os cálculos sobre o elemento mestre, segue

$$
k_{i j}^{\Omega_{n}}=\int_{\Omega^{e}}\left[-\Delta t \alpha\left(\frac{\partial \hat{\psi}_{i}}{\partial x} \frac{\partial \hat{\psi}_{j}}{\partial x}+\frac{\partial \hat{\psi}_{i}}{\partial y} \frac{\partial \hat{\psi}_{j}}{\partial y}\right)+\hat{\psi}_{i} \hat{\psi}_{j}\right]\left|\frac{\partial(x, y)}{\partial(\xi, \eta)}\right| d \xi d \eta
$$

onde

$$
\left|\frac{\partial(x, y)}{\partial(\xi, \eta)}\right|=\left|\frac{\partial x}{\partial \xi} \frac{\partial y}{\partial \eta}-\frac{\partial x}{\partial \eta} \frac{\partial y}{\partial \xi}\right|
$$

A integral resultante é resolvida através da regra de Quadratura Gaussiana, isto é

$$
\int_{\hat{\Omega}} \hat{G}(\xi, \eta) d \xi d \eta=\sum_{l=1}^{N e} \hat{G}\left(\xi_{l}, \eta_{l}\right) w_{l}
$$

Após calcular $k_{i j}^{\Omega_{n}}$, com $i, j=1,2,3$ e $n=1, \ldots, N e$ tem-se uma matriz de massa local para cada elemento. A matriz de massa global é calculada como sendo a contribuição da matriz de massa de cada elemento.

De forma análoga, calcula-se o vetor de carga $f_{i}^{\Omega_{n}}$ para cada elemento, localmente, e sua respectiva contribuição global.

Finalmente, obtêm-se o seguinte sistema linear:

$$
k_{i j}^{\text {global }} u_{j}=f_{i}^{\text {global }}
$$

Resolvendo-se o sistema linear (4.32) encontra-se os valores de $u_{j}$ que correspondem a encontrar $T_{p}^{(n+1)}$. 


\subsection{Discretização da Equação do Transporte das Con- centrações de Espécies Constituintes}

Os procedimentos de resolução da equação do transporte das concentrações de espécies constituintes são os mesmos descritos para a equação do transporte da temperatura.

Será discretizada aqui a equação do transporte das espécies constituintes dada de forma geral, isto é, para $n$ constituintes.

Considere a equação do transporte das concentrações de espécies constituintes (1.8). Utilizando a formulação Semi-Lagrangeana para a derivada material, tem-se

$$
\frac{D c_{i}}{D t}=\frac{c_{i p}^{(n+1)}-c_{i p^{*}}^{(n)}}{\Delta t}
$$

Substituindo-se (4.33) em (1.8), tem-se

$$
\frac{c_{i p}^{(n+1)}-c_{i p^{*}}^{(n)}}{\Delta t}=\nabla \cdot\left(\lambda_{D_{i}} \nabla c_{i}\right)+\sum_{\bar{n}=1}^{\bar{n}_{\max }}\left(\sum_{\substack{j=1 \\ \pi_{j} \in \Pi_{\bar{n}}}}^{N P_{\bar{n}}} \mu_{i j}^{\prime} \prod_{p=1}^{\bar{n}} c_{\pi_{j p}}^{\alpha_{j \pi_{j p}}}-\sum_{\substack{j=1 \\ \pi_{j} \in \Pi_{\bar{n}}}}^{N P_{\bar{n}}} c_{i}^{\gamma_{i j}} \mu_{i j}^{\prime \prime} \prod_{p=1}^{\bar{n}} c_{\pi_{j p}}^{\beta_{\pi_{j p} j}}\right)+S_{i}
$$

Como a resolução será de forma desacoplada, segue que a concentração de interesse no ponto $p$ será dada no tempo $n+1$ e as outras concentrações no tempo $n$, isto é

$$
\frac{c_{i p}^{(n+1)}-c_{i p^{*}}^{(n)}}{\Delta t}=\nabla \cdot\left(\lambda_{D_{i}} \nabla c_{i}^{(n+1)}\right)+\sum_{\bar{n}=1}^{\bar{n}_{\max }}\left(\sum_{\substack{j=1 \\ \pi_{j} \in \Pi_{\bar{n}}}}^{N P_{\bar{n}}} \mu_{i j}^{\prime} \prod_{p=1}^{\bar{n}}\left(c_{\pi_{j p}}^{\alpha_{j \pi_{j}}}\right)^{n}-\sum_{\substack{j=1 \\ \pi_{j} \in \Pi_{\bar{n}}}}^{N P_{\bar{n}}}\left(c_{i}^{\gamma_{i j}}\right)^{(n+1)} \mu_{i j}^{\prime \prime} \prod_{p=1}^{\bar{n}} c_{\pi_{j p}}^{\beta_{\pi_{j p} j}}\right)+S_{i},
$$

\subsubsection{Linearização}

Note que na equação $(4.35)$, o termo $\left(c_{i p}^{\gamma_{i j}}\right)^{(n+1)}$ pode ser não linear, o que torna a equação (4.35) complicada de se resolver, para isso, adota-se o processo de linearização, que consiste em escrever a expressão do termo a ser calculado, que está apresentando um comportamento não linear, em um termo linear, mais simples de ser resolvido, isto é, escrevendo-o como sendo o termo de interesse no tempo anterior, que é conhecido, subtraindo 1 de sua potência atual, multiplicando o mesmo pelo termo no tempo $n+1$ que é a incógnita de interesse, que agora passa a ser considerada linear eliminando-se a potência que à tornava não linear. Isto é, o termo $\left(c_{i}^{\gamma_{i j}}\right)^{(n+1)}$, será escrito como:

$$
\left(c_{i p}^{\gamma_{i j}}\right)^{(n+1)}=\left(c_{i p}^{\gamma_{i j}-1}\right)^{n}\left(c_{i p}\right)^{n+1}
$$


Assim, linearizando e isolando a concentração de interesse $c_{i p}^{(n+1)}$ em (4.35) obtêm-se

$$
\begin{aligned}
& -\nabla \cdot\left(\lambda_{D_{i}} \nabla\left(c_{i p}\right)^{(n+1)}\right)+c_{i p}^{(n+1)}\left(\frac{1}{\Delta t}+\sum_{\bar{n}=1}^{\bar{n}_{\max }}\left(\sum_{\substack{j=1 \\
\pi_{j} \in \Pi_{\bar{n}}}}^{N P_{\bar{n}}}\left(c_{i}^{\gamma_{i j}-1}\right)^{n} \mu_{i j}^{\prime \prime} \prod_{p=1}^{\bar{n}} c_{\pi_{j p}}^{\beta_{\pi_{j p}}}\right)\right)= \\
& \left(\frac{c_{i}^{n}}{\Delta t} \sum_{\bar{n}=1}^{\bar{n}_{\max }}\left(\sum_{\substack{j=1 \\
\pi_{j} \in \Pi_{\bar{n}}}}^{N P_{\bar{n}}} \mu_{i j}^{\prime} \prod_{p=1}^{\bar{n}}\left(c_{\pi_{j p}}^{\alpha_{j \pi_{j p}}}\right)^{n}\right)+S_{i}\right)
\end{aligned}
$$

\subsubsection{Formulação Variacional da Equação do Transporte das Con- centrações de Espécies Constituintes}

O primeiro passo para a aproximação por Elementos Finitos é escrever a equação (4.37) em sua formulação variacional, que consiste em projetar essa equação em um espaço cuja base é conhecida e integrá-la sobre todo o domínio.

Considere a equação do transporte das concentrações de espécies (4.37) válida num domínio $\Omega$ de dimensão $m$, sujeita as seguintes condições de contorno

$$
\begin{array}{ccc}
c_{i}=g_{i}, \quad \text { em } & \Gamma_{1} \\
\frac{\partial c_{i}}{\partial \mathbf{n}}=0, \quad \text { em } & \Gamma_{2}
\end{array}
$$

com $i=1, \ldots, n$ e $n$ o número de concetrações. Onde $\Gamma=\partial \Omega$ é o bordo de $\Omega$, com $\Gamma=\Gamma_{1} \oplus \Gamma_{2}$, isto é, $\Gamma=\Gamma_{1} \cup \Gamma_{2}$ e $\Gamma_{1} \cap \Gamma_{2}=\varnothing$ e $\mathbf{n}$ é o vetor normal a $\Gamma_{2}$. Note que (4.38) representa a condição de Dirichlet em $\Gamma_{1}$ e (4.39) representa a condição de Neumann, ou condição natural em $\Gamma_{2}$.

Considere os mesmos espaços adotados na seção anterior, isto é, um espaço de dimensão infinita (4.4) e o espaço de Sobolev (4.5)

Pode-se definir os subespaços

$$
\mathbb{V}_{c_{i \Gamma}}=\left\{v \in H^{1}(\Omega): v=c_{i \Gamma} \quad \text { em } \quad \Gamma_{1}\right\}
$$

e em particular, para $c_{i \Gamma}=0$,

$$
\mathbb{V}_{0}=\left\{v \in H^{1}(\Omega): v=0 \quad \text { em } \quad \Gamma_{1}\right\}
$$

Para obter a formulação variacional do problema dado pelas equações (4.37)-(4.39), basta multiplicar (4.37) por uma função teste $v \in \mathbb{V}_{c_{i \Gamma}}$ arbitraria e integrar o resultado no domínio. Assim, o problema agora consiste em obter uma solução $c_{i} \in \mathbb{V}_{c_{i \Gamma}}$ de forma que

$$
\begin{aligned}
& \int_{\Omega}\left[-\nabla \cdot\left(\lambda_{D_{i}} \nabla\left(c_{i p}\right)^{(n+1)}\right)+c_{i p}^{(n+1)}\left(\frac{1}{\Delta t}+\sum_{\bar{n}=1}^{\bar{n}_{\max }}\left(\sum_{\substack{j=1 \\
\pi_{j} \in \Pi_{\bar{n}}}}^{N P_{\bar{n}}}\left(c_{i}^{\gamma_{i j}-1}\right)^{n} \mu_{i j}^{\prime \prime} \prod_{p=1}^{\bar{n}} c_{\pi_{j p}}^{\beta_{\pi_{j p}}}\right)\right)\right] v d \Omega \\
= & \int_{\Omega}\left[\left(\frac{c_{i}^{n}}{\Delta t} \sum_{\bar{n}=1}^{\bar{n}_{\max }}\left(\sum_{\substack{j=1 \\
\pi_{j} \in \Pi_{\bar{n}}}}^{N P_{\bar{n}}} \mu_{i j}^{\prime} \prod_{p=1}^{\bar{n}} c_{\pi_{j p}}^{\alpha_{j \pi_{j p}}}\right)+S_{i}\right)\right] v d \Omega
\end{aligned}
$$


$\forall v \in \mathbb{V}_{0}$

Aplicando a primeira forma do teorema de Green na integral

$$
\int_{\Omega}-\nabla \cdot\left(\lambda_{D_{i}} \nabla\left(c_{i p}\right)^{(n+1)}\right) d \Omega
$$

tem-se,

$$
\begin{aligned}
& \int_{\Omega}-\nabla \cdot\left(\lambda_{D_{i}} \nabla\left(c_{i p}\right)^{(n+1)}\right) d \Omega \\
= & \int_{\Omega} \lambda_{D_{i}} \nabla\left(c_{i p}\right)^{(n+1)} \nabla v d \Omega+\int_{\Gamma} v\left(\lambda_{D_{i}} \nabla\left(c_{i p}\right)^{(n+1)}\right) \cdot \mathbf{n} d \Gamma
\end{aligned}
$$

onde

$$
\begin{aligned}
& \int_{\Gamma} v\left(\lambda_{D_{i}} \nabla\left(c_{i p}\right)^{(n+1)}\right) \cdot \mathbf{n} d \Gamma \\
= & \int_{\Gamma_{1}} v\left(\lambda_{D_{i}} \nabla\left(c_{i p}\right)^{(n+1)}\right) \cdot \mathbf{n} d \Gamma+\int_{\Gamma_{2}} v\left(\lambda_{D_{i}} \nabla\left(c_{i p}\right)^{(n+1)}\right) \cdot \mathbf{n} d \Gamma
\end{aligned}
$$

Utilizando as condições de contorno (4.38) e (4.39), segue que,

$$
v \in \mathbb{V}_{0} \Longrightarrow v=0 \quad \text { em } \quad \Gamma_{1}
$$

e pelas condições naturais, $\left(\nabla c_{i}\right) \cdot \mathbf{n}=0 \mathrm{em} \Gamma_{2}$.

Logo,

$$
\int_{\Gamma} v\left(\lambda_{D_{i}} \nabla\left(c_{i p}\right)^{(n+1)}\right) \cdot \mathbf{n} d \Gamma=0
$$

Assim,

$$
\begin{aligned}
& \int_{\Omega}\left[-\nabla \cdot\left(\lambda_{D_{i}} \nabla\left(c_{i p}\right)^{(n+1)}\right)+c_{i p}^{(n+1)}\left(\frac{1}{\Delta t}+\sum_{\bar{n}=1}^{\bar{n}_{\max }}\left(\sum_{\substack{j=1 \\
\pi_{j} \in \Pi_{\bar{n}}}}^{N P_{\bar{n}}}\left(c_{i}^{\gamma_{i j}-1}\right)^{n} \mu_{i j}^{\prime \prime} \prod_{p=1}^{\bar{n}} c_{\pi_{j p}}^{\beta_{\pi_{j p}}}\right)\right)\right] v d \Omega \\
= & \int_{\Omega}\left[\left(\frac{c_{i}^{n}}{\Delta t} \sum_{\bar{n}=1}^{\bar{n}_{\max }}\left(\sum_{\substack{j=1 \\
\pi_{j} \in \Pi_{\bar{n}}}}^{N P_{\bar{n}}} \mu_{i j}^{\prime} \prod_{p=1}^{\bar{n}} c_{c_{\pi_{j p}}}^{\alpha_{j \pi_{j p}}}\right)+S_{i}\right)\right] v d \Omega
\end{aligned}
$$

Portanto, define-se as seguintes formas:

$$
\begin{gathered}
K\left(\alpha, c_{i}, v\right)=\int_{\Omega}\left[-\nabla \cdot\left(\lambda_{D_{i}} \nabla\left(c_{i p}\right)^{(n+1)}\right)+c_{i p}^{(n+1)}\left(\frac{1}{\Delta t}+\sum_{\bar{n}=1}^{\bar{n}_{\max }}\left(\sum_{\substack{j=1 \\
\pi_{j} \in \Pi_{\bar{n}}}}^{N P_{\bar{n}}}\left(c_{i}^{\gamma_{i j}-1}\right)^{n} \mu_{i j}^{\prime \prime} \prod_{p=1}^{\bar{n}} c_{\pi_{j p}}^{\beta_{\pi_{j p} j}}\right)\right)\right] v d \Omega \\
m(f, v)=\int_{\Omega}\left[\left(\frac{c_{i}^{n}}{\Delta t} \sum_{\bar{n}=1}^{\bar{n}_{\max }}\left(\sum_{\substack{j=1 \\
\pi_{j} \in \Pi_{\bar{n}}}}^{N P_{\bar{n}}} \mu_{i j}^{\prime} \prod_{p=1}^{\bar{n}} c_{\pi_{j p}}^{\alpha_{j \pi_{j p}}}\right)+S_{i}\right)\right] v d \Omega
\end{gathered}
$$


a formulação variacional do problema de transporte das concentrações de espécies dado por (4.37)-(4.39) pode ser reescrito da seguinte maneira:

Encontrar $c_{i} \in \mathbb{V}_{c_{i \Gamma}}$ tal que

$$
K\left(\alpha, c_{i}, v\right)=m(f, v)
$$

para $i=1, \ldots, n$, onde $n$ é o número de concentrações consideradas.

\subsubsection{Método de Galerkin para a Equação do Transporte das Con- centrações de Espécies Constituintes}

Utilizando o método de Galerkin para a equação (1.8), pode-se proceder da mesma forma que na equação do transporte da temperatura, isto é, substituindo-se $v$ por $\psi_{m}$ e $c_{i}^{n+1}$ por $U^{n+1}$ dadas em (4.37), tem-se

$$
\begin{aligned}
& \int_{\Omega} \lambda_{D_{i}} \nabla\left(\sum_{N} \psi_{N} c_{i N}^{(n+1)}\right) \cdot \nabla\left(\psi_{m}\right) d \Omega+ \\
& \int_{\Omega} \sum_{N} \psi_{N} c_{i N}^{(n+1)} \psi_{m}\left(\frac{1}{\Delta t}+\sum_{\bar{n}=1}^{\bar{n}_{\max }}\left(\sum_{\substack{j=1 \\
\pi_{j} \in \Pi_{\bar{n}}}}^{N P_{\bar{n}}}\left(c_{i}^{\gamma_{i j}-1}\right)^{n} \mu_{i j}^{\prime \prime} \prod_{p=1}^{\bar{n}} c_{\pi_{j p}}^{\beta_{\pi_{j p} j}}\right)\right) d \Omega \\
& =\int_{\Omega}\left(\frac{c_{i}^{n}}{\Delta t} \sum_{\bar{n}=1}^{\bar{n}_{\max }}\left(\sum_{\substack{j=1 \\
\pi_{j} \in \Pi_{\bar{n}}}}^{N P_{\bar{n}}} \mu_{i j}^{\prime} \prod_{p=1}^{\bar{n}}\left(c_{\pi_{j p}}^{\alpha_{j \pi_{j p}}}\right)^{n}\right)+S_{i}\right) \psi_{m} d \Omega
\end{aligned}
$$

que define uma equação para cada nó livre da malha, isto é $m=1, \ldots, M$. Como $\Omega$ é discretizado por uma malha de elementos $\Omega^{e}$, e como a integral de um elemento $e$ não tem contribuição nas integrais dos outros elementos da malha, pode-se escrever

$$
\begin{array}{r}
\sum_{e} \int_{\Omega^{e}} \sum_{N}\left(\lambda_{D_{i}} \nabla\left(\psi_{N} c_{i N}^{(n+1)}\right) \cdot \nabla \psi_{m}+\right. \\
\psi_{N} c_{i N}^{(n+1)} \psi_{m}\left(\frac{1}{\Delta t}+\sum_{\bar{n}=1}^{\bar{n}_{\text {max }}}\left(\sum_{\substack{j=1 \\
\pi_{j} \in \Pi_{\bar{n}}}}^{N P_{\bar{n}}}\left(c_{i}^{\gamma_{i j}-1}\right)^{n} \mu_{i j}^{\prime \prime} \prod_{p=1}^{\bar{n}} c_{\pi_{j p}}^{\beta_{\pi_{j p} j}}\right)\right) d \Omega \\
=\sum_{e} \int_{\Omega^{e}}\left(\frac{c_{i}^{n}}{\Delta t} \sum_{\bar{n}=1}^{\bar{n}_{\max }}\left(\sum_{\substack{j=1 \\
\pi_{j} \in \Pi_{\bar{n}}}}^{\mu_{i j}^{\prime}} \prod_{p=1}^{\bar{n}}\left(c_{\pi_{j p}}^{\alpha_{j \pi_{j p}}}\right)^{n}\right)+S_{i}\right) \psi_{m} d \Omega
\end{array}
$$


onde as integrais são agora avaliadas em cada elemento $\Omega^{e}$. Note que $\psi_{m}$ restrito ao elemento $e$ é exatamente $\psi_{m}^{e}$, e que $\sum_{N} \psi_{m}^{e} c_{1 N}^{(n+1)}$ restrito ao elemento $e$ é $\sum_{j \in e} \psi_{j}^{e} c_{1 j}^{(n+1)}$, resultando

$$
\begin{array}{r}
\sum_{e} \int_{\Omega^{e}} \sum_{j \in e}\left(\lambda_{D_{i}} \nabla\left(\psi_{j}^{e} c_{i j}^{(n+1)}\right) \cdot \nabla \psi_{m}^{e}+\right. \\
\psi_{j}^{e} c_{i j}^{(n+1)} \psi_{m}^{e}\left(\frac{1}{\Delta t}+\sum_{\bar{n}=1}^{\bar{n}_{\max }}\left(\sum_{\substack{j=1 \\
\pi_{j} \in \Pi_{\bar{n}}}}^{N P_{\bar{n}}}\left(c_{i}^{\gamma_{i j}-1}\right)^{n} \mu_{i j}^{\prime \prime} \prod_{p=1}^{\bar{n}} c_{\pi_{j p}}^{\beta_{\pi_{j p} j}}\right)\right) d \Omega \\
=\sum_{e} \int_{\Omega^{e}}\left(\frac{c_{i}^{n}}{\Delta t} \sum_{\bar{n}=1}^{\bar{n}_{\max }}\left(\sum_{\substack{j=1 \\
\pi_{j} \in \Pi_{\bar{n}}}}^{N P_{\bar{n}}} \mu_{i j}^{\prime} \prod_{p=1}^{\bar{n}}\left(c_{\pi_{j p}}^{\alpha_{j \pi_{j p}}}\right)^{n}\right)+S_{i}\right) \psi_{m}^{e} d \Omega .
\end{array}
$$

Note que em (4.53) o índice $j$ agora varia localmente dentro do elemento $(j=1,2,3$ pois nesse caso será utilizado o elemento triangular linear), e que o índice $m$ ainda varia globalmente $(m=1, \ldots, M)$. Mantendo-se uma correspondência biunívoca entre a numeração local $\left(\psi_{i}^{e}\right)$ e a numeração global $\left(\psi_{m}^{e}\right)$, a equação $(4.53)$ pode ainda ser escrita como

$$
\begin{array}{r}
\sum_{e} \int_{\Omega^{e}} \sum_{i, j \in e}\left(\lambda_{D_{i}} \nabla \psi_{i}^{e} \cdot \nabla\left(\psi_{j}^{e} c_{i j}^{(n+1)}\right)+\right. \\
\psi_{j}^{e} c_{i j}^{n+1} \psi_{i}^{e}\left(\frac{1}{\Delta t}+\sum_{\bar{n}=1}^{\bar{n}_{\max }}\left(\sum_{\substack{j=1 \\
\pi_{j} \in \Pi_{\bar{n}}}}^{N P_{\bar{n}}}\left(c_{i}^{\gamma_{i j}-1}\right)^{n} \mu_{i j}^{\prime \prime} \prod_{p=1}^{\bar{n}} c_{\pi_{j p}}^{\beta_{\pi_{j p} j}}\right)\right) d \Omega \\
=\sum_{e} \int_{\Omega^{e}} \sum_{i \in e}\left(\frac{c_{i}^{n}}{\Delta t} \sum_{\bar{n}=1}^{\bar{n}_{\max }}\left(\sum_{\substack{j=1 \\
\pi_{j} \in \Pi_{\bar{n}}}}^{\bar{n}} \mu_{i j}^{\prime} \prod_{p=1}^{\alpha_{j \pi}}\left(c_{\pi_{j p}}^{\alpha_{j p}}\right)^{n}\right)+S_{i}\right) \psi_{i}^{e} d \Omega
\end{array}
$$

Assim,

$$
\begin{array}{r}
\sum_{e} \sum_{i, j \in e}\left[\int_{\Omega^{e}} \lambda_{D_{1}} \nabla \psi_{i}^{e} \cdot \nabla\left(\psi_{j}^{e}\right)+\right. \\
\left.\psi_{j}^{e} \psi_{i}^{e}\left(\frac{1}{\Delta t}+\sum_{\bar{n}=1}^{\bar{n}_{\max }}\left(\sum_{\substack{j=1 \\
\pi_{j} \in \Pi_{\bar{n}}}}^{N P_{\bar{n}}}\left(c_{i}^{\gamma_{i j}-1}\right)^{n} \mu_{i j}^{\prime \prime} \prod_{p=1}^{\bar{n}} c_{\pi_{j p}}^{\beta_{\pi_{j p} j}}\right)\right) d \Omega\right] c_{1 j}^{n+1} \\
=\sum_{e} \sum_{i \in e} \int_{\Omega^{e}}\left(\frac{c_{i}^{n}}{\Delta t} \sum_{\bar{n}=1}^{\bar{n}_{\max }}\left(\sum_{\substack{j=1 \\
\pi_{j} \in \Pi_{\bar{n}}}}^{N P_{\bar{n}}} \mu_{i j}^{\prime} \prod_{p=1}^{\bar{n}}\left(c_{\pi_{j p}}^{\alpha_{j \pi_{j p}}}\right)^{n}\right)+S_{i}\right) \psi_{i}^{e} d \Omega
\end{array}
$$

Logo a equação (4.55) define um sistema linear

$$
\sum_{j=1}^{N e} k_{i j}^{e} u_{j}^{e}=f_{i}^{e}
$$

onde, $N e$ é o número de elementos, portanto

$$
k_{i j}^{e}=\int_{\Omega^{e}} \lambda_{D_{1}} \nabla \psi_{i}^{e} \cdot \nabla\left(\psi_{j}^{e}\right)+\psi_{j}^{e} \psi_{i}^{e}\left(\frac{1}{\Delta t}+\sum_{\bar{n}=1}^{\bar{n}_{\max }}\left(\sum_{\substack{j=1 \\ \pi_{j} \in \Pi_{\bar{n}}}}^{N P_{\bar{n}}}\left(c_{i}^{\gamma_{i j}-1}\right)^{n} \mu_{i j}^{\prime \prime} \prod_{p=1}^{\bar{n}} c_{\pi_{j p}}^{\beta_{\pi_{j p}}}\right)\right) d \Omega
$$




$$
f_{i}^{e}=\int_{\Omega^{e}}\left(\frac{c_{i}^{n}}{\Delta t} \sum_{\bar{n}=1}^{\bar{n}_{\max }}\left(\sum_{\substack{j=1 \\ \pi_{j} \in \Pi_{\bar{n}}}}^{N P_{\bar{n}}} \mu_{i j}^{\prime} \prod_{p=1}^{\bar{n}}\left(c_{\pi_{j p}}^{\alpha_{j \pi_{j p}}}\right)^{n}\right)+S_{i}\right) \psi_{i}^{e} d \Omega
$$

O domínio será discretizado em elementos triangulares linear, onde são conhecidos os valores das velocidades nos vértices, estes elementos serão mapeados por um elemento mestre triangular linear para o qual está definida as seguintes funções de forma:

$$
\begin{aligned}
\hat{\psi}_{1}(\xi, \eta) & =1-\xi-\eta \\
\hat{\psi}_{2}(\xi, \eta) & =\xi \\
\hat{\psi}_{3}(\xi, \eta) & =\eta .
\end{aligned}
$$

Fazendo os cálculos sobre o elemento mestre, tem-se

$$
\begin{aligned}
k_{i j}^{\Omega_{n}}= & \int_{\hat{\Omega}}\left(\lambda_{D_{1}}\left(\frac{\partial \hat{\psi}_{i}}{\partial x} \frac{\partial \hat{\psi}_{j}}{\partial x}+\frac{\partial \hat{\psi}_{i}}{\partial y} \frac{\partial \hat{\psi}_{j}}{\partial y}\right)\right)+ \\
& \hat{\psi}_{i} \hat{\psi}_{j}\left(\frac{1}{\Delta t}+\sum_{\bar{n}=1}^{\bar{n}_{\text {max }}}\left(\sum_{\substack{j=1 \\
\pi_{j} \in \Pi_{\bar{n}}}}^{N P_{\bar{n}}}\left(c_{i}^{\gamma_{i j}-1}\right)^{n} \mu_{i j}^{\prime \prime} \prod_{p=1}^{\bar{n}} c_{\pi_{j p}}^{\beta_{\pi_{j p} j}}\right)\right)\left|\frac{\partial(x, y)}{\partial(\xi, \eta)}\right| d \xi d \eta
\end{aligned}
$$

onde

$$
\left|\frac{\partial(x, y)}{\partial(\xi, \eta)}\right|=\left|\frac{\partial x}{\partial \xi} \frac{\partial y}{\partial \eta}-\frac{\partial x}{\partial \eta} \frac{\partial y}{\partial \xi}\right|
$$

A integral resultante será resolvida através da regra de Quadratura Gaussiana, isto é

$$
\int_{\hat{\Omega}} \hat{G}(\xi, \eta) d \xi d \eta=\sum_{l=1}^{N e} \hat{G}\left(\xi_{l}, \eta_{l}\right) w_{l}
$$

Após calcular $k_{i j}^{\Omega_{n}}$, com $i, j=1,2,3$ e $n=1, \ldots, N e$ teremos uma matriz de massa local para cada elemento. A matriz de massa global é calculada como sendo a contribuição da matriz de massa de cada elemento.

De forma análoga, calcula-se o vetor de carga $f_{i}^{\Omega_{n}}$ para cada elemento, localmente, e sua respectiva contribuição global.

Finalmente, obtêm-se o seguinte sistema linear:

$$
k_{i j}^{\text {global }} u_{j}=f_{i}^{g l o b a l}
$$

Resolvendo-se o sistema linear (4.62) encontra-se os valores de $u_{j}$ que correspondem a encontrar os valores de $c_{i}^{(n+1)}$ para cada $i=1,2, \ldots, n$. 
CAPÍTULO

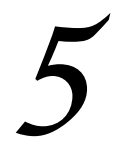

\section{Modelo de Turbulência}

\subsection{Incorporação de um Modelo de Turbulência às Equa- ções de Navier-Stokes}

Na formulação Euleriana, as equações de Navier-Stokes são escritas da seguinte forma

$$
\begin{gathered}
\nabla \cdot \mathbf{u}=0 \\
\frac{D \rho \mathbf{u}}{D t}=-\nabla p+\nabla\left[\mu\left(\nabla \mathbf{u}+\nabla \mathbf{u}^{T}\right)\right]+\rho g .
\end{gathered}
$$

O objetivo aqui é incorporar um modelo de turbulência à essas equações.

Existem poucas maneiras de se simular numericamente escoamentos incompressíveis no regime turbulento e dentre elas destacam-se três metodologias principais:

- DNS ("Direct Numerical Simulation")

- LES ("Large-Eddy Simulation")

- RANS ("Reynolds-Average Navier-Stokes")

Em DNS: as escalas de turbulência são calculadas numericamente a partir de Navier-Stokes sem levar em conta as características físicas diferentes dessas escalas.

Em LES: calcula as escalas maiores ("grid-scale") da turbulência e os efeitos das estruturas de pequenas escalas são modeladas.

Em RANS: informações sobre flutuações turbulentas são obtidas do tensor de Reynolds.

A metodologia RANS adota uma família de modelos baseados no conceito de viscosidade turbulenta por Boussinesq.

Seja $\bar{\phi}(x, t)$ a média de tempo $T$ da variável instantânea $\phi(x, y)$ definida por:

$$
\bar{\phi}=\frac{1}{T} \int_{t}^{t+T} \bar{\phi}(x, \tau) d \tau \quad T_{0}<<T<<T_{1}
$$


Sendo $\phi^{\prime}(x, t)$ o desvio de média zero em $\phi(x, t)$, a decomposição de escalas de Reynolds é definida por

$$
\phi(x, t)=\bar{\phi}(x, t)+\phi^{\prime}(x, t) .
$$

A primeira tentativa de modelar fenômenos turbulentos foi proposta por Boussinesq (1877).

Para escoamentos uni-direcionais, típicos de Camada Limite, Boussinesq propôs que a tensão de Reynolds fosse modelada por

$$
\frac{\tau^{T}}{\rho}=-\overline{\mathbf{u} u}=\nu_{T} \nabla \overline{\mathbf{u}}
$$

de tal forma que a tensão total passa a ser dada pela soma das tensões devido a difusão molecular e turbulenta do momento:

$$
\tau=\left(\tau^{L}+\tau^{T}\right)=\rho\left(\nu+\nu_{T}\right) \nabla \overline{\mathbf{u}}
$$

Frequentemente a soma dos coeficientes de difusão é denominado por viscosidade efetiva

$$
\nu_{e f f}=\nu+\nu_{T}
$$

assim,

$$
\tau=\nu_{e f f} \nabla \overline{\mathbf{u}}
$$

Focalizando no modelo para a tensão de Reynolds (5.5), tem-se,

$$
-\rho \overline{\mathbf{u} u}=\rho \nu_{T} \nabla \overline{\mathbf{u}} .
$$

Boussinesq pressupôs que a tensão turbulenta ocorre quando há gradiente de velocidade no campo médio.

Assim, com a separação das escalas de Reynolds, as equações de Navier-Stokes para o escoamento médio podem ser escritas como

$$
\begin{gathered}
\nabla \cdot \overline{\mathbf{u}}=0 \\
\frac{D \rho \overline{\mathbf{u}}}{D t}=-\nabla p+\nabla\left[\mu\left(\nabla \overline{\mathbf{u}}+\nabla \overline{\mathbf{u}}^{T}\right)-\rho \overline{\mathbf{u} \mathbf{u}}\right]+\rho g
\end{gathered}
$$

em que $\overline{\mathbf{u u}}$ é chamado de tensor de tensões de Reynolds ou tensões turbulentas que resulta das não linearidades presentes nas equações do movimento e representa os efeitos da turbulência sobre o escoamento médio.

Como, $-\rho \overline{\mathbf{u u}}=\rho \nu_{T}\left(\nabla \overline{\mathbf{u}}+\nabla \overline{\mathbf{u}}^{T}\right)$, segue que

$$
\frac{D \rho \overline{\mathbf{u}}}{D t}=-\nabla p+\nabla\left[\mu\left(\nabla \overline{\mathbf{u}}+\nabla \overline{\mathbf{u}}^{T}\right)+\mu_{T}\left(\nabla \overline{\mathbf{u}}+\nabla \overline{\mathbf{u}}^{T}\right)\right]+\rho g
$$

e, como na formulação Euleriana 


$$
\frac{D \rho \mathbf{u}}{D t}=\frac{\partial(\rho \mathbf{u})}{\partial t}+(\mathbf{u} \cdot \nabla)(\rho \mathbf{u})
$$

segue que a equação (5.12) será dada por

$$
\frac{\partial(\rho \mathbf{u})}{\partial t}+(\mathbf{u} \cdot \nabla)(\rho \mathbf{u})=-\nabla p+\nabla\left[\mu\left(\nabla \mathbf{u}+\nabla \mathbf{u}^{T}\right)+\mu_{T}\left(\nabla \mathbf{u}+\nabla \mathbf{u}^{T}\right)\right]+\rho g .
$$

Adimensionalizando a equação (5.14) através dos parâmetros admensionais e considerando a adimensionalização da viscosidade turbulenta dada por

$$
\mu_{T}=\mu_{0} \mu_{T}^{*}
$$

tem-se

$$
\left.\frac{\partial(\rho \mathbf{u})}{\partial t}+(\mathbf{u} \cdot \nabla)(\rho \mathbf{u})=-\nabla p+\nabla\left[\mu\left(\nabla \mathbf{u}+\nabla \mathbf{u}^{T}\right)+\mu_{0} \mu_{T}^{*} \nabla \mathbf{u}+\nabla \mathbf{u}^{T}\right)\right]+\rho g .
$$

Substituindo-se os termos adimensionais tem-se

$$
\begin{gathered}
\rho=\rho_{0} \rho^{*} \quad \mu=\mu_{0} \mu^{*} \quad p=\rho_{0} U^{2} p^{*} \\
g=g_{0} g^{*} \quad \mathbf{u}=U \mathbf{u}^{*} .
\end{gathered}
$$

E para os operadores diferenciais,

$$
\begin{gathered}
\frac{\partial}{\partial t}=\frac{U}{L} \frac{\partial}{\partial t^{*}} \quad \text { e } \quad \nabla=\frac{1}{L} \nabla^{*} \\
\frac{U^{2}}{L} \rho_{0} \frac{\partial\left(\rho^{*} \mathbf{u}^{*}\right)}{\partial t^{*}}+\frac{U^{2}}{L} \rho_{0}\left(\mathbf{u}^{*} \cdot \nabla^{*}\right)\left(\rho^{*} \mathbf{u}^{*}\right)=-\frac{U^{2}}{L} \rho_{0} \nabla^{*} p^{*} \\
+\frac{U}{L^{2}} \mu_{0} \nabla^{*}\left[\mu^{*}+\mu_{T}^{*}\left(\nabla^{*} \mathbf{u}^{*}+\nabla^{*}\left(\mathbf{u}^{*}\right)^{T}\right)\right]+\rho_{0} g_{0} \rho^{*} g^{*} .
\end{gathered}
$$

Logo,

$$
\begin{aligned}
& \frac{U^{2}}{L} \rho_{0} \frac{\partial\left(\rho^{*} \mathbf{u}^{*}\right)}{\partial t^{*}}+\frac{U^{2}}{L} \rho_{0}\left(\mathbf{u}^{*} \cdot \nabla^{*}\right)\left(\rho^{*} \mathbf{u}^{*}\right)=-\frac{U^{2}}{L} \rho_{0} \nabla^{*} p^{*}+ \\
& \frac{U}{L^{2}} \mu_{0} \nabla^{*}\left[\mu^{*}+\mu_{T}^{*}\left(\nabla^{*} \mathbf{u}^{*}+\nabla^{*}\left(\mathbf{u}^{*}\right)^{T}\right)\right]+\rho_{0} g_{0} \rho^{*} g^{*} .
\end{aligned}
$$

Multiplicando (5.18) por $\frac{L}{\rho_{0} U}$, tem-se

$$
\begin{aligned}
& \frac{\partial\left(\rho^{*} \mathbf{u}^{*}\right)}{\partial t^{*}}+\left(\mathbf{u}^{*} \cdot \nabla^{*}\right)\left(\rho^{*} \mathbf{u}^{*}\right)=-\nabla^{*} p^{*}+ \\
& \frac{\mu_{0}}{\rho_{0} U L} \nabla^{*}\left[\mu^{*}+\mu_{T}^{*}\left(\nabla^{*} \mathbf{u}^{*}+\nabla^{*}\left(\mathbf{u}^{*}\right)^{T}\right)\right]+\frac{L}{U^{2}} g_{0} \rho^{*} g^{*} .
\end{aligned}
$$

Substituindo $R e=\frac{\rho_{0} L U}{\mu_{0}}$ e $F r=\frac{U}{\sqrt{g_{0} L}}$, tem-se, eliminando os asterísticos

$$
\frac{\partial(\rho \mathbf{u})}{\partial t}+\mathbf{u} \cdot \nabla(\rho \mathbf{u})=-\nabla p+\frac{1}{R e} \nabla\left[\mu+\mu_{T}\left(\nabla \mathbf{u}+\nabla \mathbf{u}^{T}\right)\right]+\frac{1}{F r^{2}} \rho g
$$

na qual $\mu_{T}$ é a viscosidade turbulenta e diferentemente da viscosidade molecular (laminar) ela é uma propriedade do escoamento e não do fluido, dependendo dos mecanismos de transporte turbulento e portanto deve ser modelada. 


\subsection{Modelo Algébrico}

O modelo algébrico adotado neste trabalho provêm de um modelo de turbulência baseado na técnica de filtragem que é um modelo 2DH, proposto por Rosman e Gobbi (1990) tal que as tensões turbulentas serão sempre dissipativas e é dado por:

$$
\frac{\overline{\tau_{i j}}}{\rho_{0}}=\frac{\Lambda_{k}^{2}}{24}\left(\left|\frac{\partial U_{i}}{\partial x_{k}}\right| \frac{\partial U_{j}}{\partial x_{k}}+\frac{\partial U_{i}}{\partial x_{k}}\left|\frac{\partial U_{j}}{\partial x_{k}}\right|\right)+\left(D_{H}+D_{V}\right)\left(\frac{\partial U_{i}}{\partial x_{j}}+\frac{\partial U_{j}}{\partial x_{i}}\right)
$$

onde $i, j=1,2$ e $k=1,2$ e 3 , com $k=3$ correspondendo ao tempo $t$. Os parâmetros $\Lambda_{k}=\alpha_{k} \Delta x_{k}$ são as escalas de largura de filtragem local na dimensão $x_{k}$, sendo $\alpha_{k}$ constantes de calibração.

$D_{H}$ é o coeficiente de viscosidade turbulenta e $D_{V}$ é um coeficiente de dispersão. Onde

$$
\left(D_{H}+D_{V}\right)=S_{e} \frac{\kappa}{6} u^{*} H
$$

com

$$
u^{*}=\frac{\sqrt{g}}{C_{h}} \sqrt{U^{2}+V^{2}}
$$

onde $H$ é a altura da coluna de água, $\kappa=0.404$ é a constante de Von Karman e $S_{e}$ é uma escala de calibragem. Valores usuais de $S_{e}$ variam de 0.25 a 4.0, e na maioria das vezes o valor 1.0 fornece bons resultados. Alguns modelos de tensões turbulentas sem termos de filtragem ou semelhantes chegam a usar $S_{e}>10$.

Rosman em ([Rosman, 2006]), utilizou-se dos termos de filtragem do modelo algébrico (5.21) com a finalidade de que as tensões turbulentas fossem sempre dissipativas. Entretanto no problema aqui considerado não é necessária muita dissipação com relação às tensões turbulentas, sendo assim, neste trabalho adotou-se o mesmo modelo algébrico, desprezando, contudo, os termos de filtragem. Visto que o fato de desprezar estes termos, além de não afetar a solução do problema aqui proposto, tem a vantagem de minimizar os custos computacionais.

Logo será considerado o modelo (5.21), sem os termos de filtragem, que também é um modelo dissipativo, e é dado por:

$$
\frac{\overline{\tau_{i j}}}{\rho_{0}}=\left(D_{H}+D_{V}\right)\left(\frac{\partial U_{i}}{\partial x_{j}}+\frac{\partial U_{j}}{\partial x_{i}}\right)
$$

onde, de acordo com (5.5) $D_{H}+D_{V}=\mu_{\text {turb }}$.

$g$ é a gravidade e $C_{h}$ é o coeficiente de Cházy, dado por:

$$
C_{h}=\frac{H^{1 / 6}}{n}
$$

onde $n$ é o coeficiente de Manning. A definição do coeficiente de Cházy a partir do coeficiente de Manning apesar de muito utilizado, não é recomendável, pois $n$ é um coeficiente mais global ([Rosman, 2006]). 


\section{CAPÍTULO}

\section{Modelo 2DH}

\subsection{Introdução}

A modelagem utilizada na discretização das equações de águas rasas em duas dimensões, também é denominada de modelagem baseada na média vertical, ou modelo 2DH. Este modelo é obtido a partir da integração vertical das equações tridimensionais de Navier-Stokes para escoamentos incompressíveis com condições de contorno de fundo e de superfície. A principal limitação da modelagem 2DH é que ela não considera os efeitos da variação da velocidade e densidade na direção vertical. O modelo $2 \mathrm{DH}$ pode ser adequado, pois o escoamento da camada compreendida entre o fundo e a superfície livre comporta-se de forma homogênea, sendo predominante as velocidades horizontais. Por isso o escoamento pode ser aproximado em duas dimensões.

Considerando o escoamento isotérmico e incompressível em três dimensões, as componentes da equação de quantidade de movimento e a equação da continuidade são dadas por:

$$
\begin{gathered}
\frac{D(\rho u)}{D t}=-\frac{\partial p}{\partial x}+\left(\frac{\partial \tau_{x x}}{\partial x}+\frac{\partial \tau_{x y}}{\partial y}+\frac{\partial \tau_{x z}}{\partial z}\right)+f v \\
\frac{D(\rho v)}{D t}=-\frac{\partial p}{\partial y}+\left(\frac{\partial \tau_{y x}}{\partial x}+\frac{\partial \tau_{y y}}{\partial y}+\frac{\partial \tau_{y z}}{\partial z}\right)+f u \\
\frac{D(\rho w)}{D t}=-\frac{\partial p}{\partial z}+\left(\frac{\partial \tau_{z x}}{\partial x}+\frac{\partial \tau_{z y}}{\partial y}+\frac{\partial \tau_{z z}}{\partial z}\right)+\rho g \\
\frac{\partial u}{\partial x}+\frac{\partial v}{\partial y}+\frac{\partial w}{\partial z}=0
\end{gathered}
$$

onde $u, v$ e $w$ são as componentes do vetor velocidade nas direções $x, y$ e $z$ respectivamente. A direção vertical $z$ é positiva para cima e sua origem pode ser convenientemente definida 
no nível médio da superfície da água, $\rho$ é a densidade local do fluido, $f$ é o fator de Coriolis, $\tau$ são as tensões cisalhantes e $t$ é o tempo.

As tensões podem ser eliminadas das relações utilizando a relação constitutiva:

$$
\tau=\mu\left(\nabla u+\nabla u^{T}\right)
$$

onde $\mu$ é a viscosidade dinâmica do fluido. Logo, tem-se um sistema de quatro equações e quatro incógnitas: $u, v, w$ e $p$.

Escoamentos em grande escala, nos quais as escalas dos movimentos horizontais são pelo menos 20 vezes maiores que a profundidade, podem ser considerados como quase horizontais ou escoamentos em águas razas. Em tais situações as equações governantes do movimento são as chamadas Equações de águas Razas. Desta forma, ondas onde o comprimento é maior que a altura, são levadas em consideração. Neste caso, as acelerações e tensões verticais podem ser desprezadas, reduzindo a equação da quantidade de movimento na direção $z$ a:

$$
\frac{\partial P}{\partial z}=-\rho g
$$

Esta é a simplificação que fundamenta as equações de águas razas. Uma vez que o escoamento horizontal é independente da altura, a incompressibilidade implica que a velocidade vertical é linear em $z$. Isso pode ser obtido integrando a equação da quantidade de movimento na direção $z$ ao longo da profundidade:

$$
\int_{z}^{\eta} \frac{\partial P}{\partial z} d z=-\int_{z}^{\eta} \rho g d z
$$

Seja $(x, y) \in \omega \subset \mathbb{R}^{2}$ definido como sendo os pontos no plano horizontal $z=0$ representando a superfície de referência e seja $z \in[-h, \eta]$ o ponto na direção vertical onde $h(x, y)$ representa a profundidade e $\eta(x, y, t)$ a elevação da superfície de referência como visto na Figura (6.1).

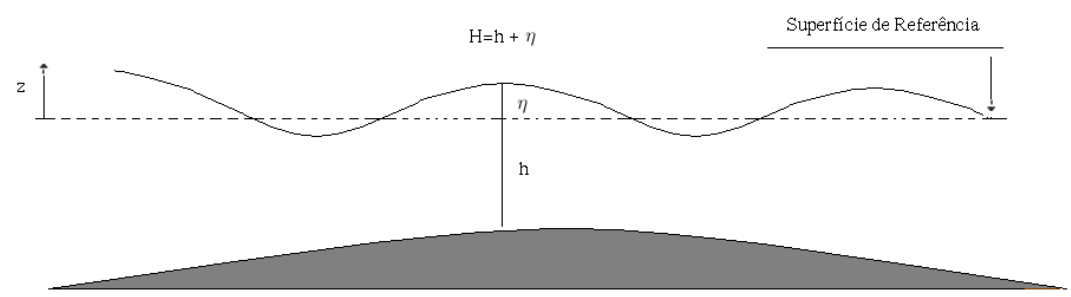

Figura 6.1: Profundidade (h), elevação $(\eta)$ e superfície de referência.

O domínio de interesse é a camada de largura $H=h+\eta$ confinada entre a superfície livre, descrito pela função $z=\eta(x, y, t)$ e o fundo, dado pela função $z=-h(x, y)$.

No caso de tratamento de reservatórios despreza-se os fatores de Coriolis, assim, aplicando estes resultados às equações de quantidade de movimento nas direções $x$ e $y$ tem-se:

$$
\frac{D(\rho u)}{D t}=-\frac{\partial p}{\partial x}+\left(\frac{\partial \tau_{x x}}{\partial x}+\frac{\partial \tau_{x y}}{\partial y}+\frac{\partial \tau_{x z}}{\partial z}\right)
$$




$$
\frac{D(\rho v)}{D t}=-\frac{\partial p}{\partial y}+\left(\frac{\partial \tau_{y x}}{\partial x}+\frac{\partial \tau_{y y}}{\partial y}+\frac{\partial \tau_{y z}}{\partial z}\right)
$$

As equações (6.8) e (6.9) juntamente com a equação da continuidade formam um sistema de três equações e quatro incógnitas $(u, v, w, \eta)$. Sendo assim, uma quarta equação é necessária para resolver este sistema. A escolha usual para essa equação é a equação da continuidade integrada ao longo da coluna d' água. Dada por:

$$
\frac{\partial \eta}{\partial t}+\frac{\partial}{\partial x} \int_{-h}^{\eta} u d z+\frac{\partial}{\partial y} \int_{-h}^{\eta} v d z=0
$$

Portanto, o modelo de águas razas em três dimensões é representado por duas equações de quantidade de movimento (6.8) e (6.9), a equação da continuidade (6.4) e a equação representativa da superfície livre (6.10). Comparando com o modelo tridimensional completo, nota-se que se o escoamento for considerado quase horizontal, a pressão $p$ pode ser substituída pela elevação $h$, e ao invés da equação da quantidade de movimento na direção $z$ tem-se a equação representativa da superfície livre.

\subsection{Modelo Baseado na Média Vertical}

O modelo 2DH é obtido pela integração vertical das equações de movimento (6.8) e (6.9), e da equação da continuidade (6.4). Para cada intervalo de tempo o módulo 2DH determina as componentes das velocidades médias ao longo da vertical na direção $x$ e $y$, $U(x, y, t)$ e $V(x, y, z)$ respectivamente, e as elevações da superfície $z=\eta(x, y, z)$. Pode-se então definir as componentes horizontais da velocidade baseada na média vertical como sendo:

$$
\begin{aligned}
& U(x, y, t)=\frac{1}{H} \int_{-h}^{\eta} u(x, y, z, t) d z \\
& V(x, y, t)=\frac{1}{H} \int_{-h}^{\eta} v(x, y, z, t) d z
\end{aligned}
$$

Considerando esta definição e supondo que $z=-h(x, y)$, a equação da continuidade, ou imposição da condição de escoamento incompressível, dada em (6.10), pode ser reescrita para um escoamento 2DH integrado ao longo da vertical. Portanto:

$$
\frac{\partial \eta}{\partial t}+\frac{\partial U H}{\partial x}+\frac{\partial V H}{\partial y}=0
$$

Considerando as condições de contorno cinemáticas no fundo e na superfície como sendo zero, e aplicando a regra de Leibnitz, pode-se integrar as equações de quantidade de movimento 3D (6.8) e (6.9), para obter:

$$
\begin{aligned}
& \frac{D U}{D t}=-g \frac{\partial \eta}{\partial x}+\frac{1}{\rho H}\left(\frac{\partial\left(H \tau_{x x}\right)}{\partial x}+\frac{\partial\left(H \tau_{x y}\right)}{\partial y}\right)+\frac{1}{\rho H}\left(\tau_{x}^{S}-\tau_{x}^{B}\right) \\
& \frac{D V}{D t}=-g \frac{\partial \eta}{\partial y}+\frac{1}{\rho H}\left(\frac{\partial\left(H \tau_{x y}\right)}{\partial x}+\frac{\partial\left(H \tau_{y y}\right)}{\partial y}\right)+\frac{1}{\rho H}\left(\tau_{y}^{S}-\tau_{y}^{B}\right)
\end{aligned}
$$

Estas são as equações da quantidade de movimento 2DH para um escoamento integrado na vertical nas direções $x$ e $y$ respectivamente. Onde $\tau_{i}^{S}$ é a tensão de atrito na superfície livre e $\tau_{i}^{B}$ é a tensão de atrito no fundo. 


\subsection{Modelo 2DH para o Transporte da Temperatura}

A equação do transporte da temperatura considerando o modelo 2DH é dada por:

$$
\frac{D T}{D t}=\frac{1}{H} \nabla \cdot(H \alpha \nabla T)
$$

onde os parâmetros desta equação são os mesmos descritos na equação (1.6).

\subsection{Modelo 2DH para o Transporte das Concentrações de Espécies Constituintes}

Devido as características hidrodinâmicas de muitos corpos de água de interesse em uma bacia hidrográfica, um modelo $2 \mathrm{DH}$ de transporte é bem adequado para a simulação da distribuição de espécies constituintes bem dissolvidas na coluna de água.

A equação do transporte das espécies constituintes para o modelo 2DH, isto é, integrada em uma camada de espessura $H$ que vai do fundo até a superfície é dada por:

$$
\frac{D c_{i}}{D t}=\frac{1}{H} \nabla \cdot\left(H \lambda_{D_{i}} \nabla c_{i}\right)+\sum_{\bar{n}=1}^{\bar{n}_{\max }}\left(\sum_{\substack{j=1 \\ \pi_{j} \in \Pi_{\bar{n}}}}^{N P_{\bar{n}}} \mu_{i j}^{\prime} \prod_{p=1}^{\bar{n}} c_{\pi_{j p}}^{\alpha_{j \pi_{j p}}}-\sum_{\substack{j=1 \\ \pi_{j} \in \Pi_{\bar{n}}}}^{N P_{\bar{n}}} c_{i}^{\gamma_{i j}} \mu_{i j}^{\prime \prime} \prod_{p=1}^{\bar{n}} c_{\pi_{j p}}^{\beta_{\pi_{j p} j}}\right)+S_{i},
$$

onde os parâmetros presentes nessa equação são os mesmos definidos para a equação das espécies constituintes (1.8).

Para simplificar a notação considera-se:

$$
\sum R E=\sum_{\bar{n}=1}^{\bar{n}_{\text {max }}}\left(\sum_{\substack{j=1 \\ \pi_{j} \in \Pi_{\bar{n}}}}^{N P_{\bar{n}}} \mu_{i j}^{\prime} \prod_{p=1}^{\bar{n}} c_{\pi_{j p}}^{\alpha_{j \pi_{j p}}}-\sum_{\substack{j=1 \\ \pi_{j} \in \Pi_{\bar{n}}}}^{N P_{\bar{n}}} c_{i}^{\gamma_{i j}} \mu_{i j}^{\prime \prime} \prod_{p=1}^{\bar{n}} c_{\pi_{j p}}^{\beta_{\pi_{j p}}}\right)+S_{i}
$$

que reprenta as reações cinéticas para cada concentração de espécie constituinte a ser considerada e o termo fonte.

Assim, a equação (6.17) será escrita:

$$
\frac{D c_{i}}{D t}=\frac{1}{H} \nabla \cdot\left(\lambda_{T_{D_{i}}} \nabla c_{i}\right) \sum R E
$$

onde $\lambda_{T_{D_{i}}}=H \lambda_{D_{i}}$ que poderá ser um escalar ou tensor, dependendo do modelo mais especificamente a ser considerado.

O modelo 2DH das equações dos transportes será utilizado para o cálculo do transporte em corpos de água razos, enquanto que o modelo 2D calcula o transporte na superfície da água.

Um dos principais indicadores da qualidade da água é o oxigênio dissolvido indispensável para a manutenção dos organismos aeróbios [Mota, 2003] e para o equilíbrio ambiental como um todo. Em condições normais, as águas constituem ambientes bastante pobres em oxigênio, devido é baixa solubilidade. A presença de certos poluentes, principalmente os de origem orgânica, diminui ainda mais a concentração de OD, podendo levar a extinção dos organismos aquáticos aeróbios que ajudam a decompor a matéria orgânica a partir do 
consumo do oxigênio dissolvido. O que pode provocar o surgimento de outras formas de vida no meio anaeróbio produzindo resíduos tóxicos.

As discretizações das equações do transporte da temperatura e das espécies constituintes 2DH seguem os mesmos procedimentos das equações em 2D descritos no Capítulo 4. 


\section{Problemas-teste para o Transporte da}

\section{Temperatura e das Concentrações de Espécies}

Constituintes

\subsection{Introdução}

São apresentados neste capítulo dois problemas-teste com solução analítica, um para o transporte da temperatura e o outro para o transporte das concentrações de espécies constituintes.

\subsection{Transporte da Temperatura}

Considera-se o seguinte problema:

Um líquido viscoso escoa entre duas placas paralelas horizontais (Canal). Sendo que uma delas é mantida à temperatura T1 e a outra é temperatura T2, como mostra a Figura (7.1):

As equações da continuidade, de Navier-Stokes e da temperatura aplicáveis ao problema tomam a forma:

$$
\begin{gathered}
\frac{\partial u}{\partial x}+\frac{\partial v}{\partial y}=0 \\
u \frac{\partial u}{\partial x}+v \frac{\partial u}{\partial y}=-\frac{1}{\rho} \frac{\partial p}{\partial x}+\nu\left(\frac{\partial^{2} u}{\partial x^{2}}+\frac{\partial^{2} u}{\partial y^{2}}\right) \\
u \frac{\partial v}{\partial x}+v \frac{\partial v}{\partial y}=-\frac{1}{\rho} \frac{\partial p}{\partial y}+\nu\left(\frac{\partial^{2} v}{\partial x^{2}}+\frac{\partial^{2} v}{\partial y^{2}}\right) \\
u \frac{\partial T}{\partial x}+v \frac{\partial T}{\partial y}=\alpha\left(\frac{\partial^{2} T}{\partial x^{2}}+\frac{\partial^{2} T}{\partial y^{2}}\right)
\end{gathered}
$$


$\mathrm{T} 2$

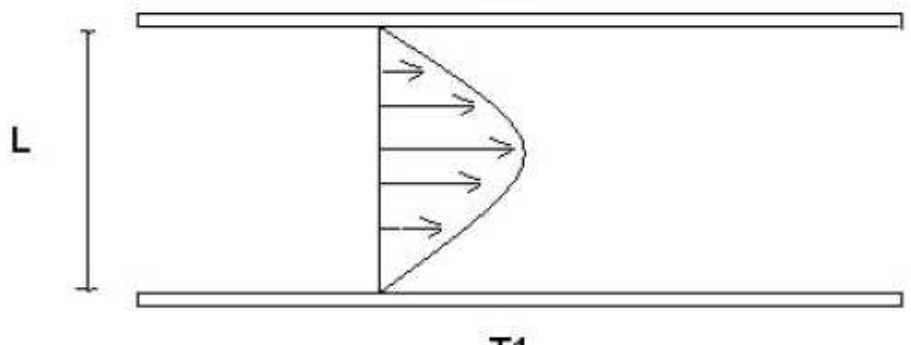

T1

Figura 7.1: Escoamento de um fluido entre duas placas planas e paralelas.

Como $\frac{\partial u}{\partial x}=0$ temos, pela equação da continuidade que $\frac{\partial v}{\partial y}=0$, isto é, $v$ é constante ao longo da direção $y$. Como $v=0$ junto com as placas conclui-se que esta componente da velocidade é identicamente nula. Em consequência as equações do problema reduzem-se a :

$$
\begin{gathered}
\frac{\partial^{2} u}{\partial y^{2}}=\frac{1}{\mu} \frac{d p}{d x} . \\
u \frac{\partial T}{\partial x}=\alpha\left(\frac{\partial^{2} T}{\partial x^{2}}+\frac{\partial^{2} T}{\partial y^{2}}\right)
\end{gathered}
$$

onde $\frac{d p}{d x}$ é o gradiente de pressão que é constante ao longo do escoamento. A equação da componente da velocidade $u$ é desacoplada da equação da temperatura, então tem-se:

$$
\begin{gathered}
\frac{\partial^{2} u}{\partial y^{2}}=\frac{1}{\mu} \frac{\partial p}{\partial x} . \\
u=-\frac{1}{2 \mu}\left(\frac{L^{2}}{4}-y^{2}\right)
\end{gathered}
$$

A vazão em massa é dada por:

$$
\dot{m}=-\rho \frac{d p / d x}{12 \mu} L^{3}
$$

Para obter a expressão de $\frac{\partial T}{\partial x}$ utiliza-se a expressão que relaciona o balanço de energia dada por,

$$
\dot{m} c_{p} \frac{\partial T}{\partial x}=2 q
$$

Como $\frac{d T}{d x} \neq f(y)$, obtemos:

$$
\frac{\partial T}{\partial x}=\frac{2 q}{\dot{m} c_{p}}
$$


Sendo assim, a dependência da temperatura ao longo de $x$ é dada por pela seguinte equação:

$$
T=T_{1}+\frac{24 \mu q}{\rho c_{p} L^{3}(-d p / d x)} x
$$

Dessa forma, o perfil da temperatura é portanto:

$$
T=T_{1}-\frac{21}{64} \frac{q L}{\kappa}+\frac{24 \mu q}{\rho c_{p} L^{3}(-d p / d x)} x+\frac{3 q}{\kappa L^{3}}\left(\frac{L^{2}}{2} y^{2}-\frac{y^{4}}{3}\right)
$$

onde $q$ é o fluxo de calor e é dado por:

$$
q=\frac{\kappa A}{L}\left(T_{2}-T_{1}\right)
$$

$A$ é a área das faces das placas e $\kappa$ é a condutividade térmica do fluido.

Maiores detalhes sobre o desenvolvimento desse problema pode ser encontrado em [Pontes, 2003].

\subsection{Transporte de Concentrações de Espécies Consti- tuintes}

Para que se conheça e controle a qualidade da água são utilizados modelos capazes de expressar as complexas interações ocorridas dentro do corpo d'água receptor. A utilização de modelo de qualidade de ambientes naturais ou canais artificiais envolve o uso de parâmetros físicos, químicos e biológicos, que precisam ser bem avaliados para que o modelo forneça resultados confiáveis [Rosman, 2006].

Toda formulação que se desenvolve é consequência da aplicação do balanço de massa sobre a porção do fluido pelo qual partículas são transportadas.

Os poluentes são alterados devido aos processos físicos de advecção e difusão e processos bioquímicos e físicos de convecção.

Com a introdução de matéria orgânica em um dado curso de água, esta é degradada pelas bactérias presentes no meio, ocasionando um consumo de oxigênio e acarretando uma diminuição do oxigênio dissolvido na água. Ao se distanciar do ponto de descarga da matéria orgânica, considerando como constante a taxa de degradação, esta passa a diminuir a jusante, região compreendida entre o observador e a foz de um curso d'água, do ponto de descarga, ocasionando a diminuição da atividade das bactérias e consequentemente minimizando o consumo de oxigênio.

Os modelos de qualidade de água tentam simular a evolução da degradação do nível de oxigênio dissolvido na água, auxiliam na compreensão destes problemas e na tomada de decisões.

O modelo pioneiro no desenvolvimento desta modelagem foi desenvolvido em 1925 e é conhecido como Modelo Streeter-Phelps que relaciona o Oxigênio Dissolvido (OD) e os valores da Demanda Bioquímica de Oxigênio (DBO) e descreve o aumento e decréscimo seguinte do déficit de oxigênio à jusante de uma fonte de material orgânico. Este modelo foi posteriormente estendido para processos de nitrogênio, detalhados pelo modelo EPA com nitrificação, o QUAL1 [Orlob, 1982]. Finalmente o ciclo do fósforo e algas foi adicionado na formulação do modelo QUAL2 [Brown, 1982]. Hoje várias versões do estado-da-arte do 
modelo QUAL2 estão disponíveis dependendo da proposta do usuário. A escolha do modelo depende de muitos fatores, tais como: os objetivos da análise, a disponibilidade de dados e o tempo de resposta.

\subsection{Modelo de Cinética de Reação Química}

O modelo de cinética de reação química, que compõem um modelo de qualidade de água, aqui descrito segue uma obordagem euleriana, portanto considera-se a mesma malha de elementos finitos do modelo hidrodinâmico, permitindo assim que as componentes da velocidade calculadas pelo modelo hidrodinâmico possam ser usadas diretamente.

Os modelos de qualidade de água permitem o estudo de descargas de efluentes com diferentes temperaturas, além do estudo da influência da temperatura nas reações químicas e biológicas para cada reação específica [Rosman, 2006].

Neste trabalho considera-se o modelo de cinética de reação química das espécies constituintes OD-DBO.

\subsubsection{Modelo OD-DBO}

Para simular numericamente o transporte das espécies constituintes, dados pelas equações (1.13) e (1.14), foi considerado um modelo matemático com duas concentrações OD-DBO (Oxigênio Dissolvido e Demanda Bioquímica de Oxigênio), com soluções analíticas conhecidas, que consideram apenas a oxidação da matéria orgânica, como consumo e a reaeração atmosférica, como produção de oxigênio. Este modelo descreve o lançamento de uma fonte pontual de DBO em um corpo de água e é dado por:

$$
\begin{gathered}
\frac{D c_{5}}{D t}=D_{x x} \frac{\partial^{2} c_{5}}{\partial x^{2}}-k r c_{5} \\
\frac{D c_{6}}{D t}=D_{x x} \frac{\partial^{2} c_{6}}{\partial x^{2}}+k a\left(c_{s}-c_{6}\right)-k_{D} c_{5}
\end{gathered}
$$

onde, $c_{5}$ é a demanda bioquímica de oxigênio, $c_{6}$ é a concentração de oxigênio dissolvido, $k r$ é uma taxa de decaimento da matéria orgânica, $k_{D}$ é o coeficiente de desoxigenação, $k_{a}$ é o coeficiente de reaeração e $c_{s}$ é a concentração de saturação de oxigênio dissolvido e é dada por:

$$
c_{s}=14.6244-0.364134 T+0.0044972 T^{2}+S\left(-0.0966+0.00205 T+0.0002739 T^{2}\right)
$$

onde $T$ é a temperatura e $S$ é a salinidade.

Este modelo, dado pelas equações (7.15) e (7.16), além de ser um modelo de transporte de concentrações de espécies constituintes, é também um modelo de transporte e reação de constituintes, pois além dos constituintes serem transportados, ocorre uma reação entre eles, isto é, a DBO reage com o OD, fazendo com que o OD desapareça em uma reação química e apareça novamente em uma reaeração.

As soluções analíticas para o oxigênio dissolvido (OD) e a demanda bioquímica de oxigênio (DBO) são dadas respectivamente por:

$$
c_{5}=c_{5,0} \exp \left[\frac{U}{2 D_{x x}}\left(1-\alpha_{r}\right) x\right]
$$




$$
c_{6}=c_{6,0} \frac{k_{D}}{k_{a}-k_{r}}\left(\frac{\exp \left[\frac{U}{2 D_{x x}}\left(1-\alpha_{r}\right) x\right]}{\alpha_{r}}-\frac{\exp \left[\frac{U}{2 D_{x x}}\left(1-\alpha_{a}\right) x\right]}{\alpha_{a}}\right)
$$

onde

$$
\alpha_{r}=\sqrt{1+\frac{4 k_{r} D_{x x}}{U^{2}}} \quad \alpha_{a}=\sqrt{1+\frac{4 k_{a} D_{x x}}{U^{2}}}
$$

Valores na literatura mostram que $k_{D}$ pode variar entre $0,5 /$ dia, para águas com grande concetração de matéria orgânica, e 0,09/dia para rios com águas limpas; o coeficiente de reaeração varia com a profundidade e com a velocidade do curso de água, podendo assumir valores entre 0,20/dia, para rios profundos e lentos, e 1,20/dia para rios rápidos e rasos. Para este trabalho foi considerada taxas de consumo menores e maiores taxas de fontes de OD, isto é, menores coeficientes de desoxigenação e decaimento da matéria orgânica e maior coeficiente de reaeração, de acordo com os valores que foram adotados no trabalho de [Cunha, 2003]. 
CAPÍTULO 8

\section{Resultados Numéricos e Validação}

\subsection{Introdução}

Neste Capítulo são apresentados os resultados obtidos para o transporte da temperatura, o transporte das espécies constituintes e para o modelo de turbulência. Todas as simulações foram realizadas considerando escoamentos de fluidos incompressíveis na presença de contornos rígidos e a validação considera os problemas-teste descritos no Capítulo 7 para $2 \mathrm{D}$ e $2 \mathrm{DH}$.

A validação do código computacional foi feita comparando os resultados numéricos, obtidos para cada modelo, com valores exatos de soluções analíticas e com valores experimentais como é o caso do modelo de turbulência. Foram desenvolvidos testes para os modelos de transporte de temperatura, do transporte das espécies constituintes e para o modelo de turbulência.

As simulações foram feitas considerando os seguintes problemas: escoamento em um canal, simulação em domínio com geometria curva, simulação de uma placa com contração, escoamento em uma expansão brusca e simulação em uma geometria de um terreno: Caledônia, para o caso 2D. Simulação no canal e na geometria cocho para o caso 2DH e simulação em uma expansão brusca para o modelo de turbulência.

\subsection{Simulação do Escoamento em um Canal}

\subsubsection{Temperatura}

Para o estudo e validação dos resultados aqui apresentados, considera-se o escoamento de um fluido entre duas placas paralelas, como mostrado na Figura (7.2), onde o escoamento é da esquerda para a direita.

Foi feita uma simulação considerando as placas T1 e T2 mantidas a uma temperatura constante de $30^{\circ} \mathrm{C}$. Os resultados dessa simulação podem ser vistos nas Figuras (8.1) e (8.2),onde, na Figura (8.1) é apresentado o perfil da temperatura, na saída de fluido do canal, da solução numérica juntamente com a solução analítica e na Figura (8.2) é 
apresentada a solução em todo o canal. Na Figura (8.2), nota-se que ao entrar no canal, a temperatura das camadas de fluido mais próximas das paredes sobem mais do que as das camadas próximas ao eixo do escoamento que se encontram distantes da fonte de calor.

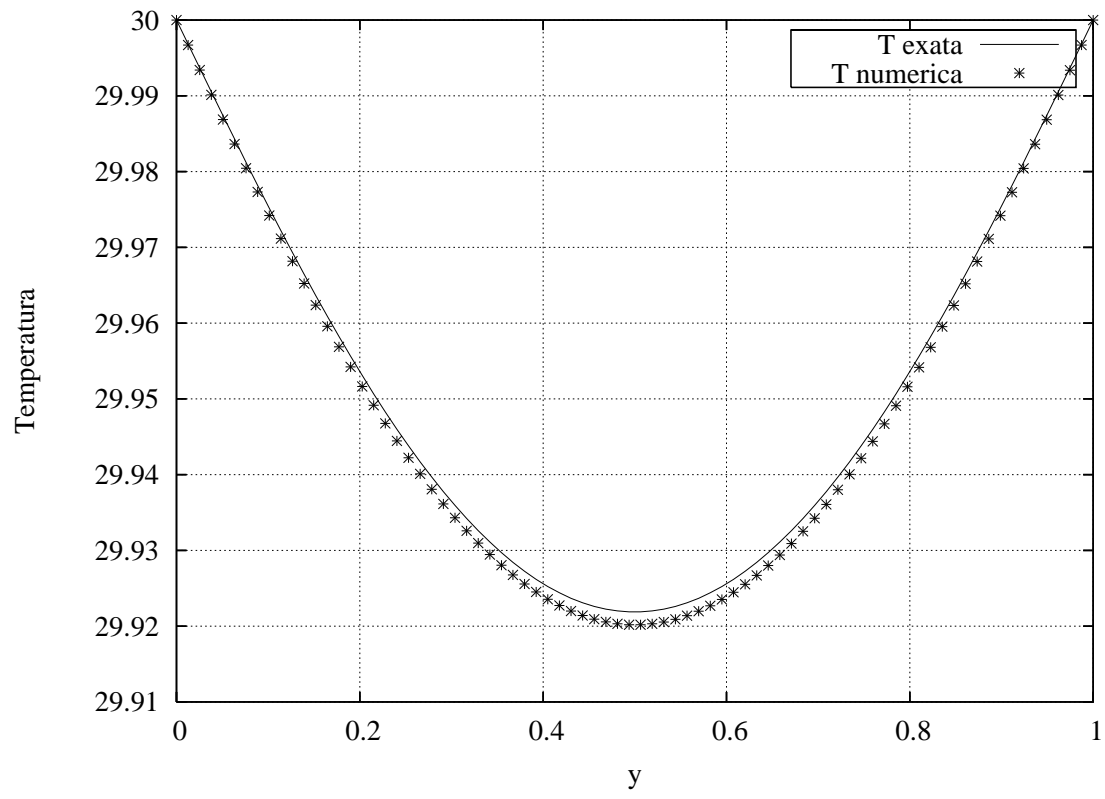

Figura 8.1: Comparação entre os resultados numéricos e a solução analítica da temperatura na saída de fluido do canal

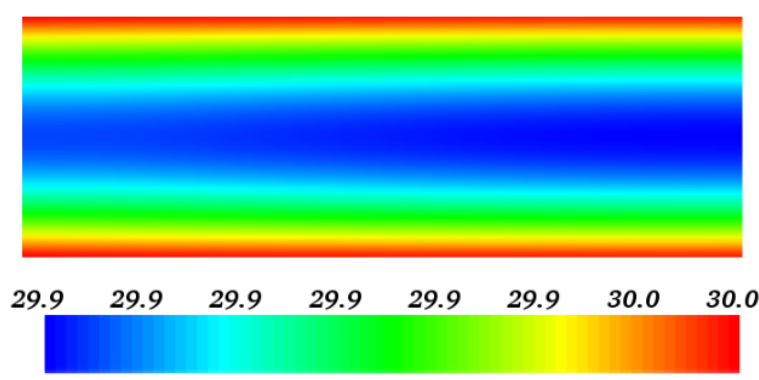

Figura 8.2: Solução numérica em todo o canal

O modelo utilizado para os dois problemas é descrito a seguir:

- Dimensão do domínio: $3,0 \mathrm{~m} \times 1,0 \mathrm{~m}$;

- Diâmetro do injetor $(L): 1,0 \mathrm{~m}$;

- Velocidade de injeção $(U)$ : parabólica;

- Coeficiente de viscosidade cinemática $(\nu): 1,0 \mathrm{~m}^{2} \mathrm{~s}^{-1}$;

- Parâmetros de escala: $L=1,0 \mathrm{~m}$ e $U=1,0 \mathrm{~ms}^{-1}$;

- Número de Reynolds $(R e=U L / \nu): 1,0$; 
- Densidade: $\rho=1,0$;

- Coeficiente de condutividade térmica do fluido $\kappa$ : 1,0 ;

- Calor específico $c_{p}: 1,0$.

Para o transporte da temperatura observa-se que o método utilizado fornece bons resultados, visto que a solução numérica apresenta uma excelente concordância com a solução analítica. Nessa simulação o erro absoluto foi da ordem de $10^{-5}$ para o exemplo considerado.

Na Figura (8.3) são mostrados os resultados obtdos em um teste de convergência deste problema para diversos valores de $\Delta t$, considerando uma malha computacional com 3000 nós.

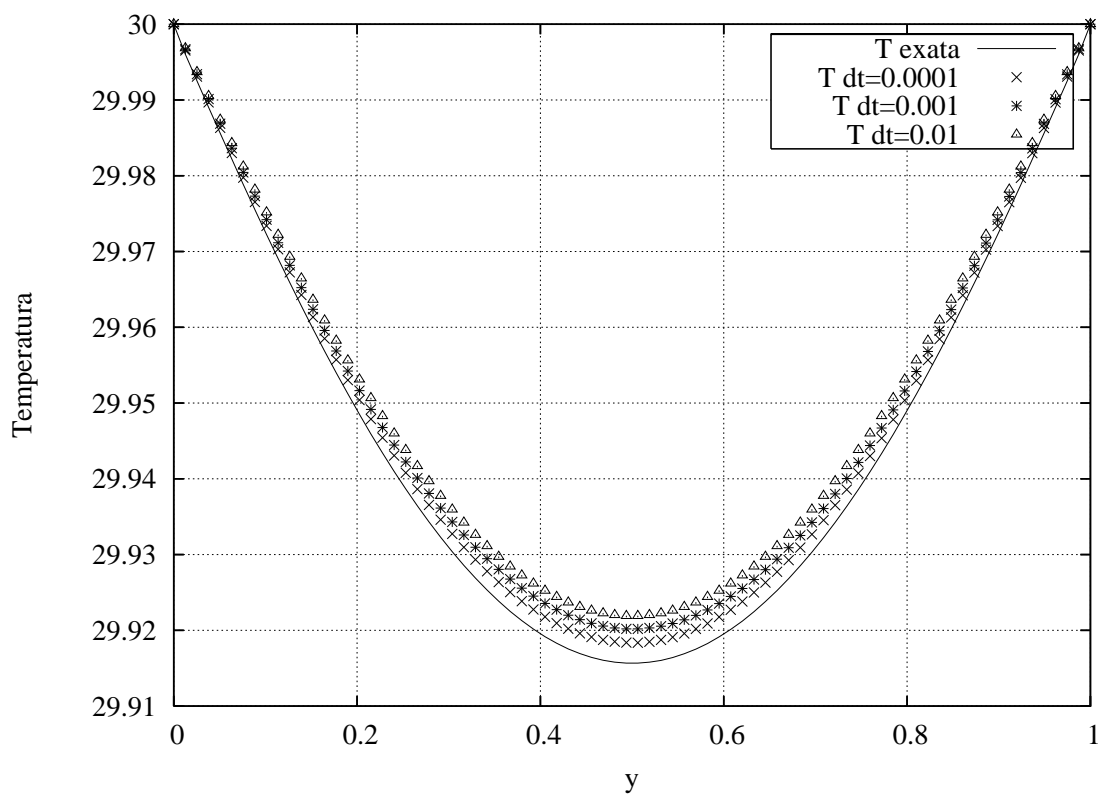

Figura 8.3: Teste de convergência para a temperatura com, $\Delta t=0,01, \Delta t=0,001 \mathrm{e}$ $\Delta t=0,0001$.

Observa-se que diminuindo o valor de $\Delta t$, a solução numérica se aproxima mais da solução analítica. Mostrando portanto a convergência do método.

\subsubsection{Espécies Constituintes}

Para simular numericamente o transporte das concentrações de espécies constituintes foi considerado o modelo de cinética de reação química das espécies constituintes OD-DBO, apresentado no Capítulo 7, que descreve o lançamento de uma fonte pontual de DBO em um corpo de água.

Para obter as equações que modelam o ciclo OD-DBO das equações (1.13) e (1.14), foram feitas atribuições a cada termo presente nas equações (1.13) e (1.14) aos termos correspondentes em (7.15) e (7.16), como mostra a tabela abaixo:

Para o problema considerado, adotou-se os seguintes parâmetros:

- Dimensão do domínio: 0,2m x 23,4m 


\begin{tabular}{|l|c|}
\hline equação (1.13) & equação (1.14) \\
\hline$c_{1}=c_{5}$ & $c_{2}=c_{6}$ \\
\hline$\lambda_{D_{1}}=D_{x x}$ & $\lambda_{D_{2}}=D_{x x}$ \\
\hline$\mu_{11}^{\prime \prime}=k r$ & $\mu_{21}^{\prime \prime}=k a$ \\
\hline$\gamma_{11}=2$ & $\gamma_{21}=2$ \\
\hline$\beta_{21}=0$ & $\beta_{11}=0$ \\
\hline$S_{1}=0$ & $S_{2}=k a c_{s}-k r c_{5}$ \\
\hline
\end{tabular}

Tabela 8.1: Atribuições para cada parâmetro da equação geral do transporte das concentrações de espécies constituintes de acordo com o modelo de cinética de reação química OD-DBO.

- Velocidade $U=0,03 m s^{-1}$

- Temperatura da água $T=25^{0} \mathrm{C}$

- Coeficiente de desoxigenação $K_{D}=0,50 /$ dia

- Coeficiente de reaeração $K_{a}=0,90 /$ dia

- Taxa de decaimento da matéria orgânica $K_{r}=0,30 /$ dia

- Condição inicial para DBO $C_{5,0}=10,0 \mathrm{mg} / \mathrm{l}$

- Condição inicial para OD $C_{6,0}=8,3 \mathrm{mg} / \mathrm{l}$

- Densidade: $\rho=1,0$;

- Coeficiente de condutividade térmica do fluido $\kappa: 1,0$;

- Calor específico $c_{p}=1,0$;

- Salinidade $S=1,0$.

Para este modelo foram obtidos os seguintes resultados:

A Figura (8.4) mostra a comparação entre os resultados numéricos e a solução analítica para o Oxigênio Dissolvido e a Demanda Bioquímica de Oxigênio no meio do canal, na direção do escoamento $(x)$. Pode-se observar através desse gráfico que há uma excelente concordância entre os resultados fornecidos pelo método e a solução analítica tanto para a DBO como para o OD. O erro absoluto para este problema foi da ordem de $10^{-4}$.

As Figuras (8.5) e (8.6) mostram a solução em todo o canal para a DBO e o OD respectivamente. Observa-se na Figura (8.6), que representa o consumo de oxigênio dissolvido ao longo do corpo de água onde se processa a decomposição da matéria orgânica, qual é o trecho que sofre as consequências da poluição e em qual região o curso de água volta a restabelecer as condições anteriores, podendo assim ter uma previsão da qualidade da água. Entretanto, tais conclusões só são possíveis com a especificação correta dos coeficientes utilizados para descrever as reações cinéticas. 


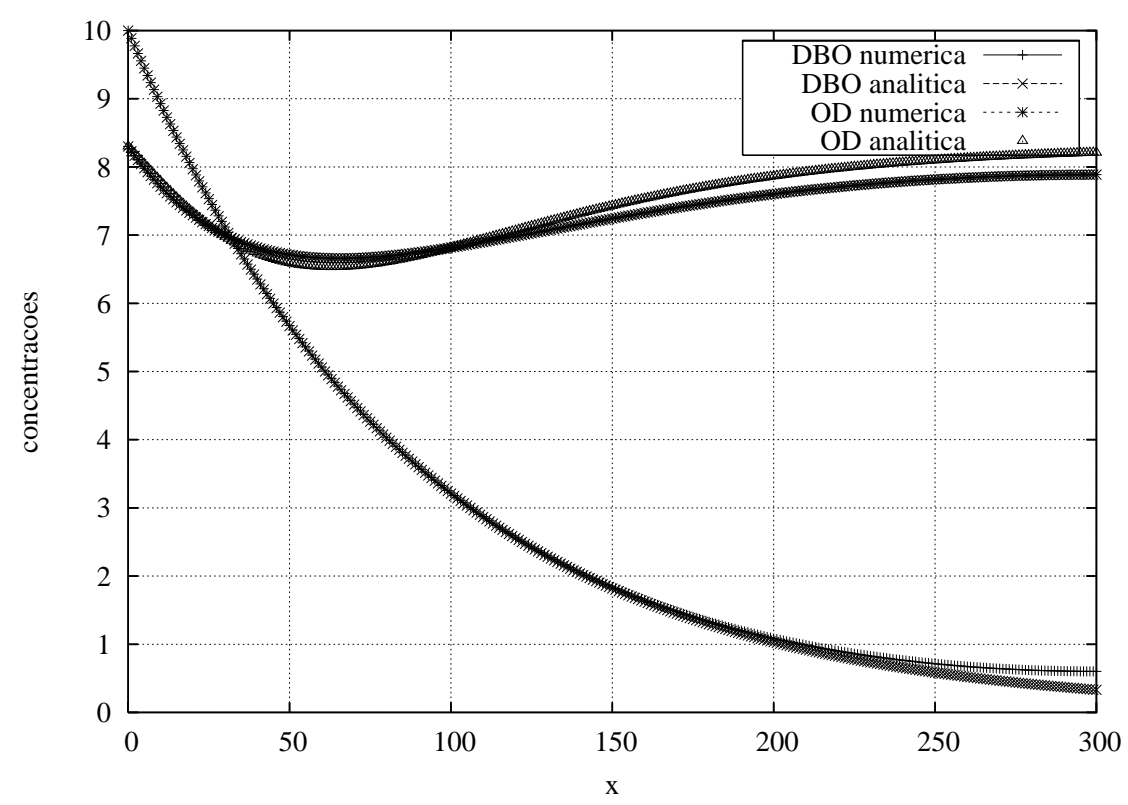

Figura 8.4: Comparação entre os resultados numéricos e a solução analítica no meio do canal e na direção do escoamento.
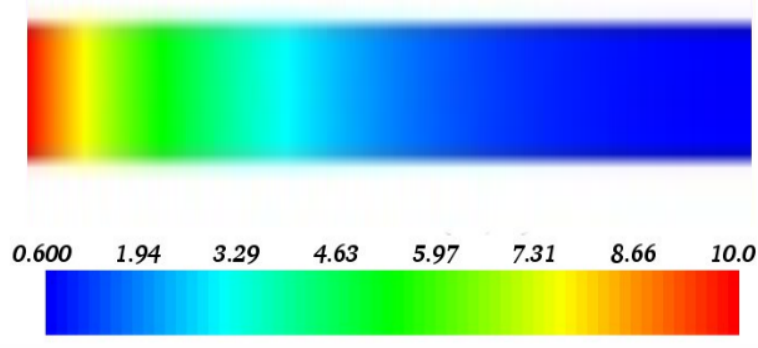

Figura 8.5: Solução numérica em todo o canal para a DBO.

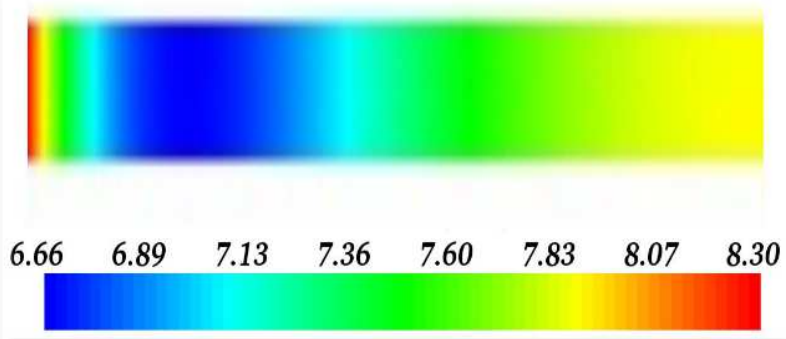

Figura 8.6: Solução numérica em todo o canal para o OD.

\subsubsection{Simulação de uma mancha de DBO no canal}

A simulação seguinte foi realizada considerando uma mancha de DBO na entrada do canal, com condição inicial $C_{5,0}=10,0 \mathrm{mg} / \mathrm{l}$ para a DBO e $C_{6,0}=0,0 \mathrm{mg} / \mathrm{l}$ para o OD. Para as quais foram obtidos os seguintes resultados:

Observa-se na Figura (8.7) que a mancha de DBO, colocada na entrada de fluido do 

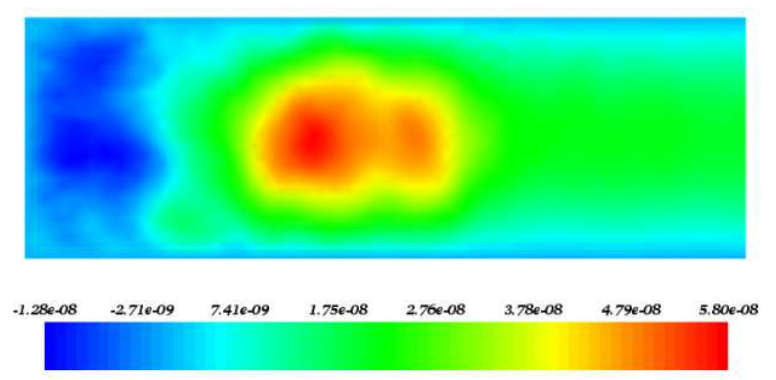

Figura 8.7: Mancha de DBO no canal.

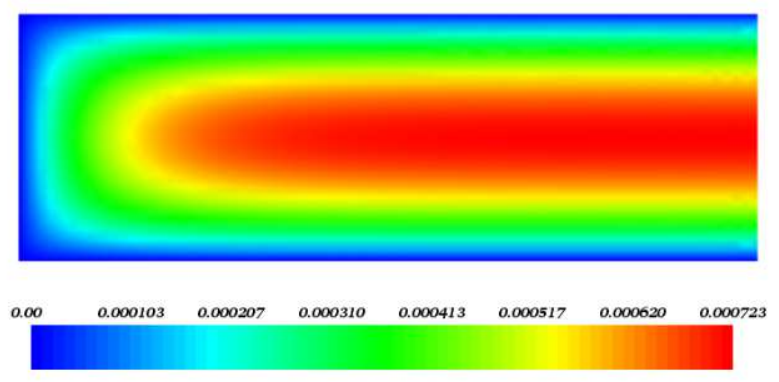

Figura 8.8: Comportamento do OD.

canal, é transportada em direção à saída de fluido do canal, diminuindo a cada instante de tempo sua concentração inicial.

Na Figura (8.8), observa-se um aumento gradativo na concentração de OD, isso devido à reaeração atmosférica.

\subsection{Simulação em Domínio com Geometria Curva}

Nesta seção serão apresentas as simulações numéricas de um problema bidimensional num domínio com geometria curva. A Figura (8.9) mostra o domínio e a Figura (8.10) mostra a malha discretizada em elementos finitos gerada pelo Easymesh.

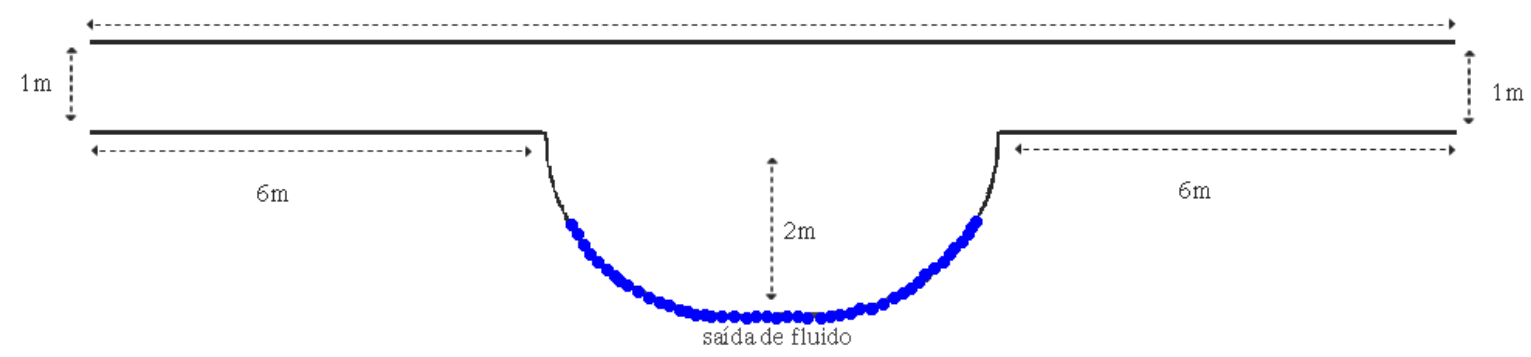

Figura 8.9: Geometria utilizada na simulação do problema com saída de fluido em região curva.

Para uma simulação do problema em questão, o seguinte modelo foi empregado: 


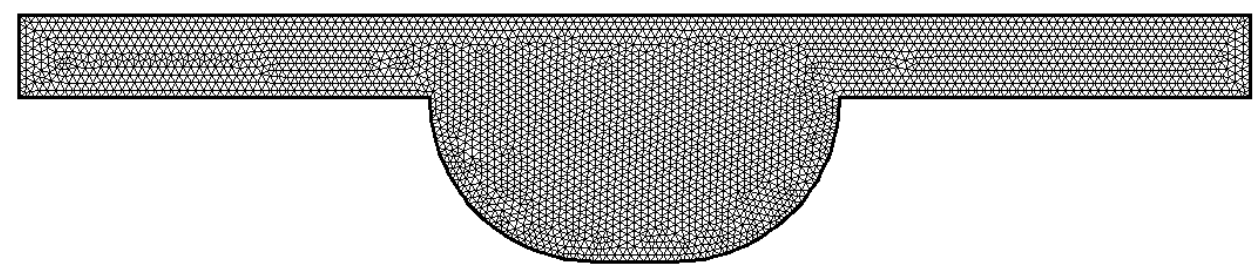

Figura 8.10: Malha da geometria curva gerada pelo Easymesh.

- Velocidade de injeção: $U=0,03 \mathrm{~ms}^{-1}$;

- Parâmetros de escala $U=1,0 m s^{-1}$ e $L=1,0 m$;

- Número de Reynolds: Re=100.

Considerando as entradas de fluido à esquerda e a direita da parte superior da geometria e a saída de fluido na parte curva da geometria, como mostra a Figura (8.9) obteve-se, através do módulo Hydro, o seguinte resultado para a velocidade:

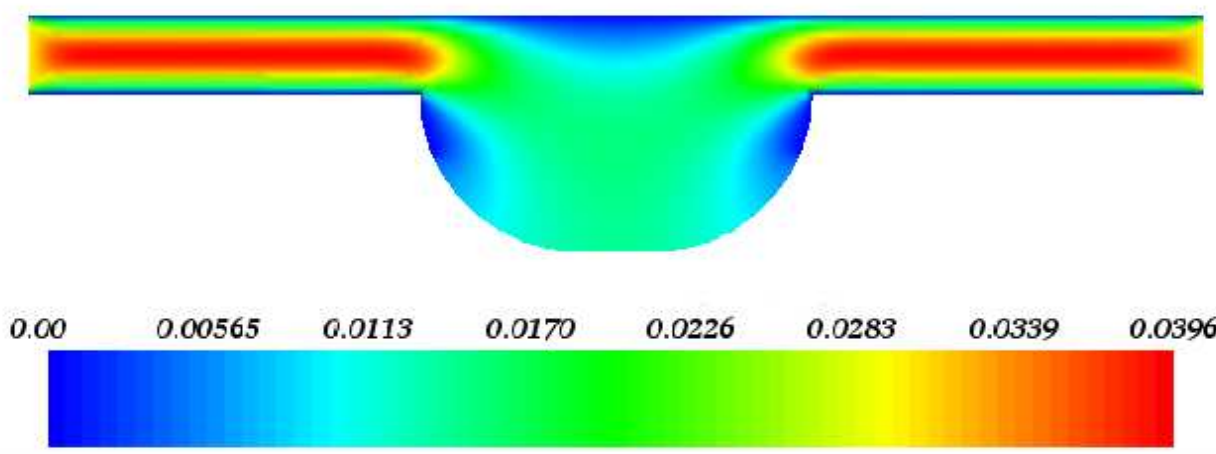

Figura 8.11: Velocidade com saída de fluido na curva da geometria.

\subsubsection{Temperatura}

Para simular o transporte da temperatura considerando a mesma geometria, foram obtidos os seguintes resultados:

Nas Figuras (8.12) e (8.13), são mostrados os resultados obtidos em um certo intervalo de tempo até a sua convergência, mostrada na Figura (8.13).

Para o problema considerado, foram adotados os seguintes parâmetros:

- Densidade: $\rho=1,0$;

- Coeficiente de condutividade térmica do fluido $\kappa: 1,0$;

- Calor específico $c_{p}: 1,0$.

- Temperatura nos contornos rígidos: $T=25^{0} \mathrm{C}$. 

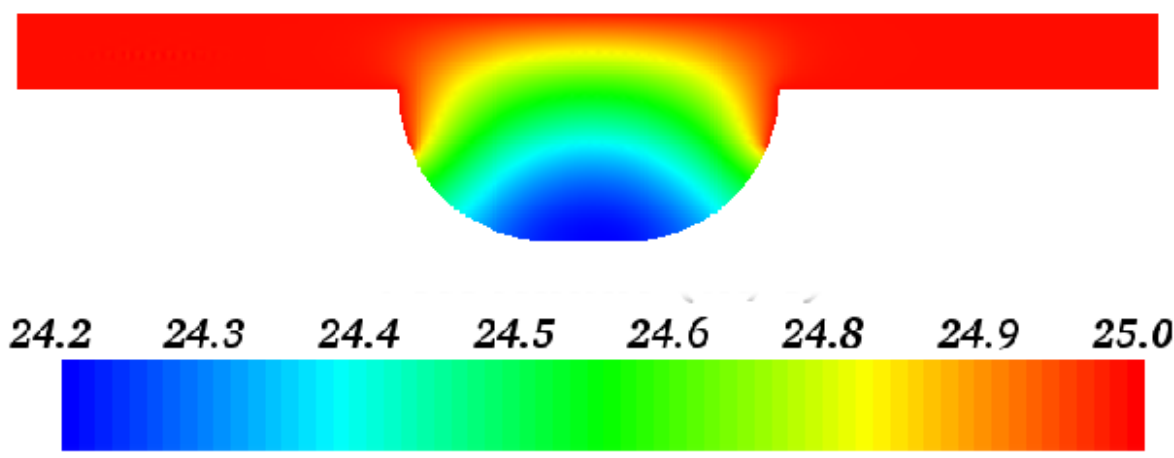

Figura 8.12: Temperatura com saída de fluido na curva da geometria.
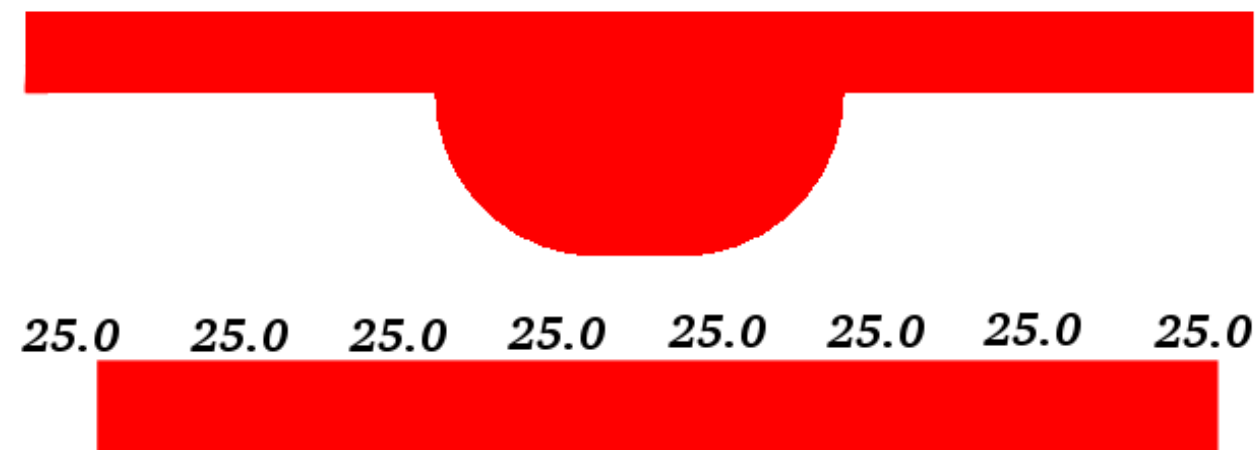

Figura 8.13: Temperatura com saída de fluido na curva da geometria.

Observa-se através das figuras acima que os resultados fornecidos são condizentes com os resultados obtidos com o problema teste, isto é, a temperatura do fluido fica mais elevada próxima às paredes da geometria e diminui próximo a saída de fluido, até atingir sua convergência.

\subsubsection{Espécies Constituintes}

Para simular numericamente o transporte das espécies constituintes na mesma geometria foram obtidos os seguintes resultados para os constituintes OD e DBO:

O modelo aqui empregado é o mesmo utilizado na simulação considerando o escoamento no canal.

Observa-se através da Figura (8.14) que o comportamento da DBO é o mesmo obtido na simulação do canal. O mesmo acontece com o OD como mostra a Figura (8.15). Isto é, o OD decai devido a reação com a DBO e volta a restabelecer as condições anteriores devido a reaeração atmosférica.

\subsubsection{Simulação de uma mancha de DBO e OD na geometria curva}

Para essa simulação, foi considerada uma mancha de DBO na entrada de fluido à esquerda na geometria com condição inicial $c_{5,0}=10,0 \mathrm{mg} / \mathrm{l}$ e uma mancha de OD na entrada de fluido à direita na geometria com condição inicial $c_{6,0}=8,3 \mathrm{mg} / \mathrm{l}$, e com condições de 

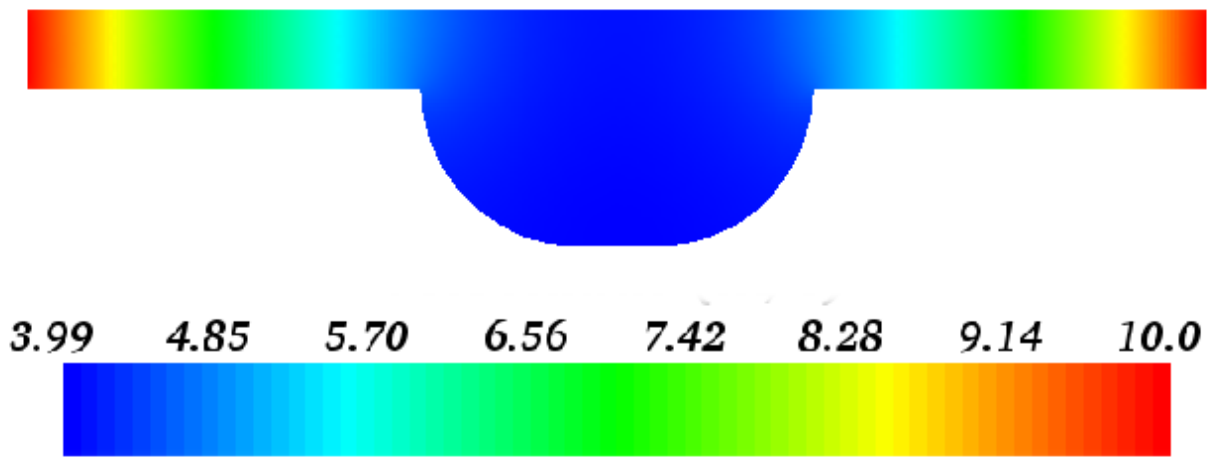

Figura 8.14: Transporte de DBO na geometria curva.

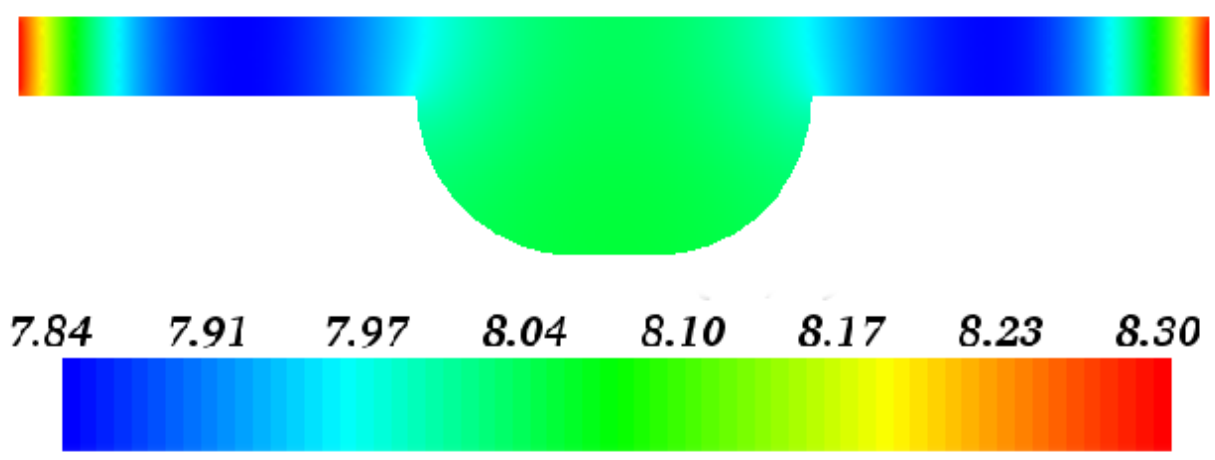

Figura 8.15: Transporte de OD na geometria curva.

contorno $c_{5,0}=0,0 \mathrm{mg} / \mathrm{l}$ para a $\mathrm{DBO}$ e $c_{6,0}=0,0 \mathrm{mg} / \mathrm{l}$ para o OD.

Nas Figuras (8.16), (8.17), (8.18) e (8.19) observa-se que o comportamento dos constituintes OD e DBO são os mesmos apresentados nas simulações anteriores. 

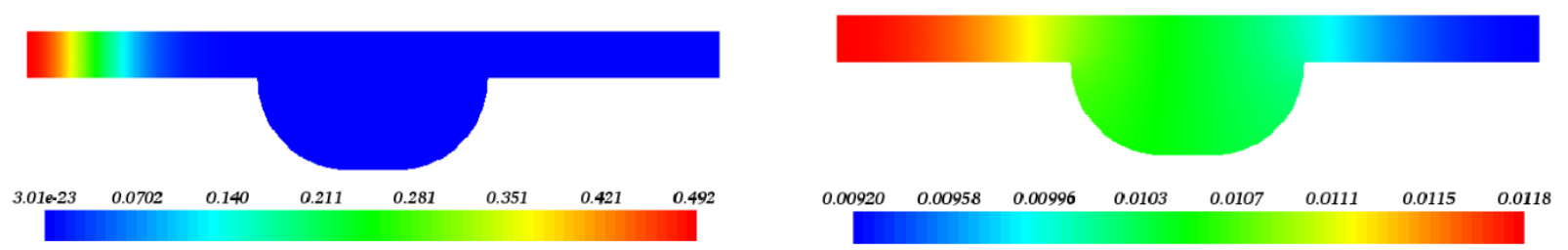

Figura 8.16: Mancha de DBO na entrada de fluido da geometria curva em $t \approx 60 \mathrm{~s}$

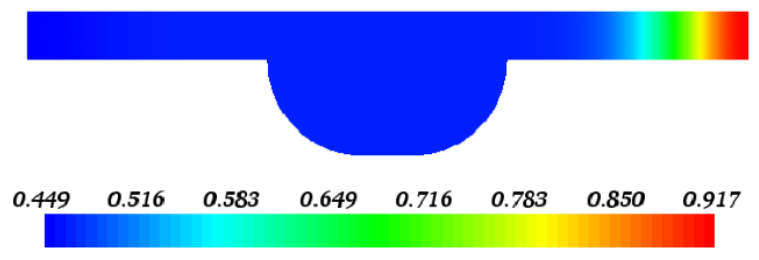

Figura 8.17: Mancha de DBO na entrada de fluido da geometria curva em $t \approx 24 h$

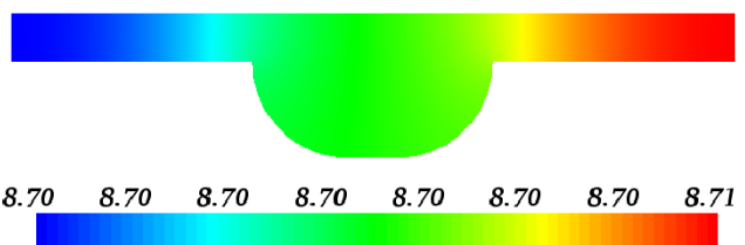

Figura 8.18: Mancha de OD na entrada de fluido da geometria curva em $t \approx 60 \mathrm{~s}$
Figura 8.19: Mancha de OD na entrada de fluido da geometria curva em $t \approx 24 h$

\subsection{Simulação de uma Placa com Contração}

O problema da contração caracteriza-se pelo escoamento de um fluido através de um canal de diâmetro $L$ que passa a escoar em um canal de diâmetro menor $L / 4$. O domínio do escoamento para o problema é apresentado na Figura (8.20) e a malha computacional para essa geometria discretizada em elementos finitos é mostrada na Figura (8.21).

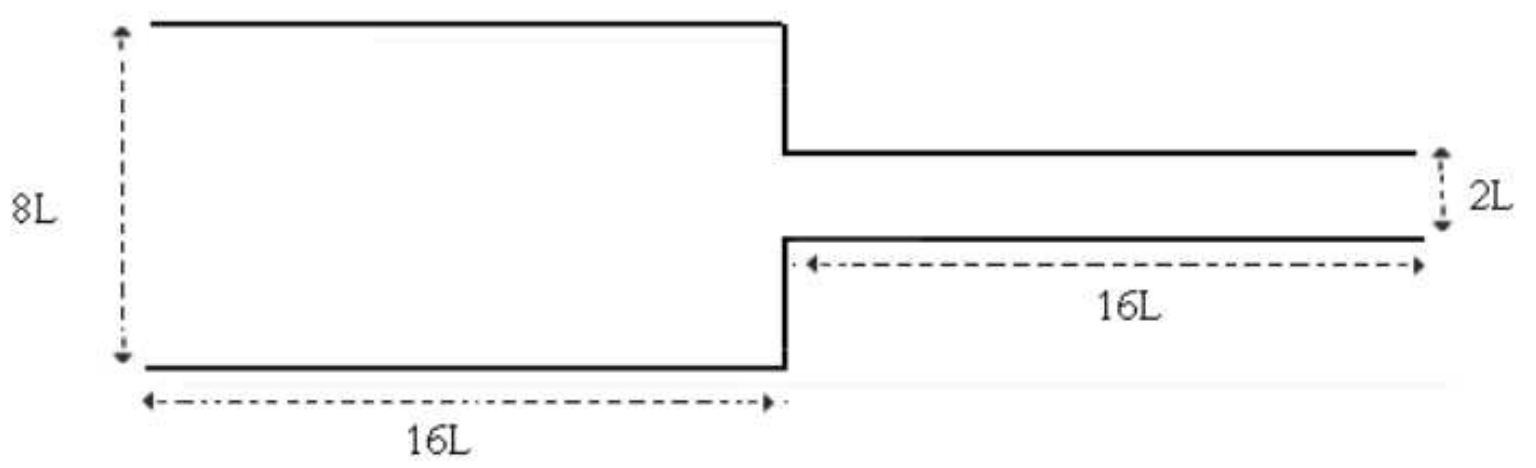

Figura 8.20: Geometria utilizada na simulação do problema em uma placa com contração.

Para uma simulação do problema em questão, o seguinte modelo foi empregado:

- Diâmetro das cavidades: $D 1=8,0 \mathrm{~cm}$ e $D 2=2,0 \mathrm{~cm}$

- Parâmetros de escala $U=1,0 \mathrm{~ms}^{-1}$ e $L=1,0 \mathrm{~m}$;

- Número de Reynolds: Re=100. 


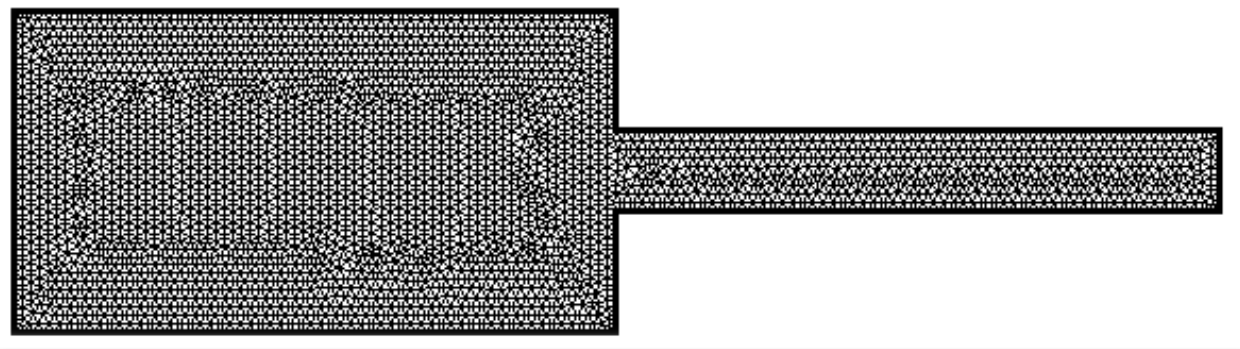

Figura 8.21: Malha gerada pelo Easymesh.

Para a simulação da velocidade através do módulo Hydro, obteve-se o seguinte resultado, mostrado na Figura (8.22).

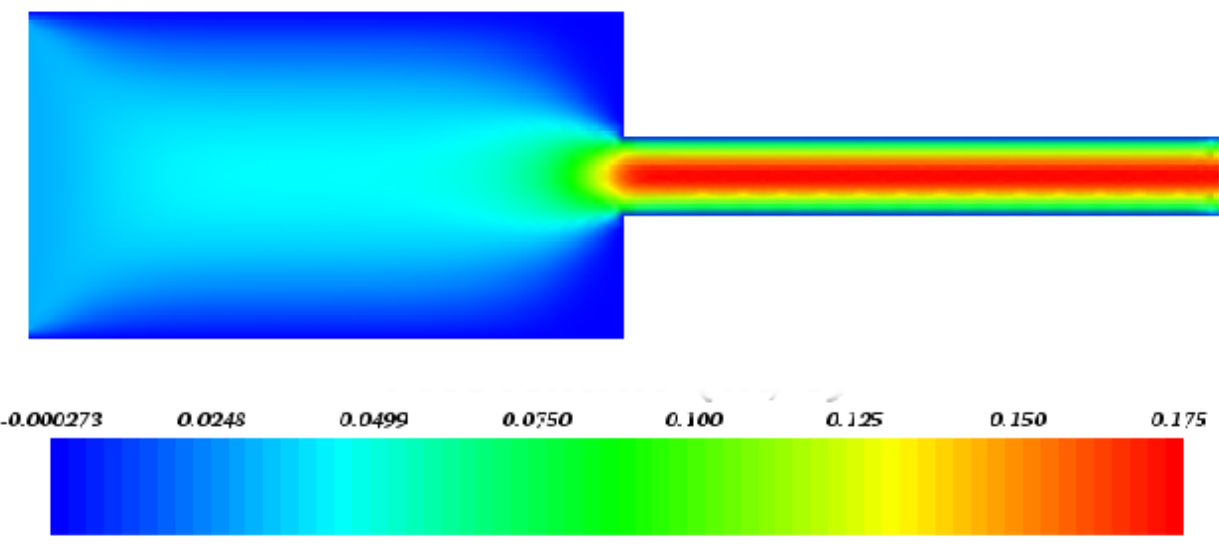

Figura 8.22: Velocidade na placa com contração.

Observa-se uma recirculação nas regiões dos cantos superiores e inferiores da primeira cavidade.

\subsubsection{Temperatura}

Utilizando a mesma malha para simular o transporte da temperatura e considerando o seguinte modelo:

- Densidade: $\rho=1,0$;

- Coeficiente de condutividade térmica do fluido $\kappa: 1,0$;

- Calor específico $c_{p}: 1,0$.

- Temperatura nos contornos rígidos: $T=25^{\circ} \mathrm{C}$.

obteve-se o seguinte resultado: 

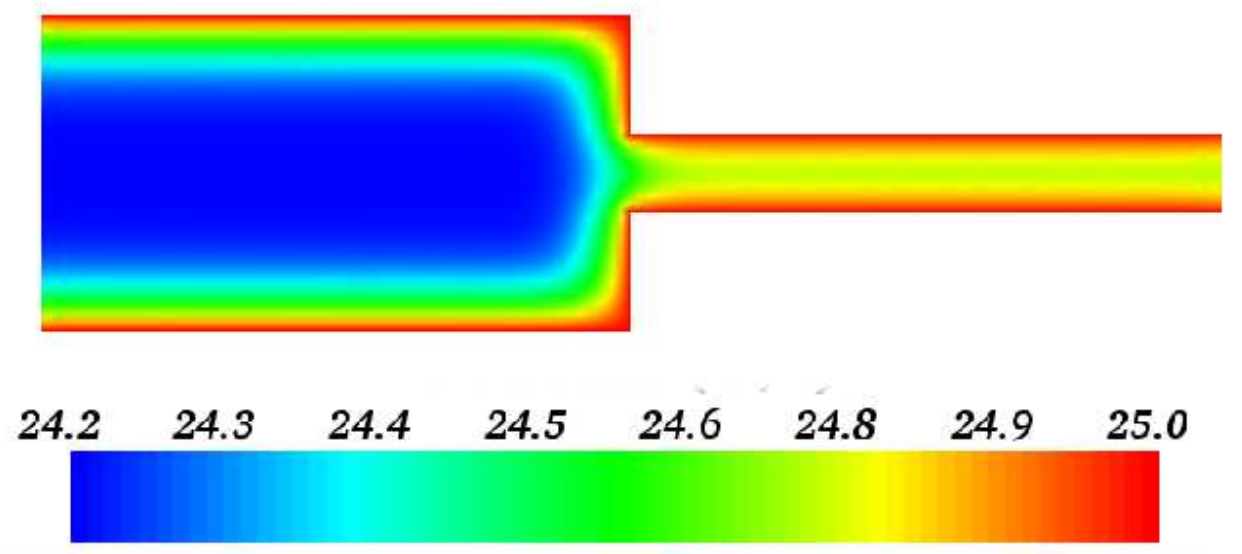

Figura 8.23: Transporte da temperatura na placa com contração.

\subsubsection{Espécies Constituintes}

Para simular o transporte das espécies constituintes na mesma geometria para o modelo de cinética de reação química OD-DBO, foi considerada a simulação de uma mancha de DBO no canto à esquerda na parte superior da geometria e uma mancha de OD à esquerda na parte inferior da geometria, adotando os seguintes parâmetros:

- Temperatura da água $T=25^{0} \mathrm{C}$

- Coeficiente de desoxigenação $K_{D}=0,50 /$ dia

- Coeficiente de reaeração $K_{a}=0,90 /$ dia

- Taxa de decaimento da matéria orgânica $K_{r}=0,30 /$ dia

- Condição inicial para DBO $C_{5,0}=10,0 \mathrm{mg} / \mathrm{l}$

- Condição inicial para OD $C_{6,0}=8,3 \mathrm{mg} / \mathrm{l}$

- Densidade: $\rho=1,0$;

- Coeficiente de condutividade térmica do fluido $\kappa: 1,0$;

- Calor específico $c_{p}: 1,0$.

Para esta simulação foram obtidos os resultados, mostrados nas figuras seguintes, onde são apresentadas as soluções em vários intervalos de tempo até a solução se tornar estável.

Observa-se nas Figuras (8.30), (8.31), (8.32), (8.33), (8.34) e (8.35) que a taxa de OD é alta no começo da simulação, decai depois de um certo intervalo de tempo e em seguida volta a aumentar, ou seja ela diminui devido a uma reação química com a DBO e aparece novamente devido a uma reaeração. A mancha de DBO colocada na entrada de fluido movimenta-se em direção à saída de fluido da geometria, se espalhando gradativamente por toda a geometria, no entanto, com uma taxa de concentração cada vez menor, como pode ser observado nas Figuras (8.24), (8.25), (8.26), (8.27), (8.28) e (8.29). O que ocorre neste fenômeno é que além de existir um transporte das concentrações de espécies constituintes, também ocorre uma reação química entre os constituintes a serem transportados. 

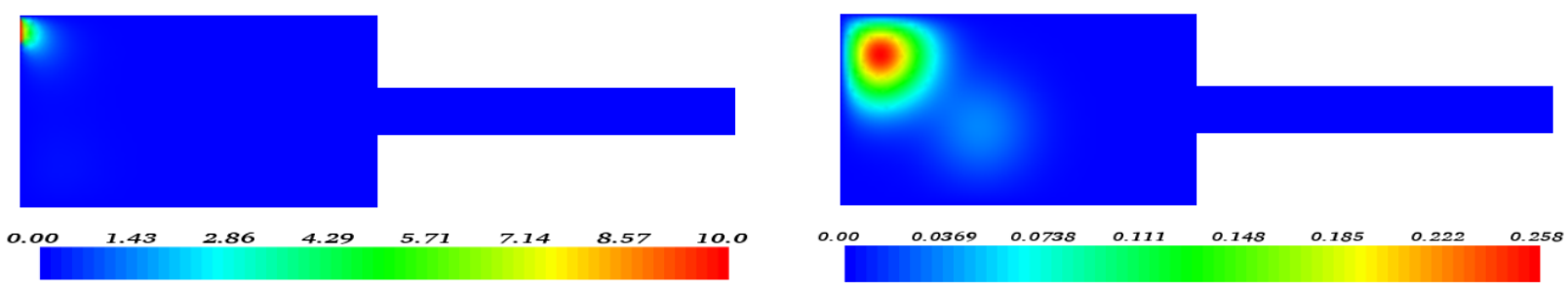

Figura 8.24: DBO em $t \approx 60 \mathrm{~s}$

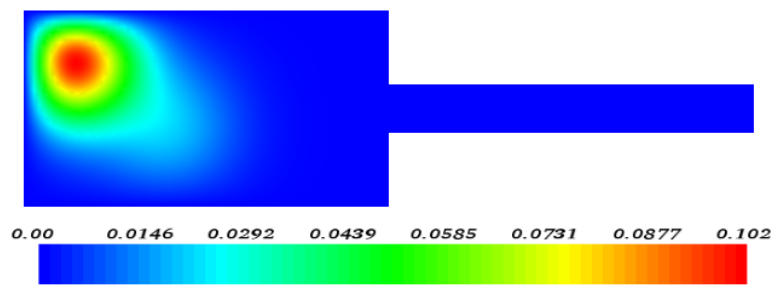

Figura 8.25: DBO em $t \approx 240 \mathrm{~s}$

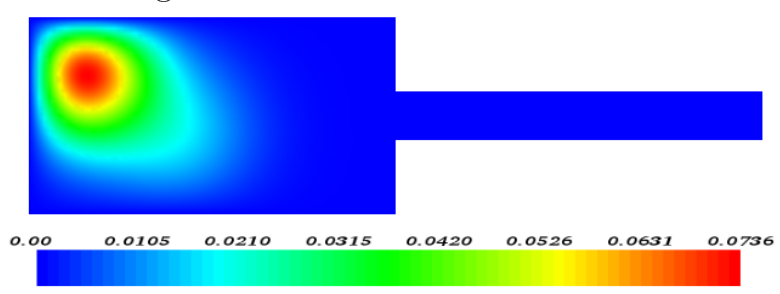

Figura 8.26: DBO em $t \approx 1 h$

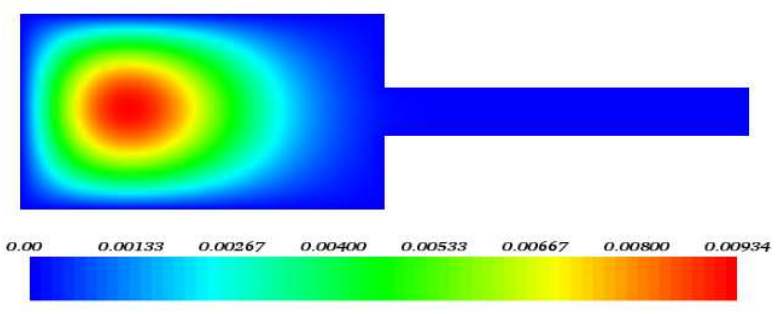

Figura 8.27: DBO em $t \approx 8 h$

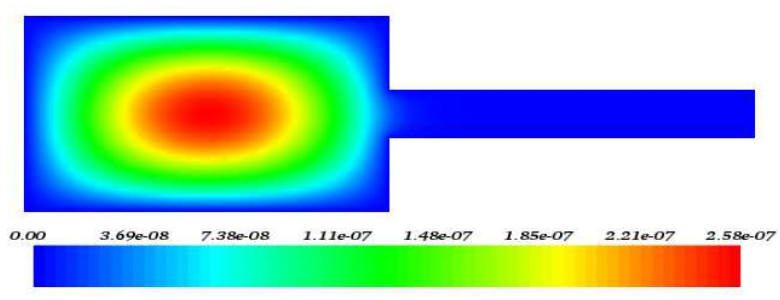

Figura 8.28: DBO em $t \approx 12 h$

Figura 8.29: DBO em $t \approx 24 h$
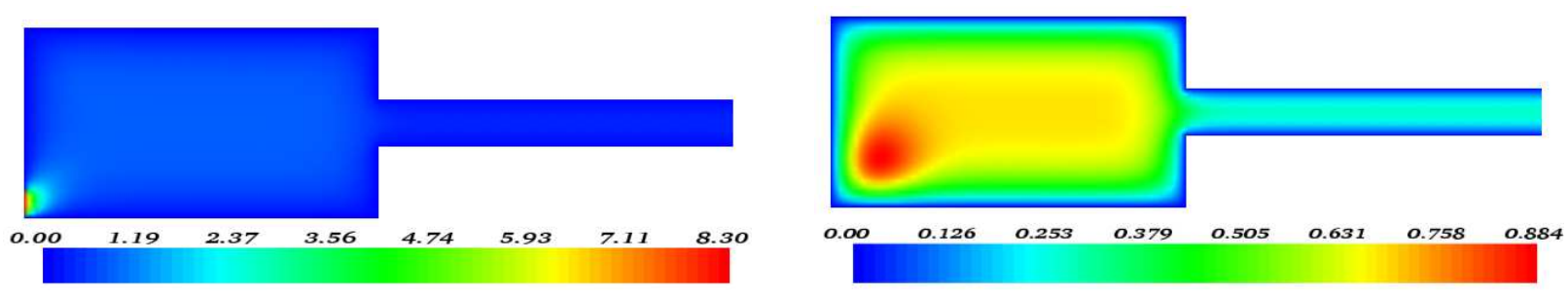

Figura 8.30: OD em $t \approx 30 s$

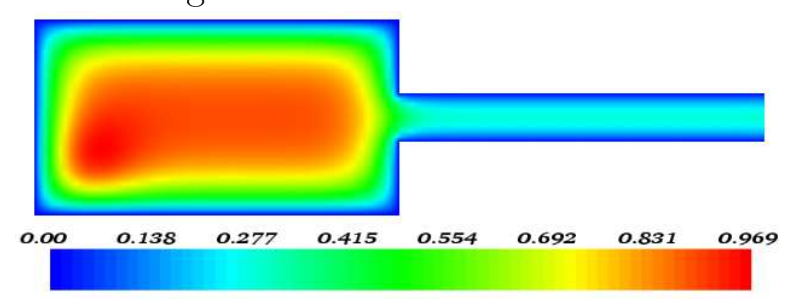

Figura 8.32: OD em $t \approx 1 h$

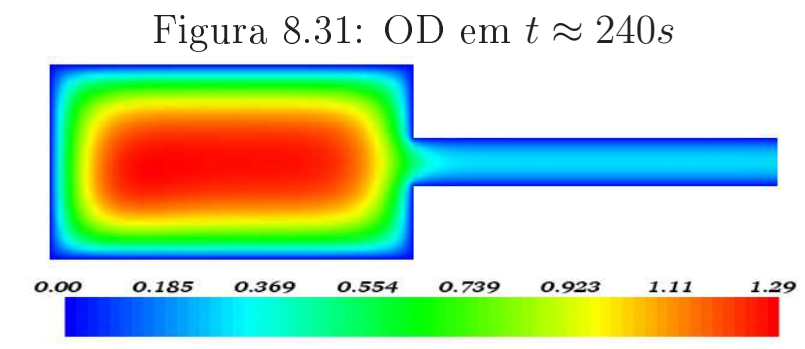

Figura 8.33: OD em $t \approx 8 h$ 


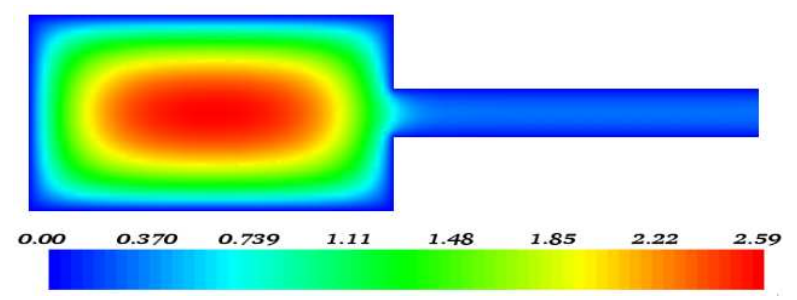

Figura 8.34: OD em $t \approx 12 h$

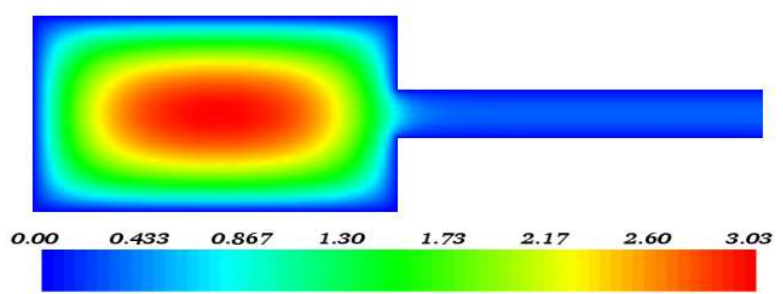

Figura 8.35: OD em $t \approx 24 h$

\subsection{Simulação numa Expansão Brusca}

Considerando o problema bidimensional numa expansão brusca [Stuart, 1991] foi realizada uma simulação para o transporte da temperatura e uma simulação para o transporte das concentrações.

A geometria do problema é mostrada na Figura (8.36), em que a altura da expansão brusca é a metade da largura do canal e a malha utilizada é mostrada na Figura (8.37).

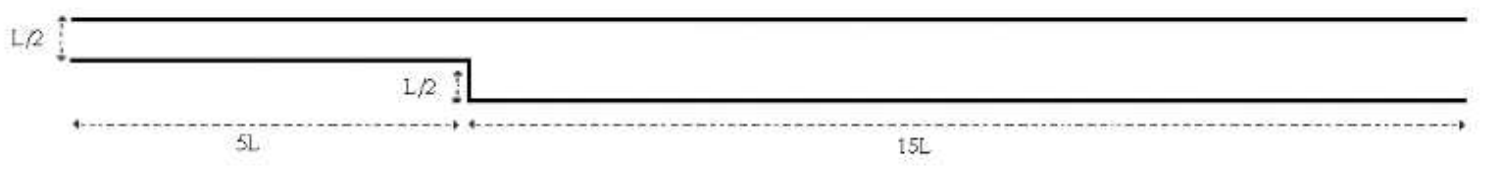

Figura 8.36: Geometria utilizada para a simulação do problema numa expansão brusca.

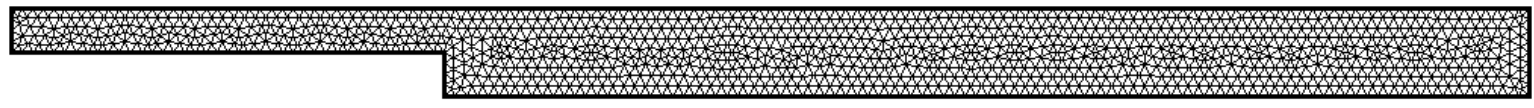

Figura 8.37: Malha não estruturada gerada pelo Easymesh.

\subsubsection{Temperatura}

Para simular o transporte da temperatura considerando a geometria (8.36) e o modelo descrito abaixo:

- Densidade: $\rho=1,0$;

- Coeficiente de condutividade térmica do fluido $\kappa: 1,0$;

- Calor específico $c_{p}: 1,0$;

- Temperatura nos contornos rígidos: $T=25^{0} \mathrm{C}$.

obteve-se o seguinte resultado: 


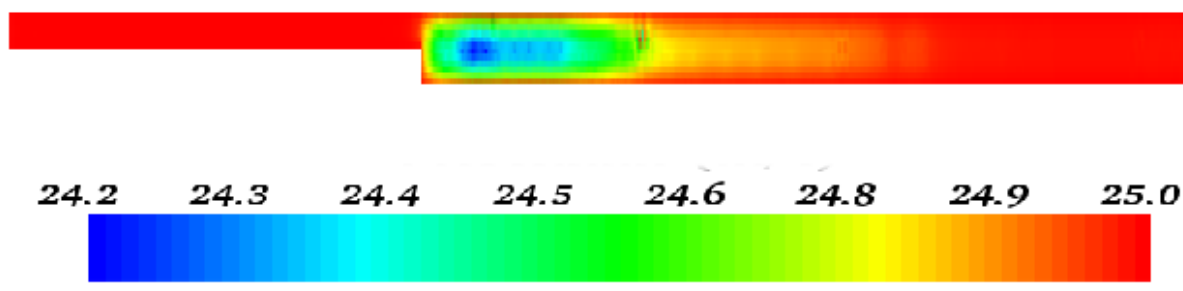

Figura 8.38: Transporte da temperatura numa expansão brusca.

Observa-se na Figura (8.38) que as camadas de fluido próximas ao contorno rígido apresentam uma temperatura mais elevada do que a das regiões que apresentam uma recirculação.

\subsubsection{Espécies Constituintes}

Para simular o transporte das espécies constituintes na mesma geometria e considerando o modelo descrito abaixo:

- Temperatura da água $T=25^{0} \mathrm{C}$

- Coeficiente de desoxigenação $K_{D}=0,50 /$ dia

- Coeficiente de reaeração $K_{a}=0,90 /$ dia

- Taxa de decaimento da matéria orgânica $K_{r}=0,30 /$ dia

- Condição inicial para DBO $C_{5,0}=10,0 \mathrm{mg} / \mathrm{l}$

- Condição inicial para OD $C_{6,0}=8,3 \mathrm{mg} / \mathrm{l}$

- Densidade: $\rho=1,0$;

- Coeficiente de condutividade térmica do fluido $\kappa: 1,0$;

- Calor específico $c_{p}: 1,0$.

foram obtidos os seguintes resultados:

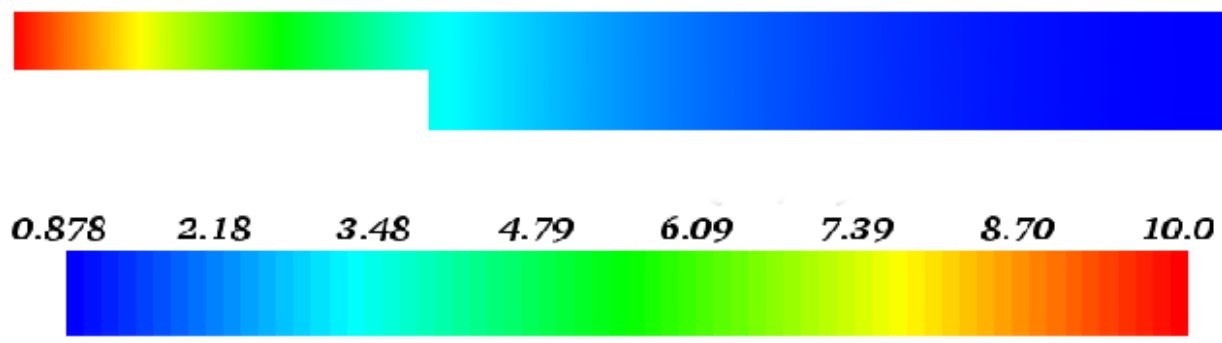

Figura 8.39: Transporte de DBO numa expansão brusca. 


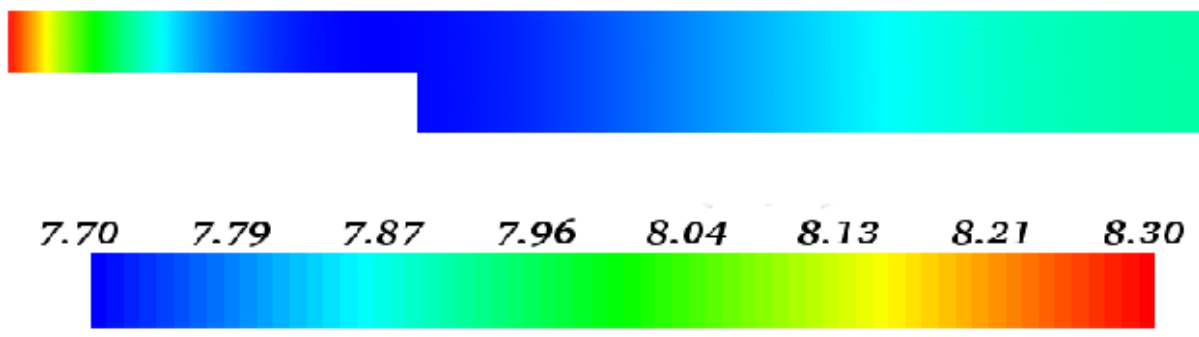

Figura 8.40: Transporte de OD numa expansão brusca.

\subsection{Resultados com uma geometria complexa}

Foi considerada a seguinte malha não estruturada, gerada no Easymesh:

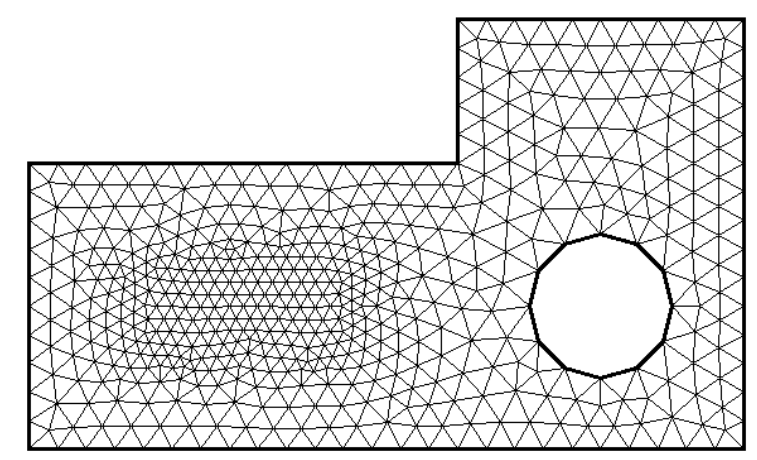

Figura 8.41: Malha não estruturada gerada pelo Easymesh.

A simulação foi realizada considerando o fluido se movendo da esquerda para a direita, sendo a saída de fluido na parte superior á direita na geometria.

\subsubsection{Temperatura}

Para simular o transporte da temperatura considerando essa geometria e o modelo descrito abaixo:

- Densidade: $\rho=1,0$;

- Coeficiente de condutividade térmica do fluido $\kappa$ : 1,0 ;

- Calor específico $c_{p}: 1,0$;

- Temperatura nos contornos rígidos: $T=25^{0} \mathrm{C}$.

obteve-se o seguinte resultado:

Observa-se na Figura (8.42) que as camadas de fluido próximas aos contornos rígidos que estão à uma temperatura constante de $T=25^{0} \mathrm{C}$ apresentam um aumento na temperatura em relação ao fluido que se encontra distante dessa fonte de calor. 


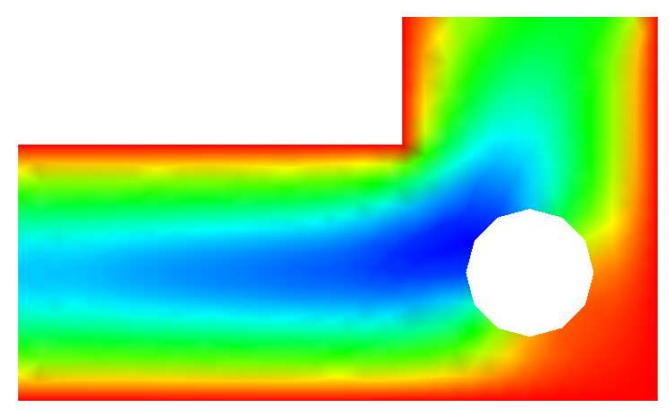

Figura 8.42: Transporte de temperatura.

\subsubsection{Espécies Constituintes}

Para simular o transporte das espécies constituintes na mesma geometria e considerando o modelo descrito abaixo:

- Temperatura da água $T=25^{0} \mathrm{C}$

- Coeficiente de desoxigenação $K_{D}=0,50 /$ dia

- Coeficiente de reaeração $K_{a}=0,90 /$ dia

- Taxa de decaimento da matéria orgânica $K_{r}=0,30 /$ dia

- Condição inicial para DBO $C_{5,0}=10,0 \mathrm{mg} / \mathrm{l}$

- Condição inicial para OD $C_{6,0}=8,3 \mathrm{mg} / \mathrm{l}$

- Densidade: $\rho=1,0$;

- Coeficiente de condutividade térmica do fluido $\kappa: 1,0$;

- Calor específico $c_{p}: 1,0$.

obteve-se os seguintes resultados:

Para a simulação do transporte da DBO, foram colocadas duas manchas desse constituinte na entrada de fluido da geometria, uma delas na parte superior e a outra na parte inferior, com uma condição inicial $c_{5,0}=10,0 \mathrm{mg} / \mathrm{l}$. Para o OD foi colocada uma mancha desse constituinte entre as duas manchas de DBO, na entrada da geometria, com uma condição inicial $c_{6,0}=8,3 \mathrm{mg} / \mathrm{l}$.

Observa-se através dos resultados obtidos, em determinados intervalos de tempo, mostrados nas figuras seguintes, que as duas manchas de DBO que são transportadas em direção à saída de fluido da geometria, se encontram após $t \approx 60 \mathrm{~s}$ e vão se espalhando gradativamente por toda a geometria, entretanto com uma taxa de concentração cada vez menor.

Quanto ao OD, observa-se que a taxa de OD é alta no começo da simulação, decai após um certo intervalo de tempo e em seguida volta a aumentar, ou seja, ela diminui devido a uma reação química com a DBO e aparece novamente devido a uma reaeração. O que ocorre neste fenômeno é que além de existir um transporte das concentrações de espécies constituintes, também ocorre uma reação química entre os constituintes a serem transportados. 


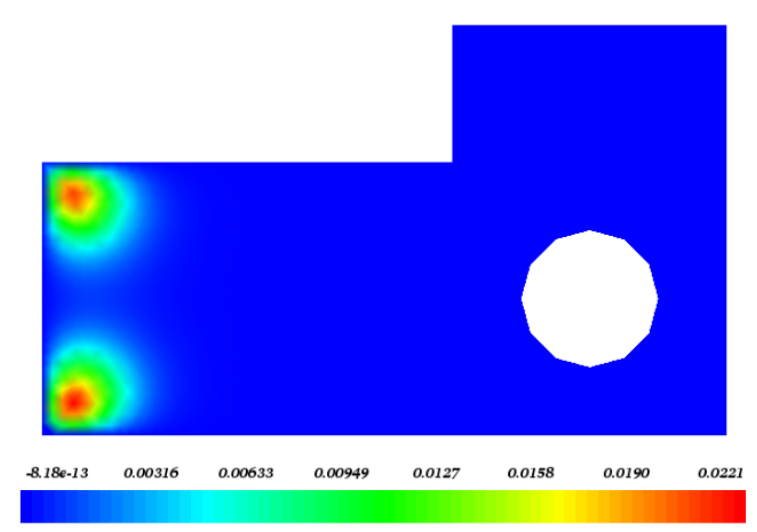

Figura 8.43: Transporte de duas manchas de DBO em $t \approx 60 \mathrm{~s}$

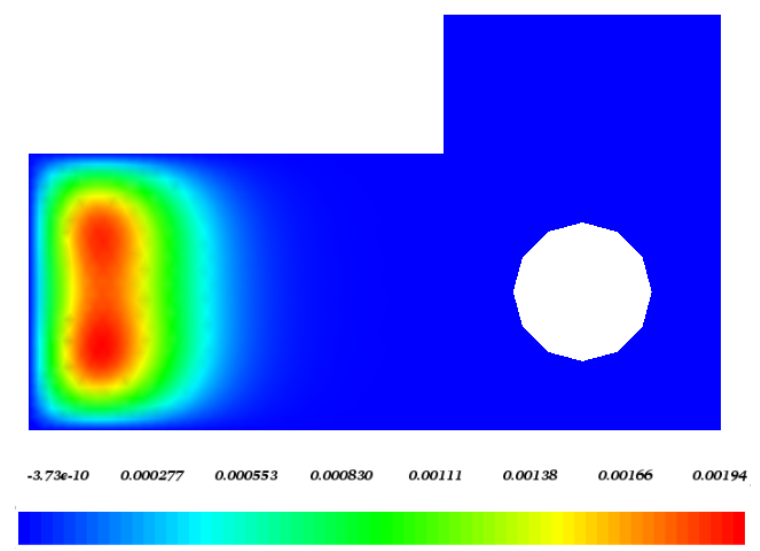

Figura 8.45: Transporte de duas manchas de DBO em $t \approx 1 h$

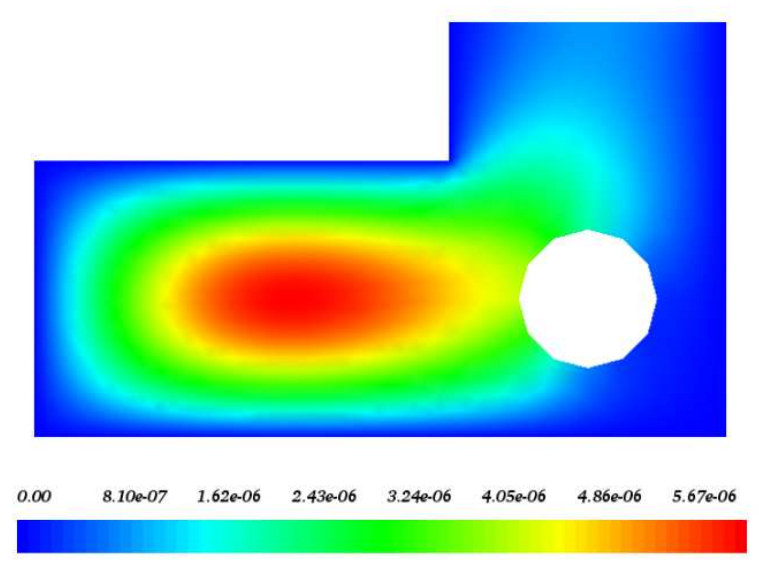

Figura 8.47: Transporte de duas manchas de $\mathrm{DBO}$ em $t \approx 12 h$

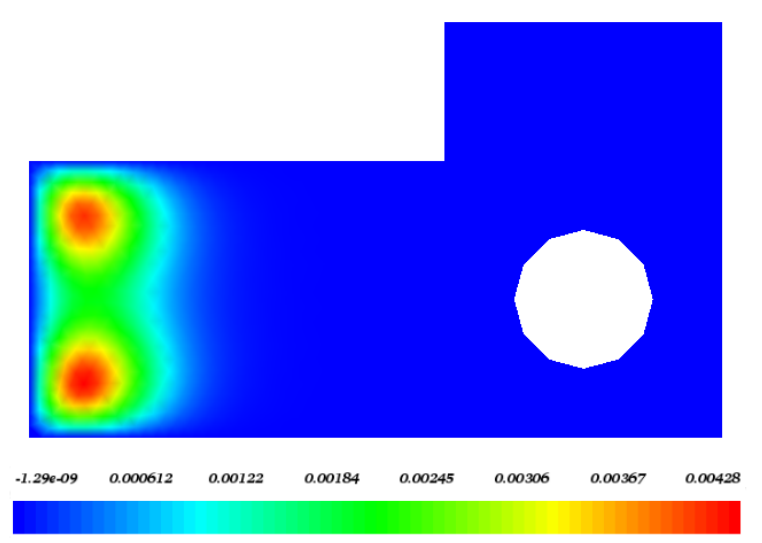

Figura 8.44: Transporte de duas manchas de DBO em $t \approx 240 s$

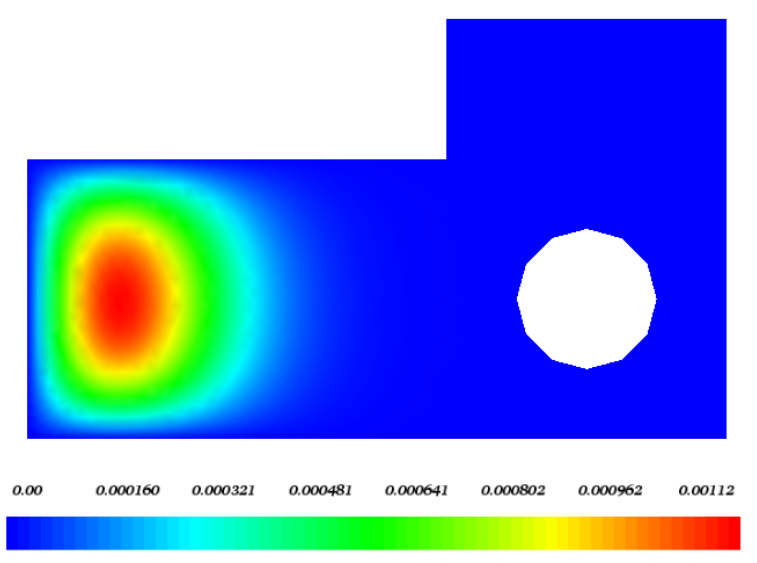

Figura 8.46: Transporte de duas manchas de $\mathrm{DBO}$ em $t \approx 8 h$

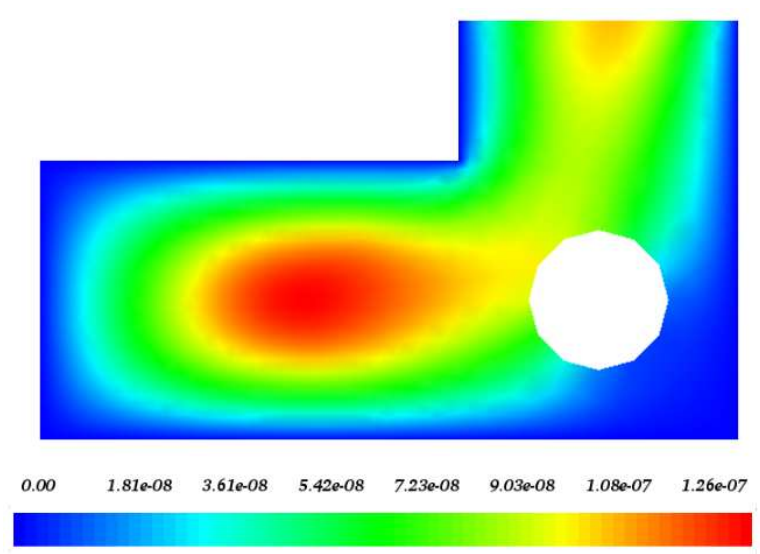

Figura 8.48: Transporte de duas manchas de DBO em $t \approx 24 h$ 


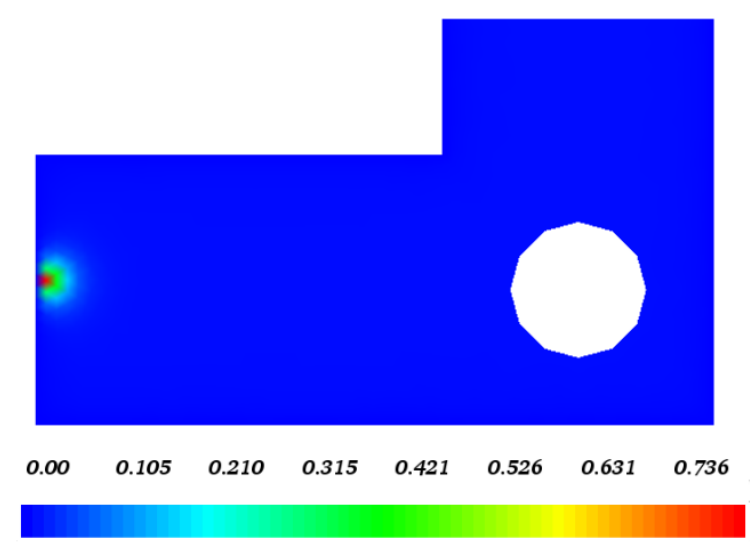

Figura 8.49: Transporte de uma mancha de $\mathrm{OD}$ em $t \approx 60 \mathrm{~s}$

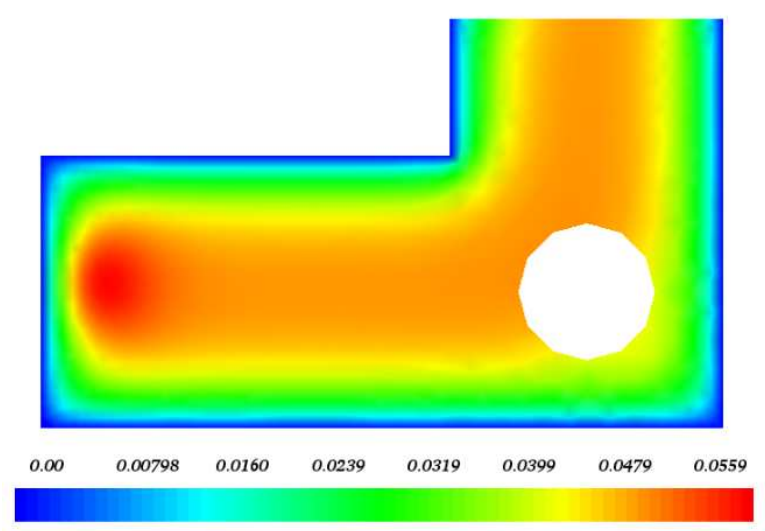

Figura 8.51: Transporte de uma mancha de $\mathrm{OD}$ em $t \approx 1 h$

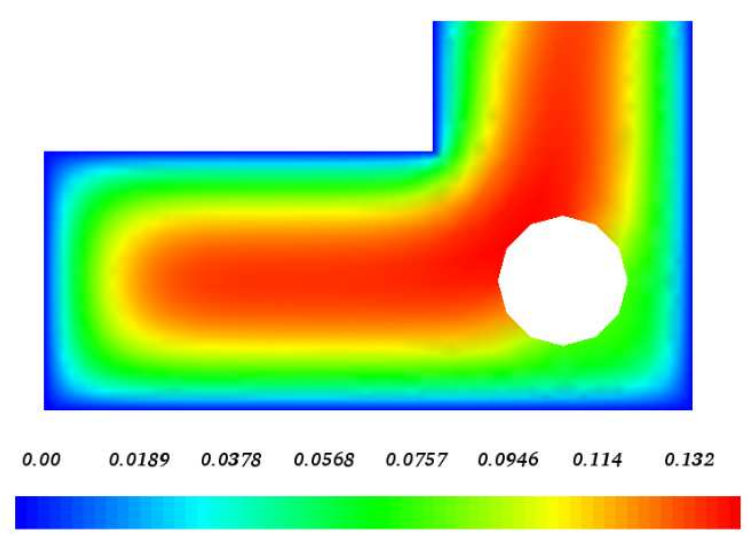

Figura 8.53: Transporte de uma mancha de OD em $t \approx 12 h$

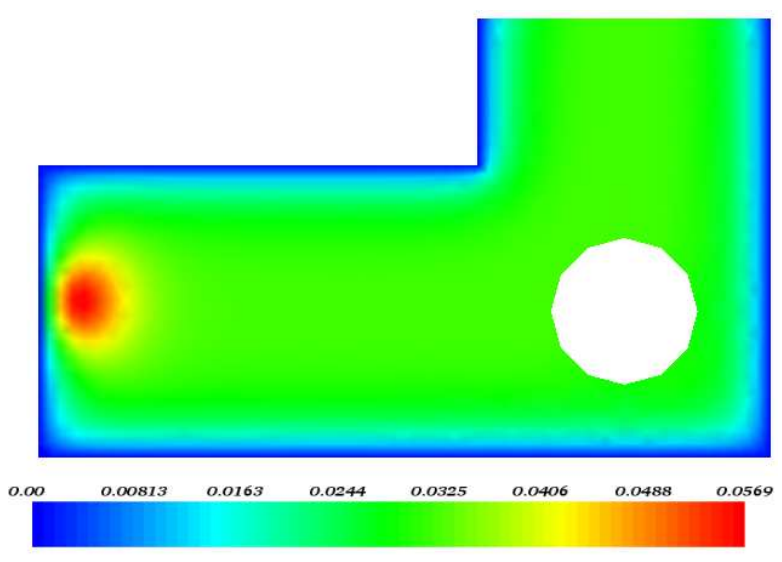

Figura 8.50: Transporte de uma mancha de OD em $t \approx 240 \mathrm{~s}$

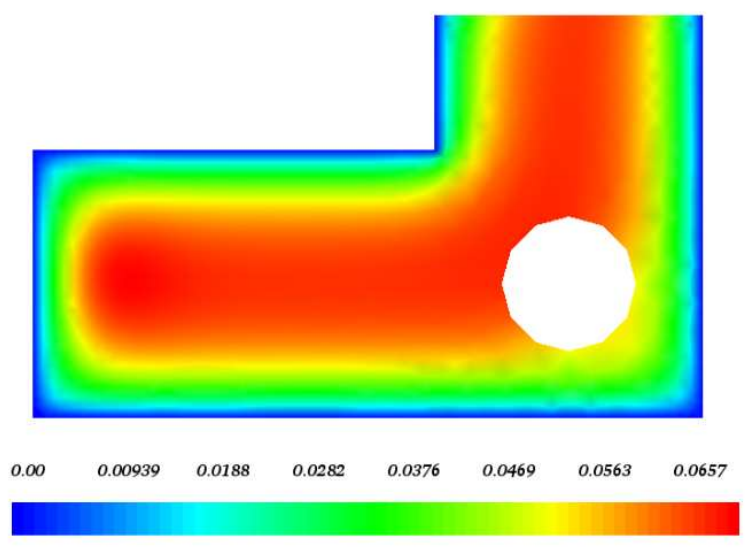

Figura 8.52: Transporte de uma mancha de $\mathrm{OD}$ em $t \approx 8 h$

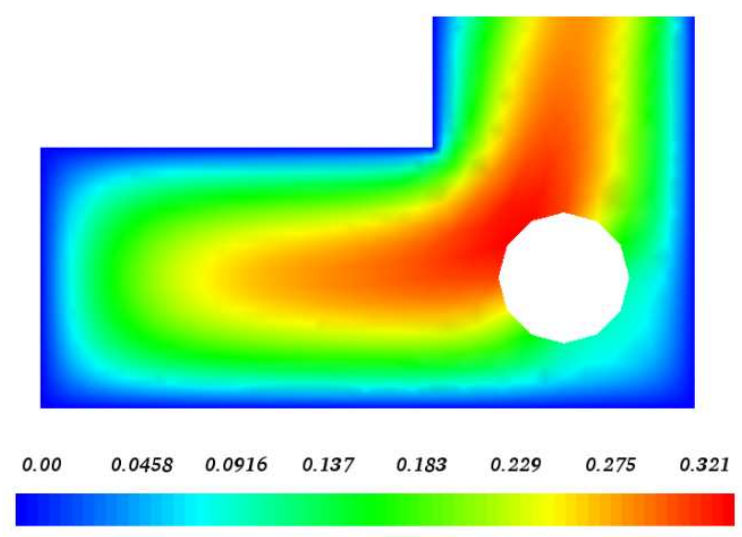

Figura 8.54: Transporte de uma mancha de OD em $t \approx 24 h$ 


\subsection{Simulação em uma geometria de um terreno: Ca- ledônia}

Nesta seção são apresentados os resultados numéricos da simulação em uma geometria representando uma região a ser alagada: Caledônia. Para esta região, foi gerada, através do módulo responsável pela geração de malha, uma malha computacional triangularizada, com triangularização de Delaunay, mostrada na Figura (8.55), que possui 4379 nós e 14268 elementos.

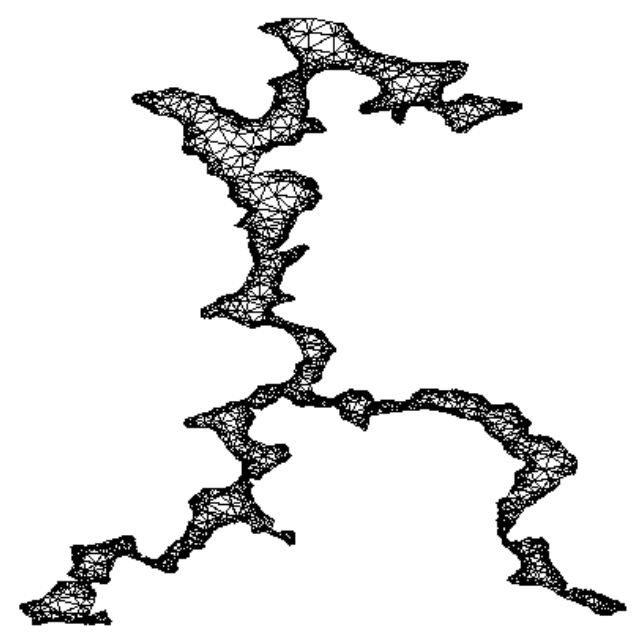

Figura 8.55: Malha representando um terreno a ser alagado: Caledônia.

Considera-se nesta geometria algumas regiões como sendo entrada de fluido e uma região como sendo saída de fluido. As entradas de fluido, estão apresentadas em azul, nas regiões 1, 2 e 3, e a saída em vermelho, na região 7 da Figura (8.56).

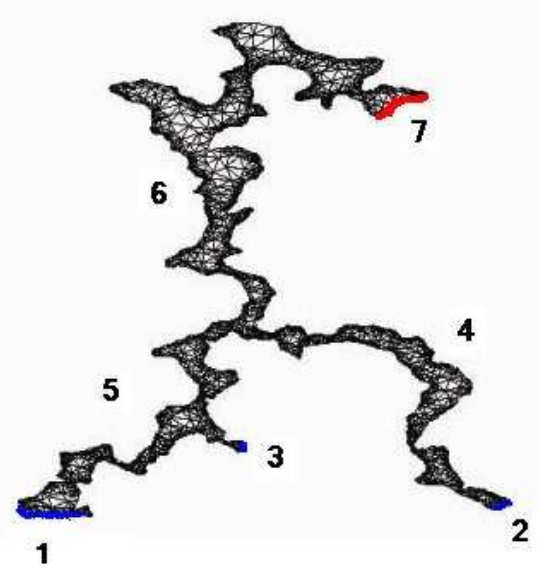

Figura 8.56: Entradas e saída de fluido na malha da Caledônia. 
Para essa geometria foram realizadas simulações para os campos de velocidade, temperatura e para o modelo de reação química dos constituintes OD-DBO.

Foram considerados os mesmos parâmetros utilizados nas simulações anteriores. Para os quais foram obtidos os seguintes resultados:

\subsubsection{Velocidade}

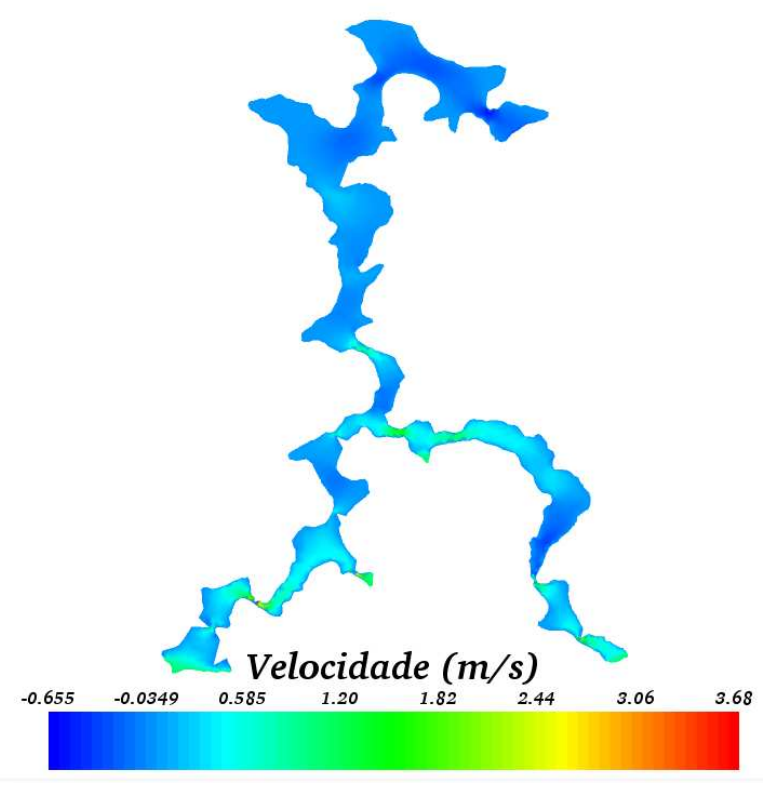

Figura 8.57: Velocidade em toda a Caledônia.

A Figura (8.57) mostra o comportamento da velocidade em toda a geometria. Observa-se ao longo de alguns trechos das regiões 4,5 e 6 que a velocidade $u$ é negativa, ou seja, nestas regiões está havendo uma recirculação do fluido.

\subsubsection{Transporte da Temperatura}

Para a simulação do transporte da temperatura, foi obtido o seguinte resultado:

Observa-se na Figura (8.58) que a temperatura é a mesma em qualquer região da geometria.

\subsubsection{Transporte dos constituintes OD-DBO}

Para a simulação do transporte de dois constituintes, considerando o Modelo Cinético de Reação Química OD-DBO, foi considerada uma condição inicial $c_{5,0}=10,0 \mathrm{mg} / \mathrm{l}$ para a $\mathrm{DBO}$ e $c_{6,0}=8,3 \mathrm{mg} / \mathrm{l}$ para o $\mathrm{OD}$, nas três entradas de fluido da geometria. Para essa simulação foram obtidos os seguintes resultados:

Observa-se na Figura (8.59), como a DBO é transportada ao longo da geometria em direção ao escoamento, nota-se que as regiões próximas às entradas de fluido estão sujeitas à maiores taxas de concentração desse constituinte do que as regiões 6 e 7 que encontram-se distantes dessas fontes, onde a concentração de DBO chega a ser nula.

Observa-se também no caso do transporte de OD mostrado na Figura (8.60) quais os trechos que apresentam um decaimento desse constituinte e em quais regiões o curso d'água 


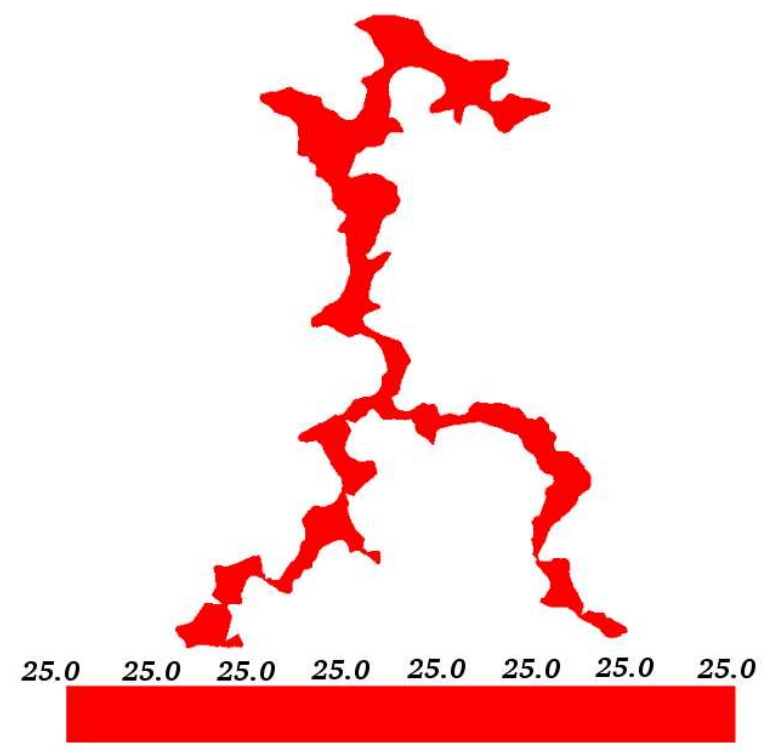

Figura 8.58: Transporte de temperatura em toda a Caledônia.

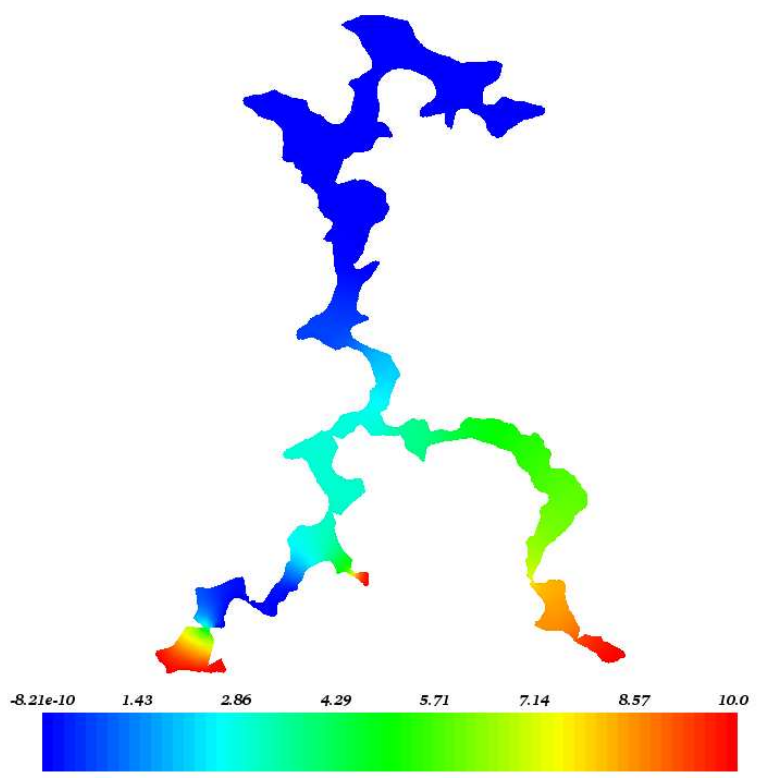

Figura 8.59: Transporte de DBO em toda a Caledônia.

volta a restabelecer as condições anteriores. Ou seja, as regiões próximas as entradas de fluido apresentam menores taxas de concentração de OD, onde existe uma baixa concentração desse constituinte, isso devido a reação química com a DBO, que faz com que o OD diminua onde a presença de DBO é maior. Nas regiões 6 e 7 a taxa de concentração de $\mathrm{OD}$ volta a aumentar devido a uma reaeração e também devido ao fato dessa região encontrar-se longe das fontes de DBO.

Observa-se através destes resultados, que a metodologia utilizada juntamente com o código computacional desenvolvido, são capazes de simular os fenômenos de interesse em diversas geometrias e condições de contorno, visto que, em todas as geometrias utilizadas, obteve-se comportamentos semelhantes ao obtido na simulação com o canal, o qual foi utili- 


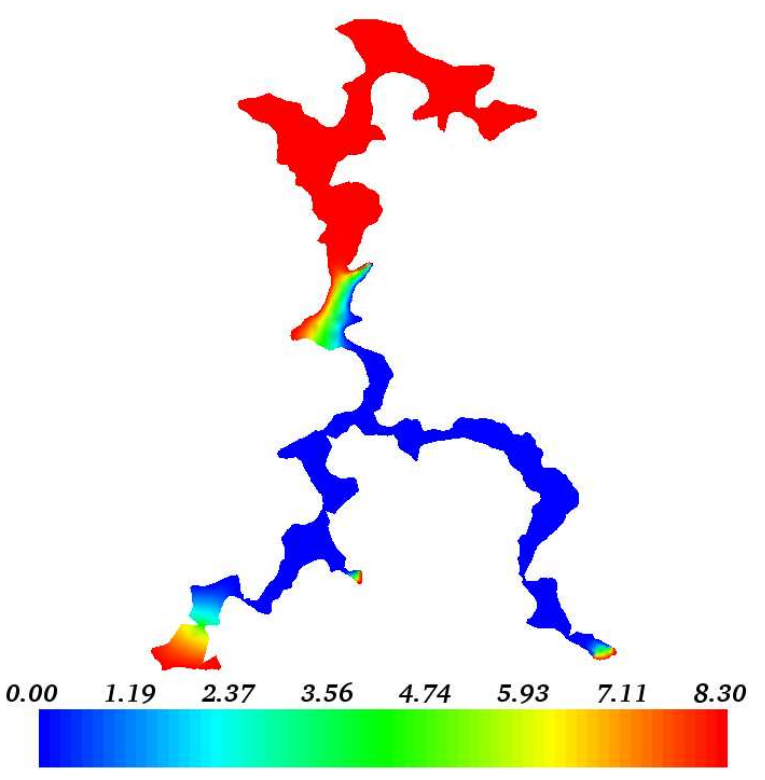

Figura 8.60: Transporte de OD em toda a Caledônia.

zado para a validação dos modelos de transporte de temperatura e de espécies constituintes aqui considerados. 


\subsection{Resultados para o Modelo 2DH}

\subsubsection{Simulação no Canal 2DH}

Para o estudo e validação dos resultados apresentados nesta seção, tanto para o transporte da temperatura, como para o transporte das espécies constituintes, foi considerada a mesma geometria apresentada na Figura (8.61), isto é, considera-se o escoamento de um fluido em um canal de altura $H$, onde o escoamento é da esquerda para a direita, variando apenas o comprimento do canal, que para a temperatura foi $9 L$ e para as espécies constituintes $24 L$, com $H=1,0 m$ e $L=1,0 m$.

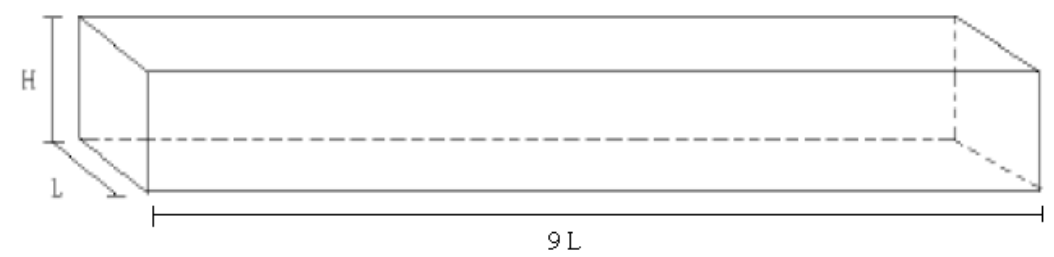

Figura 8.61: Geometria do canal 2DH.

\subsubsection{Temperatura 2DH}

Para o problema do transporte da temperatura 2DH, foi considerado o mesmo problema-teste apresentado no Capítulo 7, e os mesmos parâmetros utilizados nas simulações feitas em 2D.

Foi realizada uma simulação, onde as placas do canal foram mantidas a uma temperatura constante de $15^{\circ} \mathrm{C}$. O resultado dessa simulação pode ser observado na Figura (8.62), onde é apresentado o perfil, na saída de fluido do canal, da solução numérica juntamente com a solução analítica e também a Figura (8.63) que mostra a solução em todo o canal. Na Figura (8.63), nota-se, assim como no caso 2D, que ao entrar no canal, a temperatura das camadas de fluido mais próximas das paredes sobem mais do que as das camadas próximas ao eixo do escoamento que se encontram distantes da fonte de calor.

Para esse problema foi possível validar o modelo, visto que o erro absoluto foi da ordem de $10^{-5}$.

\subsubsection{Espécies Constituintes 2DH}

Para simular numericamente o transporte das concentrações de espécies constituintes 2DH, foi considerado o modelo de cinética de reação química dos constituintes OD-DBO, apresentado no Capítulo 7, que descreve o lançamento de uma fonte pontual de DBO em um corpo de água. Para esse modelo obteve-se os seguintes resultados:

Para o problema do transporte das espécies constituintes, foi considerado o mesmo problema-teste apresentado no Capítulo 7, Modelo de cinética de reação química OD-DBO, e os mesmos parâmetros utilizados nas simulações feitas em 2D. Com os resultados obtidos foi possível validar o simulador, visto que o erro absoluto foi da ordem de $10^{-4}$.

Assim como no caso 2D, pode ser observado na Figura (8.64), para o caso 2DH, que a comparação entre os resultados obtidos e a solução analítica para o Oxigênio Dissolvido 


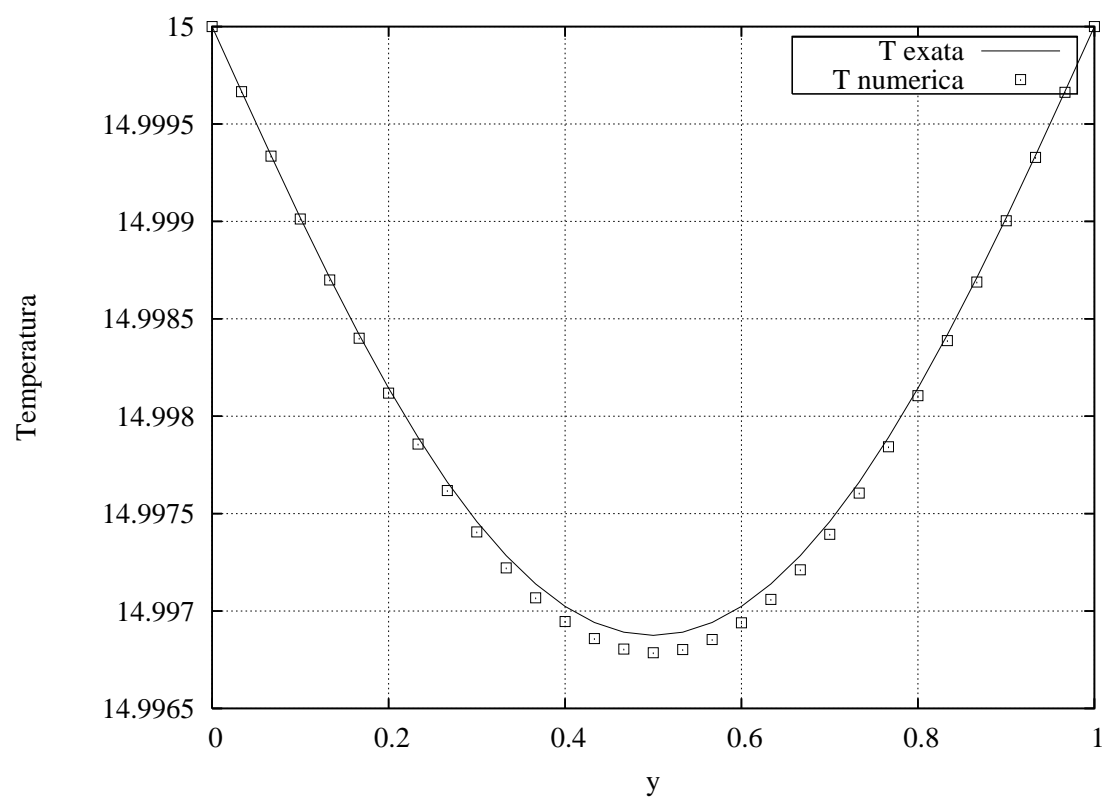

Figura 8.62: Comparação entre a solução numérica e a analítica para a temperatura 2DH na saída de fluido do canal.

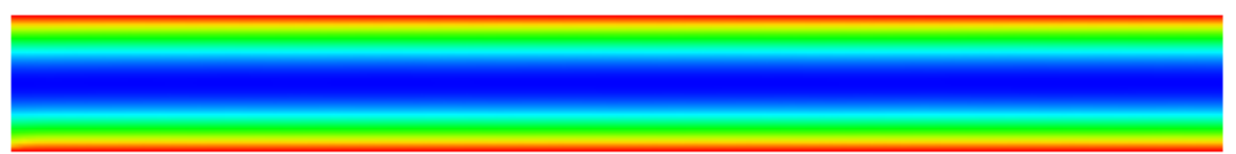

Figura 8.63: Solução numérica para a temperatura 2DH em todo o Canal.

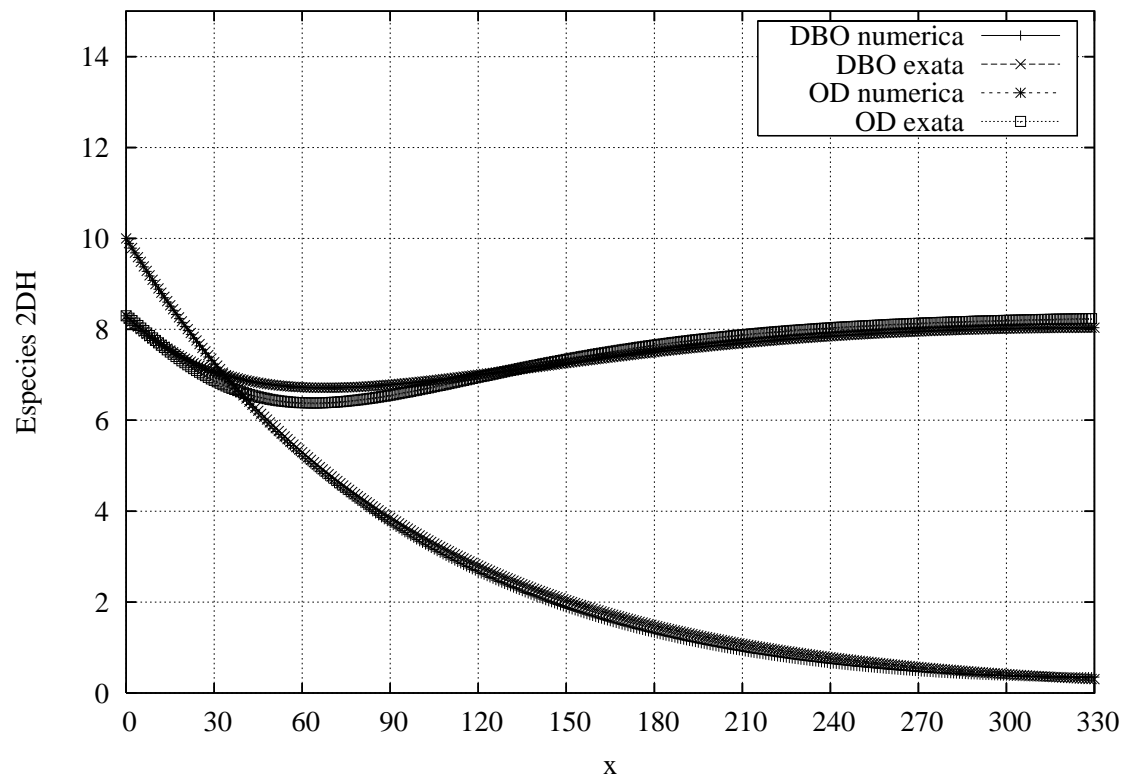

Figura 8.64: Comparação entre a solução numérica e a analítica do Modelo OD-DBO.

e a Demanda Bioquímica de Oxigênio apresentam uma excelente concordância entre os 
Figura 8.65: Solução para DBO em todo o canal.

Figura 8.66: Solução OD em todo o canal.

resultados fornecidos pelo método e a solução analítica tanto para a DBO como para o OD, como também o comportamento em todo o canal mostrados pelas Figuras (8.65) e (8.66), onde são mostrados os trechos que sofrem as consequências da poluição, Figura (8.65), e o comportamento do oxigênio dissolvido na água, Figura (8.66).

\subsection{Simulação na Geometria Cocho}

São apresentadas aqui as simulações numéricas dos transportes da temperatura e das concentrações de espécies constituintes $2 \mathrm{DH}$, considerando a geometria Cocho, mostrada na Figura (8.67), variando apenas o comprimento da geometria, isto é, $9 \mathrm{~L}$ para a temperatura e $24 L$ para as espécies constituintes. Onde, $H=1,0 m, L=1,0 m, H 1=0,33+y$ e

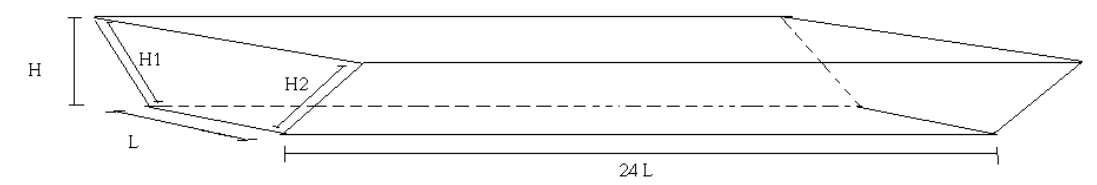

Figura 8.67: Geometria Cocho 2DH.

$H 2=1,33-y$.

\subsubsection{Temperatura}

Para o transporte da temperatura 2DH, com os mesmos parâmetros adotados na simulação anterior, foi obtido o seguinte resultado:

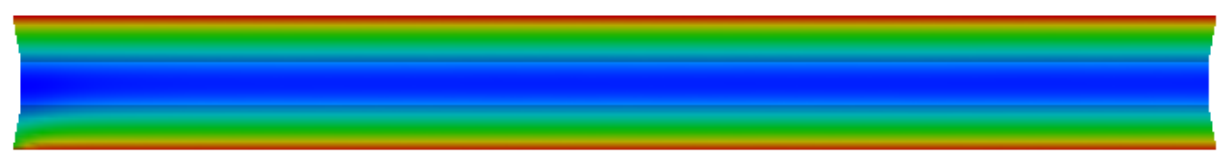

Figura 8.68: Solução numérica para a temperatura 2DH na geometria Cocho. 
Como pode ser observado na Figura (8.68), a temperatura das camadas de fluido próximas à parede sobem mais rápido que as dos fluidos próximos ao eixo da geometria.

\subsubsection{Espécies Constituintes 2DH}

Para o problema do transporte das concentrações de espécies constituintes 2DH, foi considerado o mesmo problema-teste apresentado no Capítulo 7, Modelo de Cinética de Reação Química OD-DBO, e para esse problema foram obtidos os seguintes resultados:

Figura 8.69: Solução numérica para a DBO na geometria cocho.

Figura 8.70: Solução numérica para o OD na geometria cocho.

A escala de cores referentes as Figuras (8.63), (8.65), (8.66), (8.68), (8.69) e (8.70) é dada na Figura (8.71).

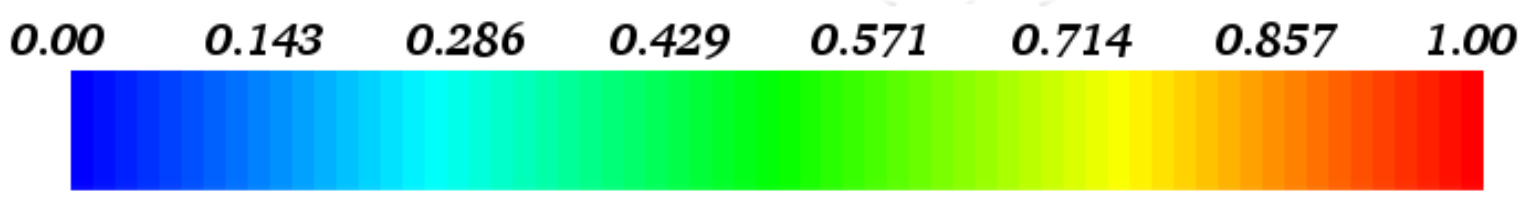

Figura 8.71: Escala de cores.

Note que o comportamento durante o transporte dos constituintes OD e DBO, ao longo do escoamento, são os mesmos obtidos com a simulação 2DH no canal. 


\subsection{Resultados para o Modelo de Turbulência}

Nesta seção são apresentados os resultados numéricos para o modelo de turbulência adotado, considerando uma geometria com expansão brusca, para vários números de Reynolds.

Um dos problemas de escoamentos de fluidos que tem sido estudado ao longo dos anos é o problema em geometria com expansão brusca. Este problema foi escolhido neste trabalho, para ser um problema-teste para o caso da turbulência, pois existem na literatura dados tanto numéricos como experimentais, permitindo assim uma avaliação do modelo adotado.

O domínio utilizado para simular este problema é mostrado na Figura (8.72) onde são considerados os seguintes parâmetros:

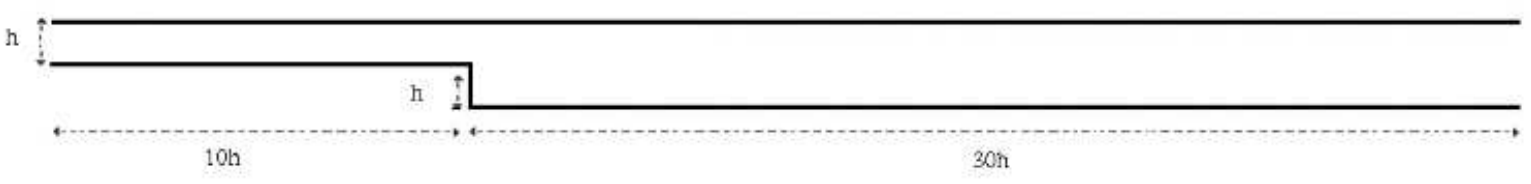

Figura 8.72: Geometria para o problema.

- altura do degrau: $\mathrm{h}=0.1 \mathrm{~m}$

- velocidade: $\mathrm{U}=1,0 \mathrm{~m} / \mathrm{s}$

estes parâmetros foram os mesmos adotados em [Ferreira, 2007] onde foram feitos testes para vários números de Reynolds. No trabalho realizado por [Ferreira, 2007], foi utilizado o Modelo de Turbulência k- $\varepsilon$.

A Tabela (8.2) mostra os valores de $x_{1}$, que é o ponto onde se forma uma recirculação, isto é, onde a velocidade troca de sinal. São mostrados os valores obtidos experimentalmente e numericamente por Armaly [Armaly, 1983], os dados numéricos de Stuart e Dochan [Stuart, 1991], os resultados de Ferreira [Ferreira, 2007] e os resultados do presente trabalho.

\begin{tabular}{|c|c||c|c|c|c|}
\hline & \multicolumn{1}{|c||}{ Experimental } & \multicolumn{4}{c|}{ Numérico } \\
\hline Re & Armaly & Armaly & Stuart and Dochan & Ferreira & Presente \\
\hline 100 & 3,06 & 2,95 & 3,13 & 3,08 & 3,1 \\
\hline 200 & 5,16 & 4,82 & 4,97 & 5,14 & 4,5 \\
\hline 400 & 8,72 & 8,04 & 8,03 & 8,24 & 8,0 \\
\hline 600 & 11,28 & 8,18 & 10,25 & 9,71 & 9,3 \\
\hline 800 & 14,34 & 7,50 & 11,47 & 10,68 & 10,08 \\
\hline
\end{tabular}

Tabela 8.2: Estimativas para $x_{1}$

Nota-se através dos dados apresentados na Tabela (8.2) que os valores obtidos para o modelo de turbulência aqui adotado fornece resultados satisfatórios. 
Os resultados apresentados na Tabela (8.2), também podem ser observados nas Figuras (8.73) e (8.74), ode são mostrados os valores de $x 1$ para os números de Reynolds 100 e 200, e os valores 400, 600 e 800 respectivamente.

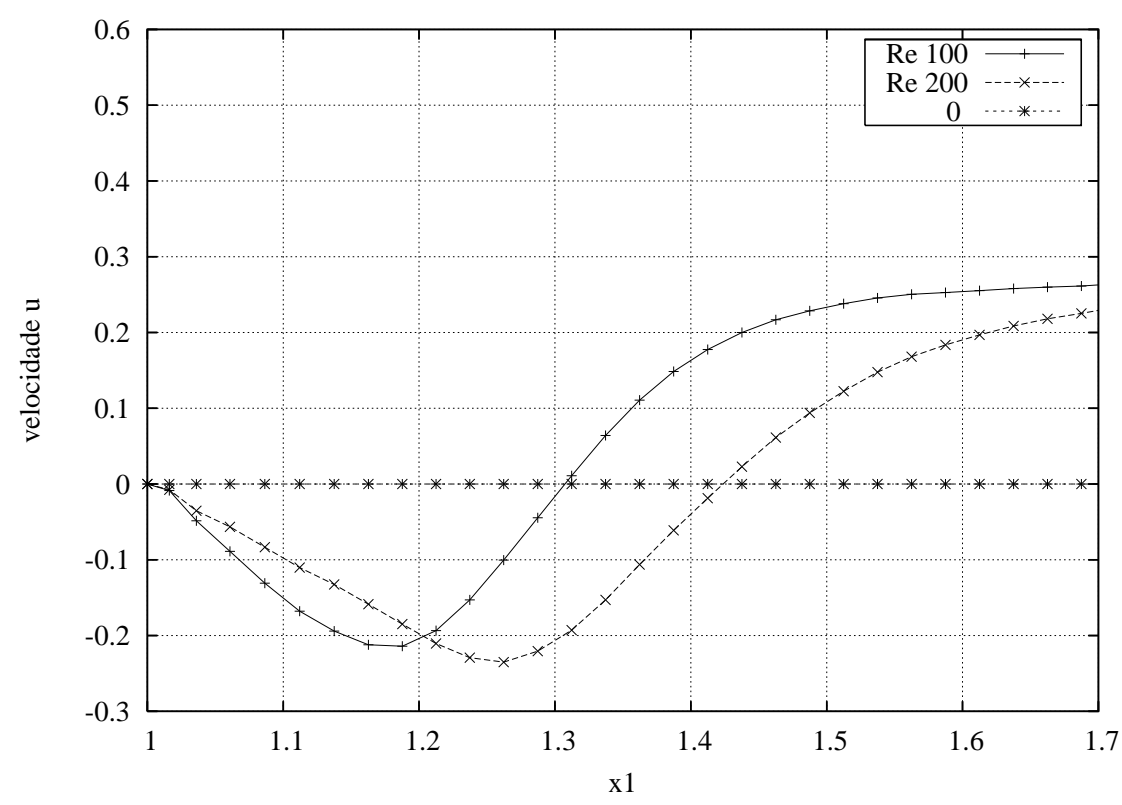

Figura 8.73: Valores de x1 para Reynolds 100 e 200.

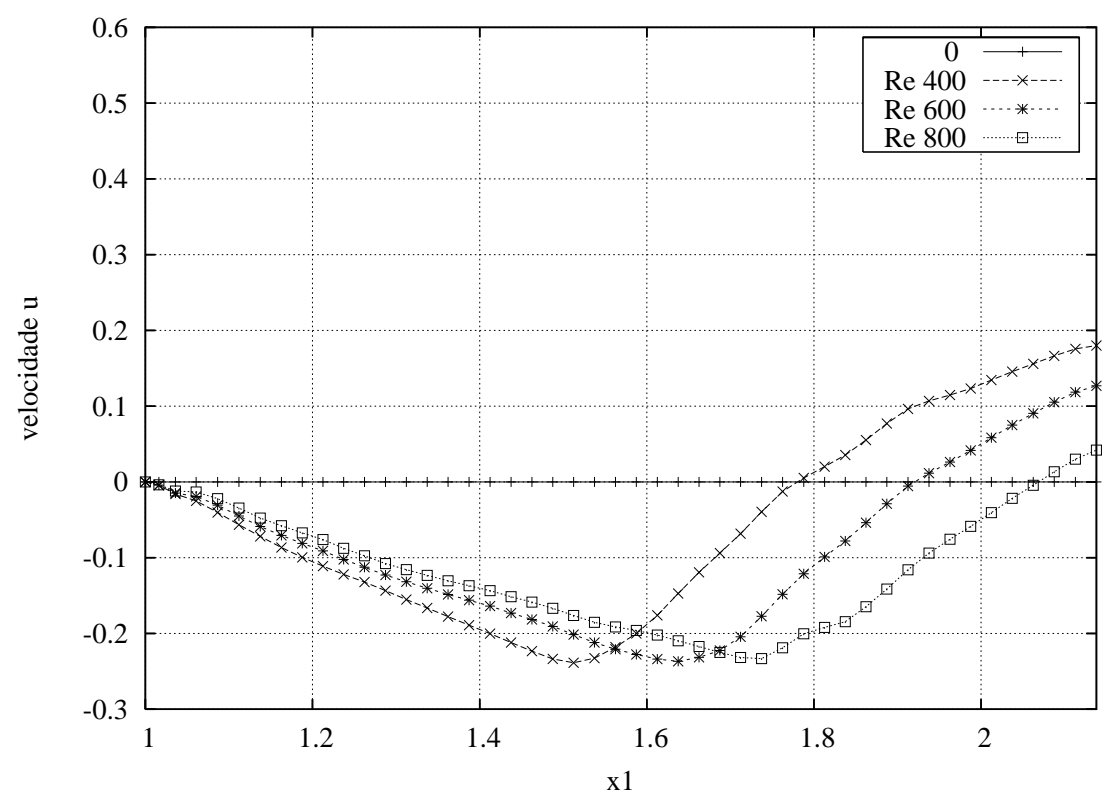

Figura 8.74: Valores de x1 para Reynolds 400, 600 e 800.

Na Figura (8.75) estão dispostos graficamente os valores de $x_{1}$ para os números de Reynolds utilizados. Foram plotados os dados de Armaly [Armaly, 1983], Stuart e Dochan [Stuart, 1991], Ferreira [Ferreira, 2007] e os resultados do presente trabalho. Através dos valores plotados, observa-se bons resultados para valores de $x_{1}$ para $0<R e<400$, pois estão próximos aos valores experimentais. Entretanto, observa-se também que para $R e \geqslant 400$ 
os resultados numéricos se distanciam dos dados experimentais, este fato pode ser explicado devido aos efeitos tridimensionais e, possivelmente, devido a transição da turbulência para altos números de Reynolds.

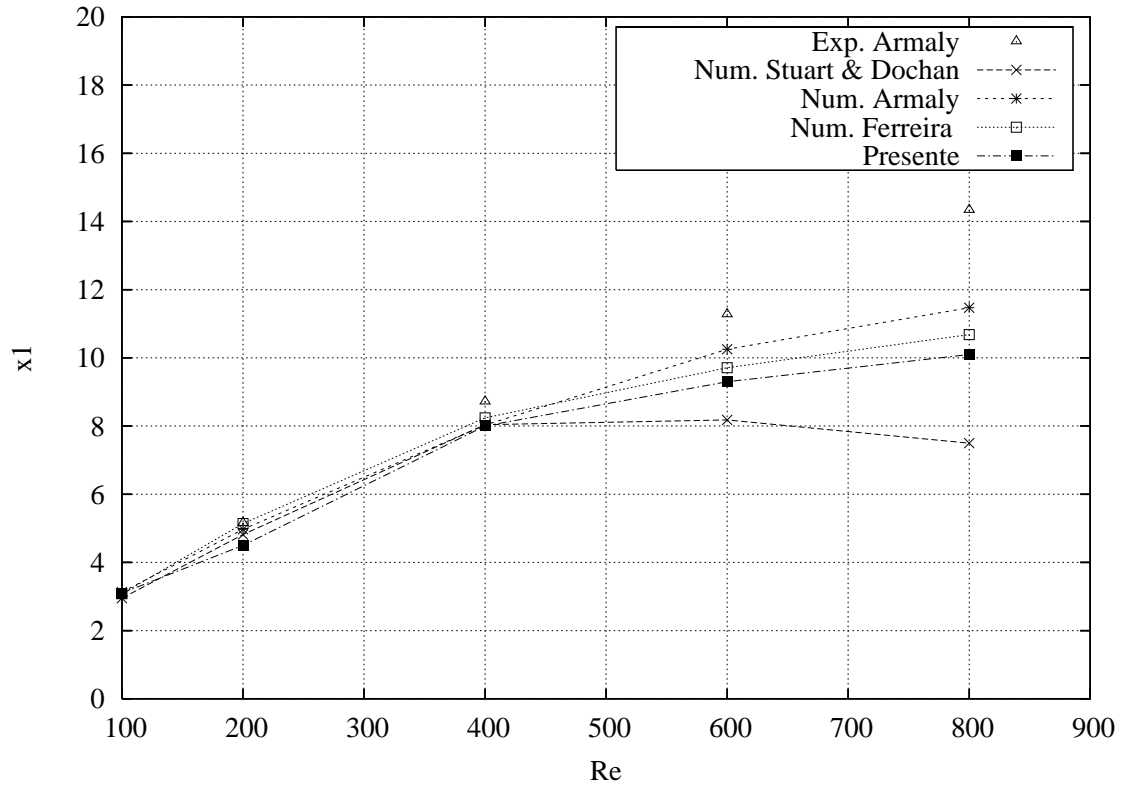

Figura 8.75: Comparação entre resultados numéricos e experimentais.

Sendo assim, conclui-se através dos resultados obtidos, que o modelo de turbulência utilizado apresenta resultados condizentes com os apresentados na literatura. 


\section{Considerações Finais}

O objetivo desse trabalho de mestrado é o desenvolvimento de simuladores das equações de transporte da temperatura e das espécies constituintes 2D e 2DH e também acrescentar um modelo de turbulência ao simulador Hydro.

Para a implementação do módulo de simulação foram utilizados o método de Elementos Finitos em uma estrutura de dados topológica OF. Para a solução das equações governantes, foram utilizados a formulação Semi-Lagrangeana e o método de Galerkin. Os simuladores foram validados considerando o problema de escoamento de fluido em um canal, tanto para o modelo $2 \mathrm{D}$ como para o $2 \mathrm{DH}$ e foram realizadas simulações de escoamento de um fluido em várias geometrias, tais como, geometria curva, expansão brusca, uma placa com contração e em uma geometria representando um terreno a ser alagado: Caledônia, em 2D, a simulação no canal e na geometria cocho para 2DH e simulação em uma expansão brusca para o modelo de turbulência. Todos os resultados obtidos mostraram concordâncias com a solução analítica esperada tanto para o transporte de temperatura como para as espécies constituintes. Com o modelo de turbulência utilizado também foram obtidos resultados condizentes com os apresentados na literatura.

Em geral, pode-se concluir que as simulações para o transporte da temperatura, das espécies constituintes $2 \mathrm{D}$ e $2 \mathrm{DH}$ e para o modelo de turbulência foram satisfatórias. Uma vantagem dessa metodologia é a sua facilidade em simular escoamentos em geometrias complexas.

Este trabalho pode ser extendido para escoamentos tridimensionais e o problema da turbulência pode ser resolvido utilizando modelos mais complexos, como é o caso do modelo de turbulência $K-\varepsilon$.

Parte deste trabalho estão no 6th Congresso Temático de Dinâmica, Controle e Aplicações, DINCON. São José do Rio Preto-SP, 2007, com o título "Simulação Numérica do Transporte Térmico e de Escalares do Modelo OD-DBO: Um Estudo de Previsão de Qualidade de água em Reservatérios Hidrelétricos" e também no XXX CNMAC, Congresso Nacional de Matemática Aplicada e Computacional, com o título "Simulação Numérica do Transporte da Temperatura e de Espécies Constituintes em Reservatérios Hidrelétricos Utilizando Método de Elementos Finitos em Malhas Não-Estruturadas". 


\section{Referências Bibliográficas}

[Armaly, 1983] Armaly B.F., Durst F., Pereira J.C.F. "Experimental and theorical investigation of bachward-facing step flow," Journal of Fluid Mechanics, 1983; 127:473-496

[Becker, 1981] E.B. Becker, G.F. Carey, and J.T. Oden, "Finite Elements An Introduction," Prentice-Hall, Inc., Englewood Cliffs, New Jersey Vol. 1, 1981.

[Bitar, 2002] Bitar, A. L., Antonio, R. M., Bianchini Jr, "Degradação anaeróbia de folhas, galhos, cascas e serapilheira". Acta Limnologica Brasiliensis, Botucatu, v.14, n.2, p.17 26, I. 2002.

[Boussinesq, 1877] Boussinesq J. Memories presentes par divers savants sciences mathematique at physiques theorie de l'ecoulement tourbillant. Academie des Sciences, Paris, 23:46, 1877.

[Bohrer, 2002] Bohrer, C. B. A., "Vegetação, paisagem e o planejamento do uso da terra". Revista GEOgraphia, Niterói-RJ, v.4, 2002.

[Brown, 1982] Brown L.C., Barnwell J.T.O "The enhanced stream water quality models QUAL2E and QUAL2E-UNCAS: US EPA," versão 3.0, 1982.

[Brum, 2001] Brum, P.R, Esteves, F.A., "Dry weight loss and chemical variation in the detritus of three species of tropical aquatic macrophytes (Eleocharis interstincta, Nymphaea ampla and Potamogeton stenostachys) through the course of decomposition". Acta Limnologica Brasiliensia, 13(1), 2001.

[Carey, 1995] Carey, G. M., Finite element modeling of environmental problems: surface and subsurface flow and transport. Graham M. Carey, editor, John Wiley \& Sons, 1995.

[Cunha, 2002] Cunha C.L., Monteiro T., Rosman P.C.C. "Modelagem bidimensional de transporte de escalares não-conservativos em corpos de água rasos," Revista Brasileira de Recursos Hídricos, Brasil, v. 7, n.2, 2002.

[Cunha, 2003] Cunha C.L., Monteiro T., Rosman P.C.C. "Avaliação da poluição em rios usando modelagem computacional," Engenharia Sanitária, Brasil, v. 8, n.3, 2003.

[Eiger, 1981] L.C. Wrobel, S. Eiger, P.C. Rosman, C.E. Tucci, J.A. Cirillo, J.P. Cabral and R.V. Silva, "Métodos numéricos em recursos hídricos," Associação Brasileira de Recursos Hídricos, 1989. 
[Ferreira, 2001] Ferreira, V. G., Cuminato, J. A., Tome, M. F., Fortuna, A., Mangiavacchi, N., Castelo, A., Nonato, L. G. 2001. "Análise e Implementação de Modelos de Turbulência k-e para Simulação de Escoamentos Incompressíveis Envolvendo Superfícies Livres e Rígidas". Tema - Tendências em Matemática Aplicada e Computacional, São Carlos: , v.2, p.81- 90 .

[Ferreira, 2007] V.G.Ferreira, C.M.Oishi, F.A. Kurokawa, M.K. Kaibara, J.A. Cuminato, A. Castelo F., N. Mangiavacchi, M.F. Tomé and S.McKee "A Combination of Implicit and Adaptative Upwind Tools for Incompressible Free Surface Flows," Communication in Numerical Methods in Engineering, 2006.

[Freire, 1998] Silvia Freire A. P. Cruz D.O.A. Equações do movimento e resultados assintóticos aplicados à teoria da camada limite. Phil. Transição e Turbulência, I Escola de Primavera, Rio de Janeiro, 1998.

[Gray, 1986] Gray, W. G , Physics-Based Modeling of Lakes, Reservoirs, and Impoundments. ASCE, 1986.

[Harlow, 1965] F. H. Harlow, J. E. Welch. "Numerical Calculation of Time-Dependent Viscous Incompressible Flow of Fluid with Free Surface" in The Physics of Fluids, 8(1): 2182-2189, 1965.

[Hirt, 1970] Hirt, C. W., Cook, J. L., Butler, T. D., 1970. "A Lagrangean Method for Calculating the Dynamics of an Incompressible Fluid with Free Surface", Journal of Computational Physics, vol. 5, pp. 103-124.

[Incropera, 1990] F.P. Incropera, and D.P. Witt, "Introduction to Heat Transfer," John Wiley \& Sons, 1990.

[Landau, 1959] L.D. Landau, and E. M. Lifschitz, "Fluid Mechanics," Pergamon Press, New York 1959.

[Launder, 1974] Launder. B. E. Spalding D. B. The numerical computation of turbulents flow. International Journal for Numerical Methods in fluids, 15:127 - 146, 1974.

[Maliska, 2003] C.R. Maliska "Transferência de Calor e Mecânica dos Fluidos Computacional," LTC Livros Técnicos e Científicos, Rio de Janeiro, 2003.

[Mangiavacchi, 2000] Mangiavacchi, N., Coutinho, A. L. G. A., Ebecken, N. , "Turbulent shallow-water model for orographic subgrid-scale perturbations". Revista Brasileira de Ciencias Mecanicas, v.XXII, n.1, 2000.

[Mota, 2003] Mota S. "Introdução à engenharia ambiental," Associação Brasileira de Engenharia Sanitária, 2003.

[Orlob, 1982] Orlob G.T. "Mathematical modeling od water quality," Wiley, Chichester, 1982.

[Pontes, 2003] J. Pontes, and N. Mangiavacchi, "Fenômenos de Transferência," Universidade Federal do Rio de Janeiro, 2003. 
[Rauch, 1998] Rauch W. "River water quality modelling: I State of the art.," Water Science Tecnology, v. 38, n.11, p. 237-244, 1998.

[Rosman, 2006] P.C. Rosman, "Referência Técnica do Sisbahia," Universidade Federal do Rio de Janeiro, 2006, Disponível em <http://www.sisbahia.coppe.ufrj.br >, Acesso: 30 de mar. de 2007.

[Sabatini, 2002] Sabatini M.H. "Expansão do sistema FreeFlow-3D para escoamentos com influência da temperatura," Instituto de Ciências Matemáticas e de Computação, 2002.

[Schladow, 1997] Schladow S.G., Hamilton D.P. "Prediction of water quality in lakes and reservoirs: Part II-Model calibration, sensitivity analysis and application," Ecological Modeling, 1997; 96: 111-123.

[Simeoni, 2005] F.S. Simeoni "Simulação de escoamentos multifásicos em malhas não estruturadas," Universidade de São Paulo - ICMC, 2005.

[Soares, 2003] C.P.B. Soares "Modelagem e Simulação de Sistemas Aquáticos em Ambiente de Geoprocessamento," Universidade Federal do Rio de Janeiro, 2003.

[Stuart, 1991] Stuart E.R., Dochan K. "An upwind differencing scheme for incompressible Navier-Stokes equations," Applied Numerical Mathematics, 1991; 8:43-64

[Veloso, 1975] Veloso, H.P. et al. 1975. As regiões fitoecológicas, sua natureza e seus recursos econômicos. Departamento Nacional da Produção Mineral. Projeto RADAMBRASIL, folha NA.20 - Boa Vista e parte das folhas NA.21 - Tumucumaque, NB.20 - Roraima e NB. 21 - Rio de Janeiro, (Levantamento de Recursos Naturais, v. 8). 